PERIOPERATIVE NURSES' EXPERIENCES OF POINT-OF-CARE NURSING

LEADERSHIP: A NARRATIVE INQUIRY

by

Victoria Gaudite, BScN, Ryerson University, 2009

\author{
A thesis \\ presented to Ryerson University \\ in partial fulfillment of the \\ requirements for the degree of \\ Master of Nursing \\ in the Program of \\ Nursing
}

Toronto, Ontario, Canada, 2015

(C) Victoria Gaudite 2015 


\begin{abstract}
AUTHOR'S DECLARATION
I hereby declare that I am the sole author of this thesis. This is a true copy of the thesis, including any required final revisions, as accepted by my examiners.
\end{abstract}

I authorize Ryerson University to lend this thesis to other institutions or individuals for the purpose of scholarly research.

I further authorize Ryerson University to reproduce this thesis by photocopying or by other means, in total or in part, at the request of other institutions or individuals for the purpose of scholarly research.

I understand that my thesis may be made electronically available to the public. 


\title{
PERIOPERATIVE NURSES’ EXPERIENCES OF POINT-OF-CARE NURSING \\ LEADERSHIP: A NARRATIVE INQUIRY
}

\author{
ABSTRACT \\ by \\ Victoria Gaudite \\ Master of Nursing, 2015 \\ Daphne Cockwell School of Nursing \\ Ryerson University, Toronto, 2015
}

Front line nurses are increasingly being encouraged to engage in point-of-care nursing leadership to positively influence the health of the persons in the healthcare team and the landscape within which care ensues. Using Connelly and Clandinin's Narrative Inquiry, I explored how perioperative nurses experience point-of-care nursing leadership in the operating room (OR). My co-participants and I engaged in narrative interviews and Schwind's Narrative Reflective Process. Participants' stories were re-constructed and analyzed using Narrative Inquiry's three levels of justification (personal, practical and social), through the theoretical lenses of Leadership Model and Person-Centred Nursing. Narrative patterns that emerge are: advocacy, relationships, and teaching and learning. The participants' stories are re-presented using poetry. Implications for nursing and healthcare include a need to embody person-centred care to inform point-of-care leadership practices. A new concept of person-centred point-of-care leadership is developed for further exploration in research. 


\section{ACKNOWLEDGEMENTS}

I would first like to thank my thesis supervisor, Dr. Jasna Krmpotić Schwind, for her support and guidance during my graduate studies. She has nurtured my soul and my mind throughout our journey together, and for that I am very grateful. I would like to express my gratitude to my thesis advisory committee members, Dr. Nancy Purdy and Dr. Lori Schindel Martin, and my external examiner, Dr. Jennifer Lapum, for their thoughtful feedback and guidance.

I would also like to thank my Narrative Inquiry Works-in-Progress group for accompanying me on my walk along the labyrinth of Narrative Inquiry.

I am very grateful for the funding support I have received over the past two years from the Daphne Cockwell School of Nursing, The School of Graduate, Ryerson University, and Studies Ontario Ministry of Training, Colleges, and Universities.

I would like to express my love and gratitude to my parents, Montserrat and Felix, and my two brothers, Enrique and Alfredo, for their unconditional love and support. I would like to thank them for being my source of joy and determination.

To my husband Michal, I am forever grateful for our past, present, and future stories of love. I would like to thank him for his kind soul, which gives my life peace and meaning.

Finally, but most importantly, I would like to thank Sandy and Alaia, who shared with me their lived stories of point-of-care nursing leadership. 


\section{DEDICATION}

To

My team of thoracic perioperative nurses

Who motivate the nursing leadership stories that I live and tell

and

To Leigh

Who inspires my past, present, and future journeys 


\section{TABLE OF CONTENTS}

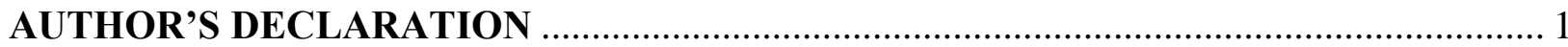

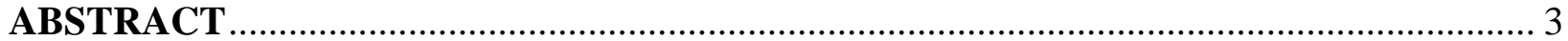

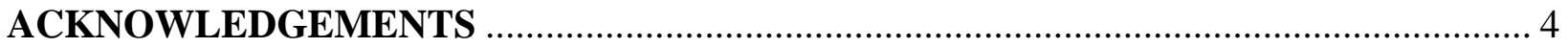

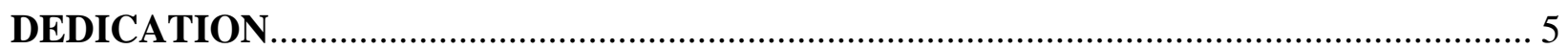

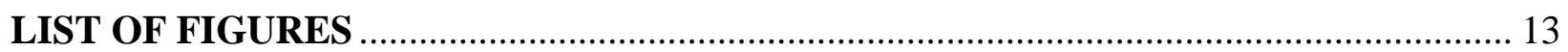

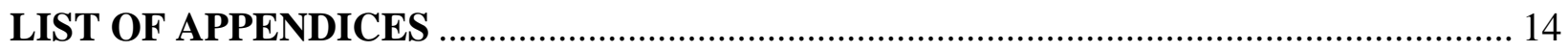

PROLOGUE

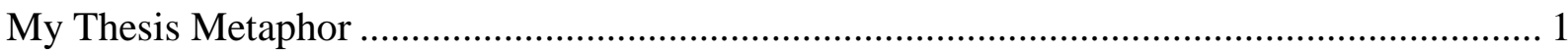

CHAPTER ONE: Introduction

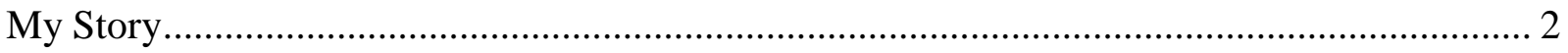

Point-of-care Nursing Leadership in the OR .................................................................. 5

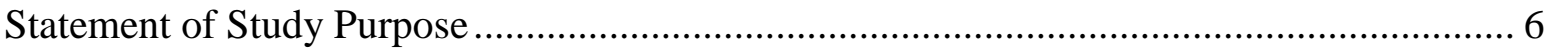

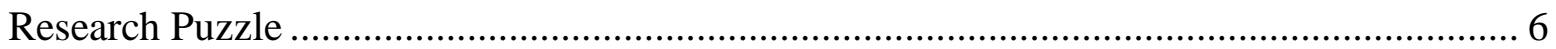

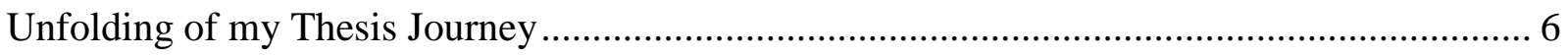

CHAPTER TWO: Literature Review and Synthesis ................................................... 9

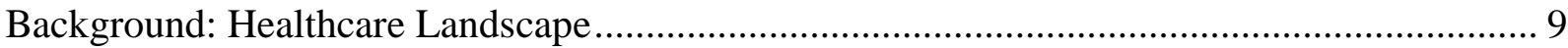

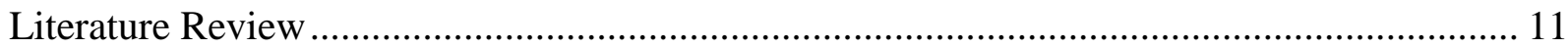

General Leadership Theory and Research .................................................................. 11 


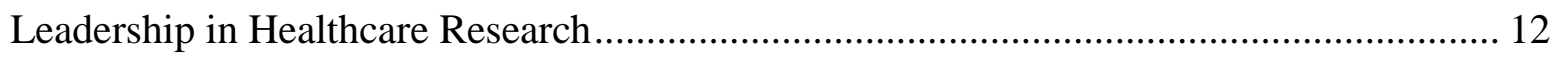

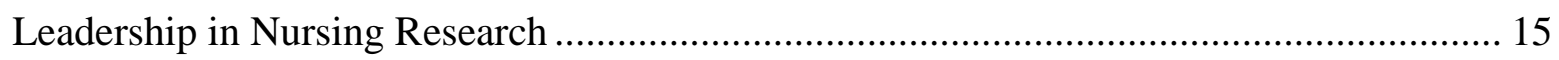

Point-of-care Nursing Leadership Theory and Research ................................................... 17

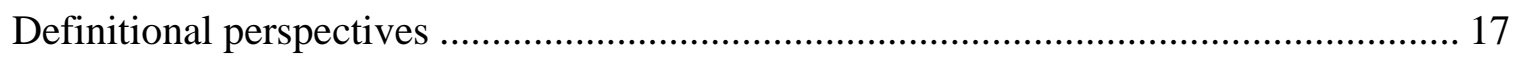

Point-of-care nursing leadership research............................................................... 18

Point-of-care Nursing Leadership and Person-Centred Care Research ............................... 20

The Need for Narratives of Point-of-care Nursing Leadership ........................................... 21

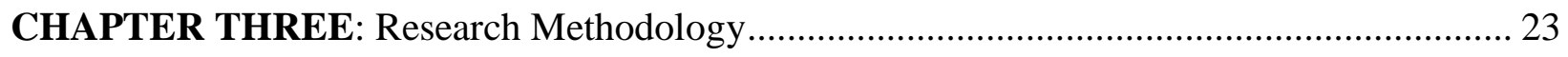

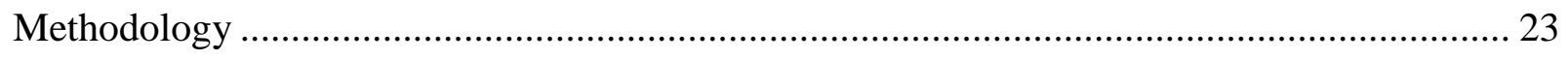

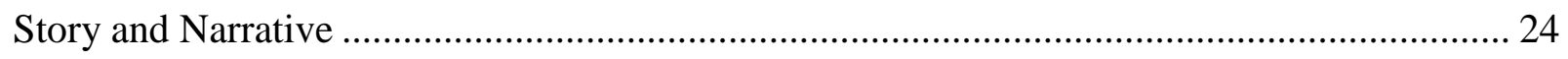

Philosophical and Theoretical Underpinnings of Narrative Inquiry ....................................... 24

Three Commonplaces of Human Experience ……………….......................................... 26

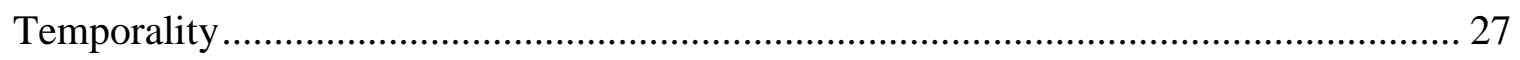

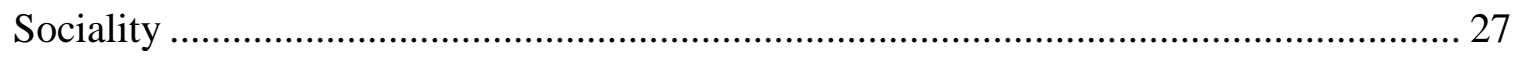

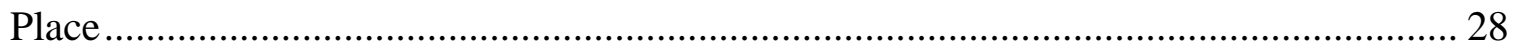

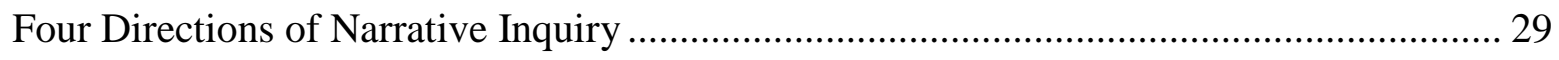

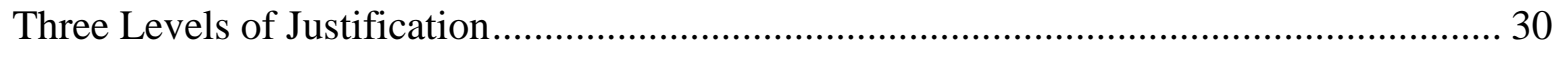

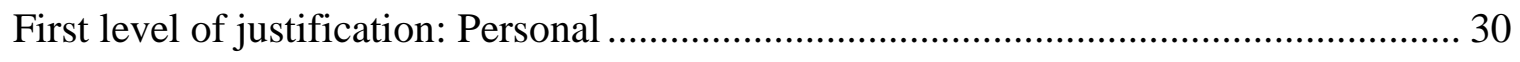

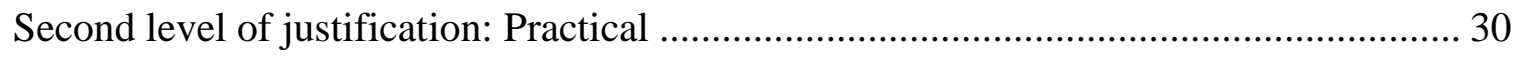

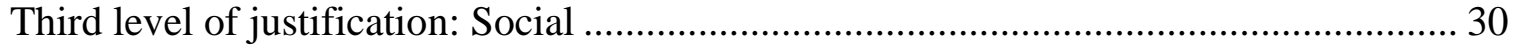


The Narrative Reflective Process .............................................................................. 30

Narrative Inquiry and Point-of-care Nursing Leadership ............................................ 32

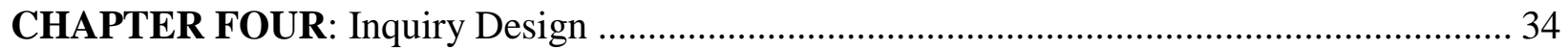

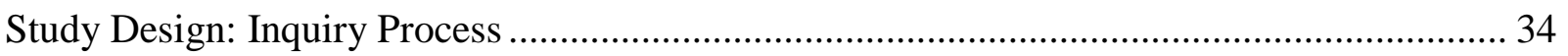

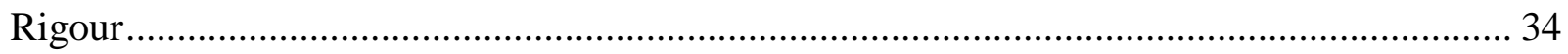

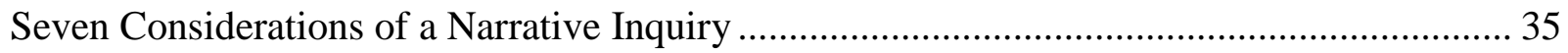

Imagining the Lifespace of the Research Puzzle ............................................................ 35

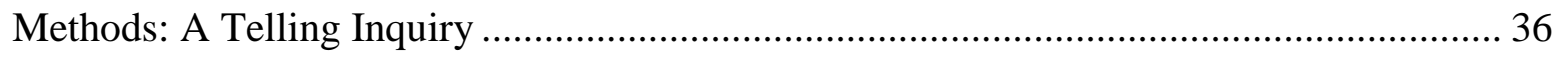

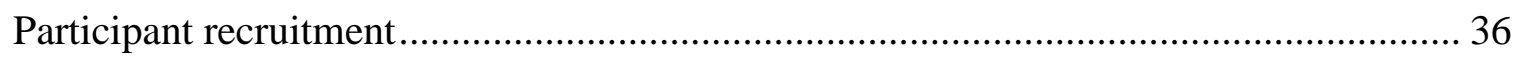

Collection of field text: Telling of lived stories .......................................................... 37

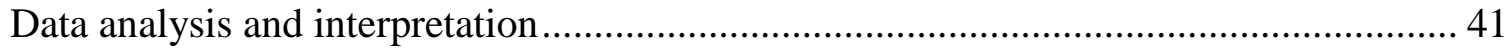

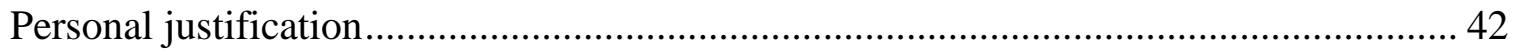

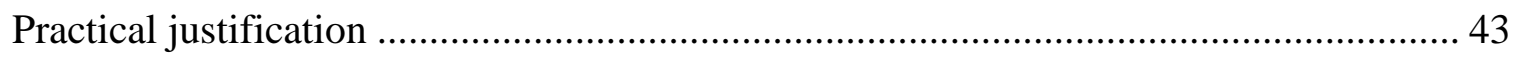

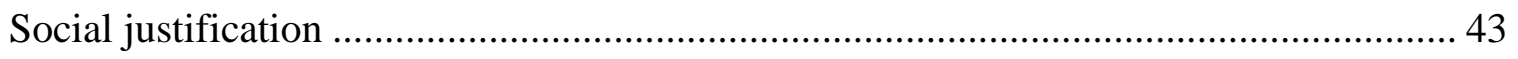

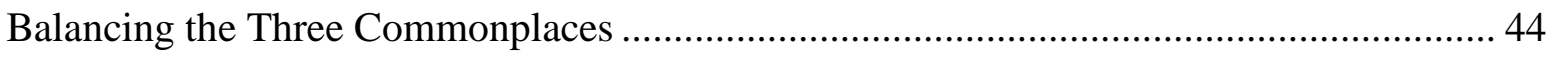

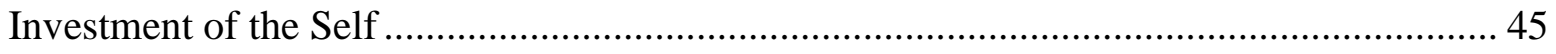

Researcher-Participant Relationship ................................................................ 46

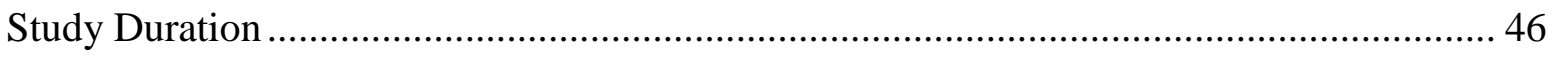

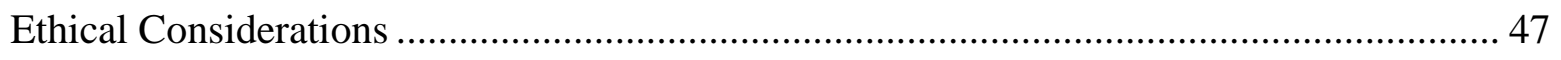

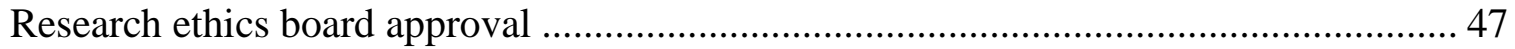

viii 
Autonomy

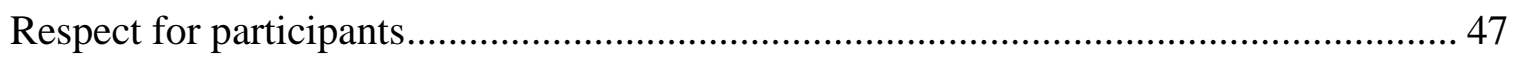

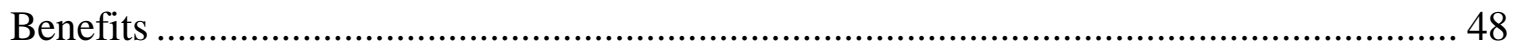

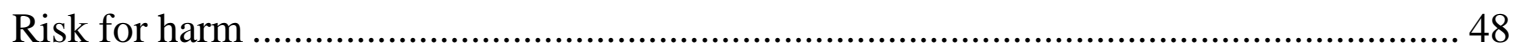

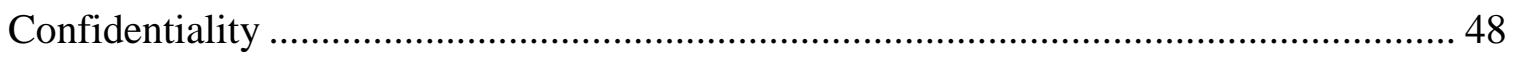

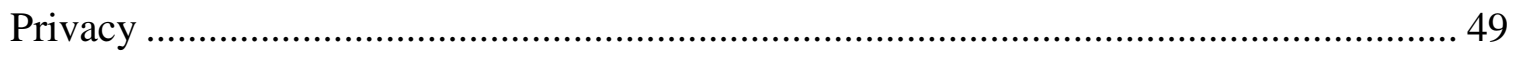

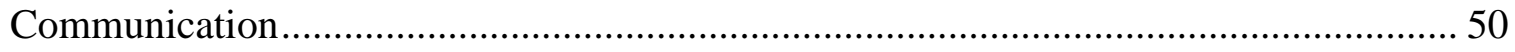

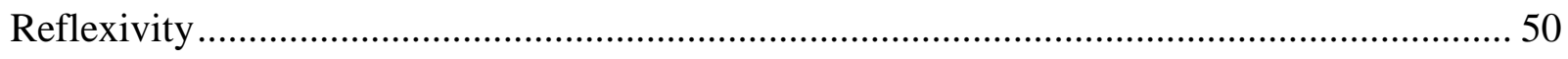

CHAPTER FIVE: Personal Justification ..................................................................... 52

A Perioperative Nurse as a Teddy bear ........................................................................ 52

First Level of Analysis: Personal Justification......................................................... 53

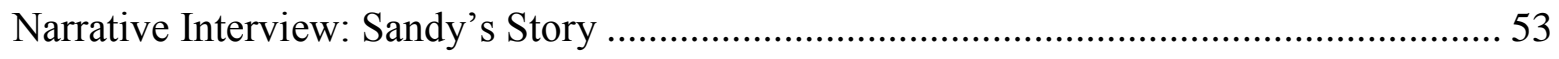

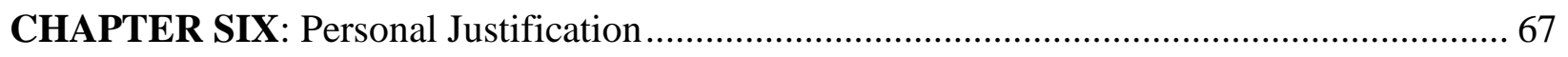

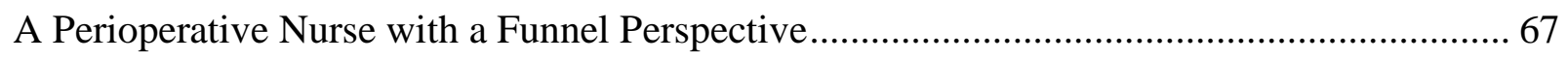

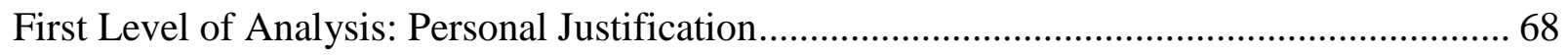

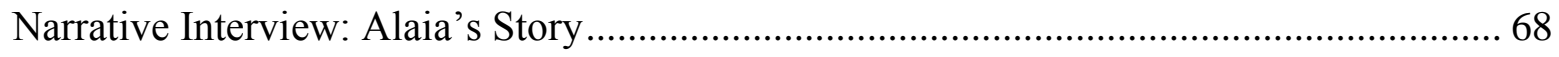

CHAPTER SEVEN: Theoretical Frameworks ........................................................... 85

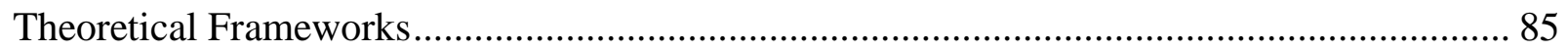

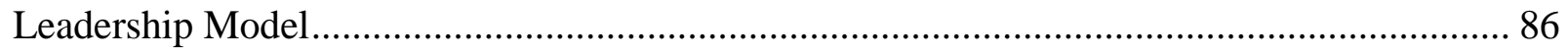

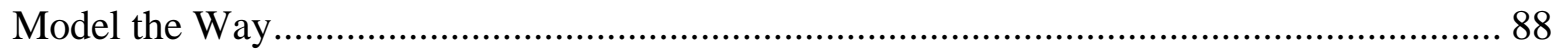




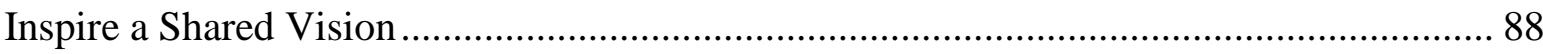

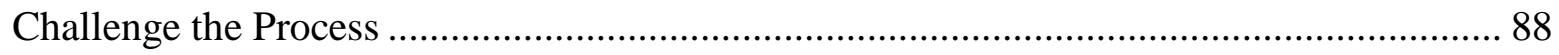

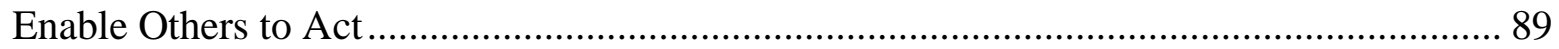

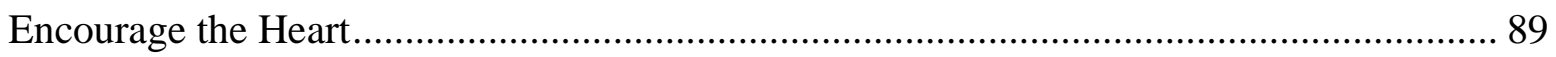

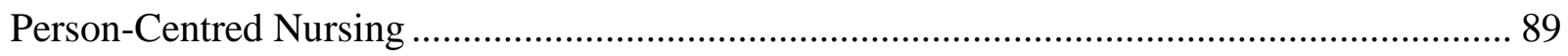

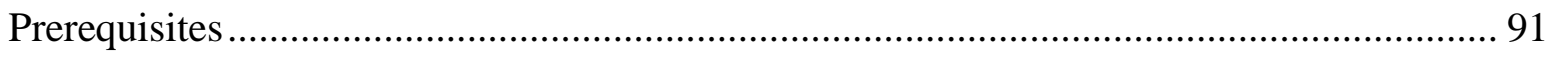

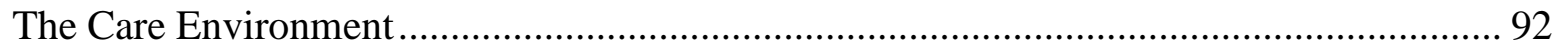

Person-Centred Care Processes............................................................................... 92

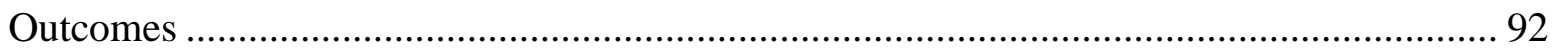

Using Two Theoretical Frameworks to Understand ....................................................... 93

Point-of-care Nursing Leadership in the OR................................................................. 93

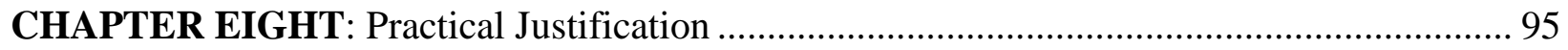

Second Level of Analysis: Practical Justification ....................................................... 95

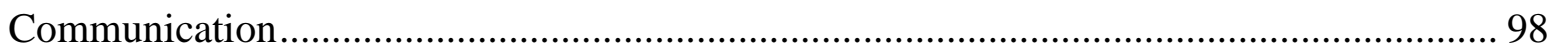

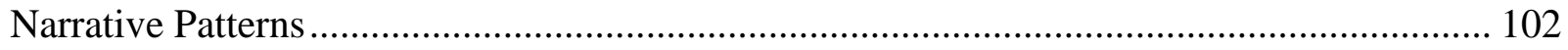

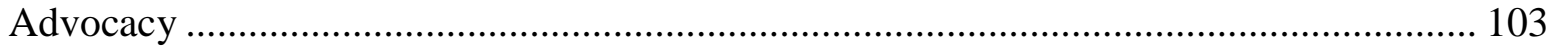

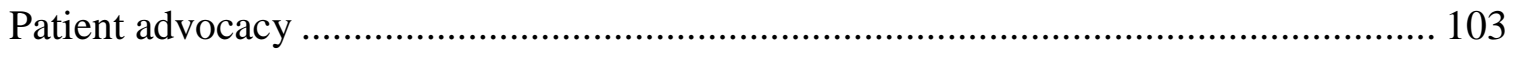

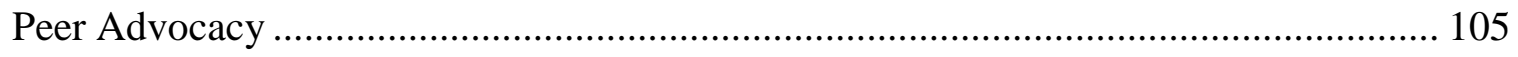

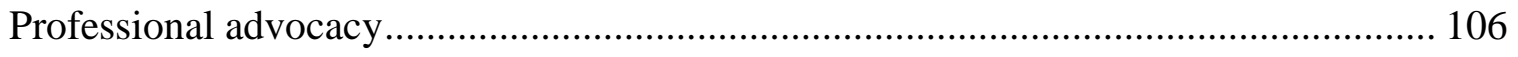

Re-presentation of narrative pattern: Advocacy ................................................... 109 


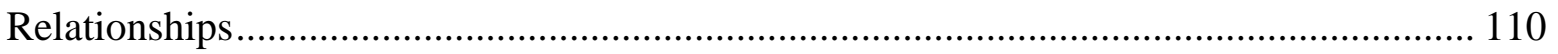

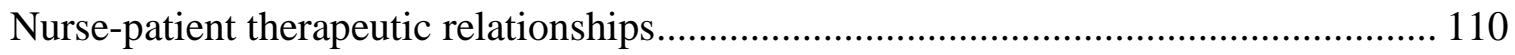

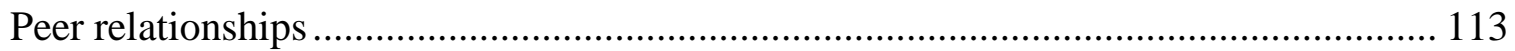

Re-presentation of narrative pattern: Relationships.................................................... 118

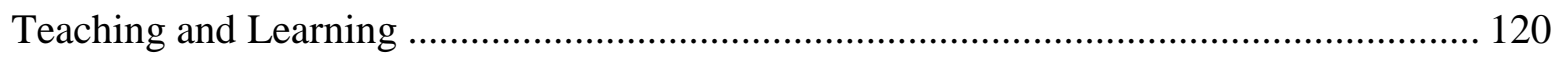

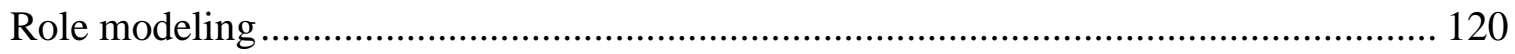

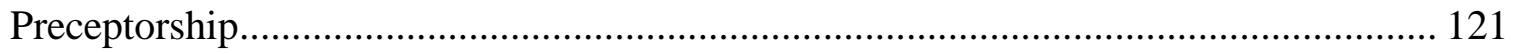

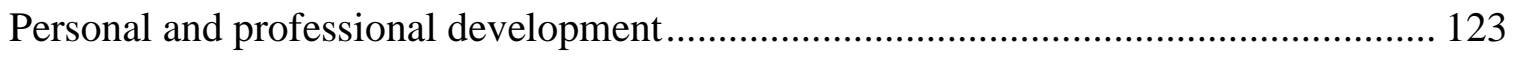

Re-presentation of narrative pattern: Teaching and learning ........................................ 125

Impact of Sandy's and Alaia's Stories on Me .................................................................. 127

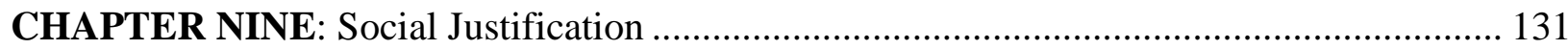

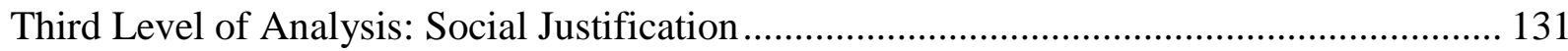

Considerations for Nursing and Healthcare Practice, Education, and Research..................... 131

Nursing and Healthcare Practice .................................................................................. 131

Nursing and Healthcare Education ........................................................................ 133

Nursing and Healthcare Research ....................................................................................... 134

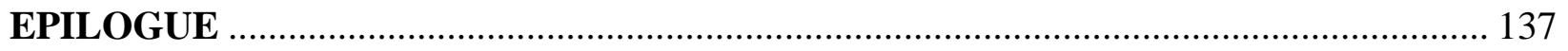

My Metaphor for Person-centred Point-of-care Leadership: Crossing Wooden Bridges .. 137

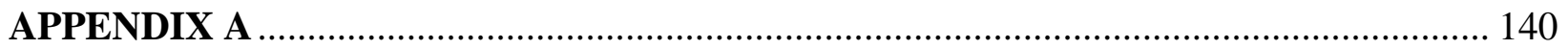

Email Invitation for Participant Recruitment ................................................................... 140 
Recruitment Poster for Participant Recruitment ......................................................... 141

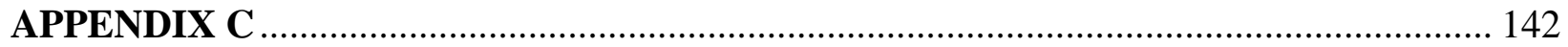

Ryerson University Research Ethics Board Approval ................................................... 142

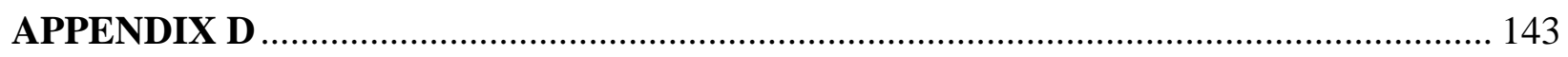

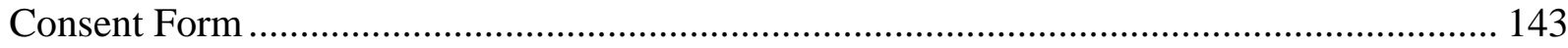

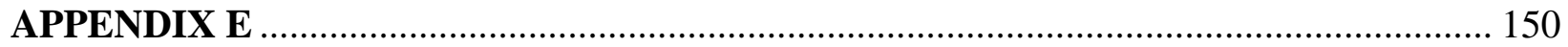

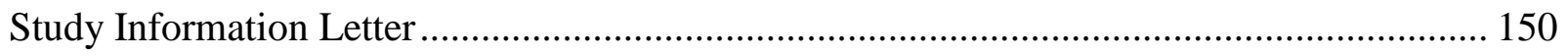

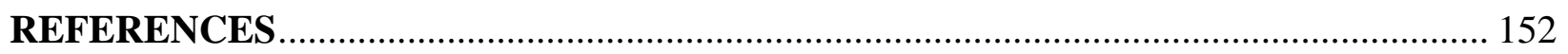




\section{LIST OF FIGURES}

Figure 1. Sandy's Metaphor of Point-of-care Nursing Leadership: A Teddy Bear.................... 64

Figure 2. Alaia's Metaphor of Point-of-care Nursing Leadership: A Funnel ........................... 83

Figure 3. Narrative Inquiry with Integration of Leadership Model and Person-Centred

Nursing ................................................................... 96

Figure 4. My Metaphor for Person-centred Point-of-care Leadership................................. 138 


\section{LIST OF APPENDICES}

APPENDIX A: Email Invitation for Participant Recruitment...........................157

APPENDIX B: Recruitment Poster for Participant Recruitment........................158

APPENDIX C: Ryerson University Research Ethics Board Approval......................159

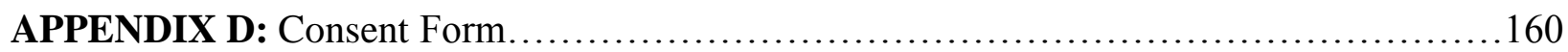

APPENDIX E: Study Information Letter.......................................... 167 


\section{MY HIKE THROUGH A MOUNTAIN: \\ PROLOGUE}

\section{My Thesis Metaphor}

As I reflect on my thesis process, I envision the metaphoric image of a hike through a mountain. My previous journeys of hiking through the vast and varied landscapes of nature have always enabled me to reach a sense of wakefulness, a form of awareness, which is required if I am to examine the multidimensional narratives of human experiences. Although mountain hikes can be an arduous process, due to rugged terrain and environmental elements, I find them invigorating and often times inspiring. The journey I undertake in this thesis is, for me, like one such mountain hike: a rigorous, yet satisfying feat. I would walk along the sunny mountain ridges and through the shadowed valleys below, exploring the hidden glens for treasures they may offer.

I invite you, dear reader, to come walk with me to discover the richness of my hiking experience, which includes two perioperative nurses who, along the way, share their stories of point-of-care leadership in the operating room (OR). I describe each step of my mountain hike at the beginning and at the end of each chapter to reflect every stage of my thesis journey. As you accompany me on this metaphoric mountain hike, I encourage you to reflect on your own experiences of point-of-care leadership, no matter where you practice professionally. Through this process you would then engage in your own journey of self-discovery, potentially enhancing your professional practice. 


\section{CHAPTER ONE}

\section{WHICH MOUNTAIN TO CLIMB?:}

\section{INTRODUCTION}

Before I start my journey, I select the mountain I want to explore. I think about my time in Iceland where I enjoyed the hikes through the mountains filled with waterfalls that echo ferocious sounds of rushing water. I am also filled with excitement when I think about the hikes I took across the glacier fields atop mountains, requiring mental and physical fortitude. I decide that my mountain hike has to be rigorous enough to challenge my abilities, and yet beautiful enough to be inspiring and fulfilling.

For me, engaging in this Narrative Inquiry, is like going on a rigorous hike. This metaphor helps me capture how I experience my thesis process. As a result, each chapter begins and ends with my story of a mountain hike.

As I start my thesis journey, I begin with personal reflections of my own point-of-care nursing leadership experiences in the OR. I go backward in time to my narrative beginnings as an advocate for a patient, named Annie, the experience that has inspired my research puzzle. This becomes the personal justification for exploring the phenomenon, two nurses' experiences of point-of-care leadership in the OR.

\section{My Story}

In order to situate myself in this Narrative Inquiry, I commence this chapter with my narrative beginnings. I reflect on my professional experiences as nurse in the OR. At the outset of my career as a perioperative nurse, I began to ask questions about the role of nurses within the context of the OR. As I developed from a novice to a proficient perioperative nurse, I found my 
voice. I witnessed my increasing ability to speak up on behalf of patients, colleagues, and myself.

When I think about point-of-care nursing leadership as a perioperative nurse, I recall a story of patient advocacy involving Annie, Dr. Smith (pseudonyms) and me.

A patient named Annie is admitted to the OR for a bowel resection. I sense that she is scared. "I don't know what is going to happen. They are still not sure how much tissue they will take out," she says. I remember my own experience as a patient and the feelings of doubt, concern, and fear. I recall wanting the assurance from one of the caregivers that I will be okay. I take hold of Annie's hand and I look into her eyes. I respond, "There is a lot of uncertainty about this procedure. I don't know how much tissue they will take out. I understand that it is causing you to feel scared. I am here with you. Along with the rest of the team, we will take care of you. We are here for you." I stay with Annie as she receives her anaesthetic medications during anaesthesia induction.

As Annie enters the maintenance stage of anaesthesia, I proceed to position Annie for the surgical procedure. There are serious implications related to nerve damage and skin breakdown if anaesthetized patients are positioned incorrectly during surgical procedures, therefore, it is my role to ensure that Annie's skin is protected and her body alignment such that it prevents tissue injury. After positioning Annie into a modified lithotomy position, Dr. Smith requests a 5 kilogram surgical bean bag be placed underneath Annie's coccyx to optimize visualization of the operative site. I know this is wrong. Annie is at high risk for intra-operative skin breakdown for 
multiple reasons: her body mass index of 17; her estimated surgical time greater than 4 hours in a modified lithotomy position; and reduced nutritional intake preoperatively.

There are two other nurses in the OR. They are silent. Questions rush through my mind: "Will my nursing colleagues support me if I ask Dr. Smith to stop? Will they alienate me? Do I have enough power to cause a shift in Dr. Smith's thinking and behaviours?" I feel conflicted in what I should do. I know this is wrong because it poses great risk to Annie's skin integrity. It could potentially cause her pain and prolong her hospital stay if a pressure ulcer develops. I remember my promise to Annie. As a patient, I would want someone to stand up for me if my health and wellbeing are compromised. I approach Dr. Smith and express my concerns by using a sensitive, but firm voice. I request that he avoid the use of the bean bag to reduce the risk of decreased oxygenation to the coccyx region and prevent the development of a pressure ulcer. Dr. Smith simply respects my recommendation, and proceeds with the surgery without the use of the surgical bean bag. I sense no residual negative attitudes between the OR team members. We move forward to care for Annie during this critical moment in her life.

As a result of this event I feel valued by my OR team colleagues, as they have supported my contributions. By expressing my position, I stay true to my commitment to Annie and the promise I have made to her. More importantly, I have prevented injury to Annie, who is at high risk for pressure ulcer development. I consider my actions to be a success. My story gives me a sense of clarity in my purpose as a perioperative nurse in the OR. 
This story for me reflects how I view point-of-care nursing leadership. For me, patient advocacy is of utmost importance. This event inspired me to explore, using Narrative Inquiry (Connelly \& Clandinin, 1990, 2006), how perioperative nurses experience point-of-care nursing leadership.

\section{Point-of-care Nursing Leadership in the OR}

Point-of-care nursing leadership is an informal form of leadership that involves a clinical nurse who is "self-directed in continuously improving his/her own practice, helping others to improve their practice, advocating for the patient, producing safe, quality patient care by the team, and contribute to solving problems within the work environment" (Heid, 2010, p. 105). I use this as my starting definition of point-of-care nursing leadership, which helps me clarify the construct before I engage in this Narrative Inquiry.

My leadership story reflects patient advocacy as a concept embedded within the construct of point-of-care nursing leadership in the OR. Patient advocacy is a process consisting of actions that preserve, represent, and safeguard the patients' rights, interests, and values (Bu \& Jezewski, 2006). The core attributes of patient advocacy include: safeguarding the autonomy of patients; acting on behalf of patients' values, benefits, and rights; and championing social justice (Bu \& Jezewski, 2006). As part of my role as a point-of-care nurse leader within the context of the OR, I am an advocate for my patients, as well as colleagues and myself.

As a perioperative nurse I am interested in exploring how perioperative nurses practice leadership. I use Narrative Inquiry to explore perioperative nurses' experience of point-of-care nursing leadership and what meaning they ascribe to this role within their practice. Through the perioperative nurses' stories, their experiences are illuminated and their point-of-care nursing leadership actions are made visible. 


\section{Statement of Study Purpose}

The purpose of this Narrative Inquiry is to gain a deeper understanding of how perioperative nurses experience point-of-care nursing leadership in the OR and to give voice to their storied experiences.

\section{Research Puzzle}

How do perioperative nurses experience point-of-care nursing leadership in the OR?

\section{Unfolding of my Thesis Journey}

As I embark on my thesis path, I reveal sign posts, which may be helpful in following my progress along the way. Firstly, in keeping with Connelly and Clandinin's Narrative Inquiry approach, I write the thesis in present tense, except in Chapter Four, where I speak about the recruitment of my participants, data collection, and seven Narrative Inquiry considerations. Writing in present tense allows me, as narrative inquirer, to stay close to the experience phenomenon under investigation, the key concept of Narrative Inquiry (Connelly \& Clandinin, 1990).

Secondly, I introduce each chapter with a description of my progress along the metaphoric mountain hike to capture the focus and the content of that particular chapter. This brief introduction is then followed by the substance of the inquiry as it is lived out in this thesis text. At the end of each chapter I return to the metaphoric mountain hike to prepare for the next step on my path.

Thirdly, the brief outline of the subsequent chapters, my hiking map, is detailed below: In Chapter Two, I begin by compiling information about my chosen mountain. To situate this Narrative Inquiry I present the background literature on nursing leadership, followed by relevant research literature in the field. 
In Chapter Three, I pack my backpack for the mountain hike. That is to say that I explicate Narrative Inquiry methodology, including its origins and philosophical and theoretical underpinnings. I also comment on the appropriateness of Narrative Inquiry, to elucidate my research puzzle.

In Chapter Four, I start to climb my chosen hiking trail. Connelly and Clandinin's (2006) seven considerations for Narrative Inquiry are explicated to demonstrate how the rigour and reflexivity, as well as ethical considerations, are maintained throughout the study. I explain how I recruited the two participants, Sandy and Alaia (pseudonyms), and how I collected and analyzed their stories of point-of-care nursing leadership in the OR.

Chapters Five and Six present the stories of two local guides and fellow hikers who help me along my mountain hike (Sandy and Alaia). Their stories of point-of-care nursing leadership are presented. The chosen and illustrated metaphor by each participant is also depicted alongside their stories. My personal interjections are embedded throughout the story to present the personal justification, the first level of analysis, of this Narrative Inquiry.

In Chapter Seven, I reach the glacier field, which I must traverse to reach the peak. I explicate the theoretical frameworks of the Leadership Model (Kouzes \& Posner, 2007) and Person-Centred Nursing (McCormack \& McCance, 2010), which emerge from the participants' stories.

In Chapter Eight, I replenish my energy by the glacier stream. During this practical justification, I use Narrative Inquiry analysis process along with the theoretical frameworks to critically analyze the nurses' stories. I explicate the prominent narrative thread (communication) that permeates all three narrative patterns. I also examine the narrative patterns of advocacy, relationships, and teaching and learning. After each narrative pattern, I re-present the 
participants' experiences in the form of a free verse poem, which reflects the corresponding pattern. I end the chapter with a reflection on the impact of the participants' stories on me, as a perioperative nurse in the OR.

In Chapter Nine, I overcome the elements of rain, ice, and wind. In this chapter I conduct the third level of analysis, the social justification. I discuss the significance and implications related to point-of-care nursing leadership for nursing and healthcare practice, education, and research, as well as the potential benefit to the broader societal context.

I end my thesis with an epilogue. I reach the summit of my mountain. Here I pause for a while to reflect on my mountain hike as a whole, the challenges and the joys, as well as the lessons learned. It is also here that I consider where my hiking spirit will lead me next. That is to say: Which peak in this mountain range will I scale next? I present my metaphor, in the form of a painting, to illustrate my new understanding of person-centred point-of-care leadership, based on my encounters with Sandy and Alaia.

In the next chapter, I discuss the background, as well as the literature review and synthesis. I identify the gaps in nursing and healthcare leadership literature.

After selecting my mountain, I find that I need to learn more about the mountain landscape, as well as the people I may encounter along the way. It is imperative that I know what lays ahead, so I can carefully prepare for my journey. 


\section{CHAPTER TWO}

\section{PREPARING FOR MY MOUNTAIN HIKE:}

\section{LITERATURE REVIEW AND SYNTHESIS}

I gather information about my chosen mountain. I locate its place on the map to learn of its altitude and the potential weather conditions I could encounter. I wonder about some of the unique traditions I might observe with the locals. Will I have access to food and water? Is there a rich biodiversity? By thinking about the mountain's conditions and the available resources, I begin to see the bigger picture of my journey and what I need to consider in order to enrich my experience and ultimately, reach the summit.

After revealing my narrative beginnings and research puzzle, I move forward on my journey of inquiry. I review and synthesize the extant literature in nursing, healthcare and beyond, related to the phenomenon of inquiry, point-of-care nursing leadership in the OR. This informs the second (practical) and the third (social) levels of justification for undertaking this Narrative Inquiry.

\section{Background: Healthcare Landscape}

It is becoming increasingly important for front line clinical nurses to engage in nursing leadership at the point of contact to effectively promote the health of the persons in their care. The twenty-first century brings forth changes in health care organizations and systems related to the aging population, technological advancements, and sophisticated consumerism (PeterO'Grady, 2001; Registered Nurses' Association of Ontario [RNAO], 2013). As the healthcare system experiences change, nursing practice is also undergoing a similar change (Heid, 2010; Mahoney, 2001). Nursing has moved into a new paradigm of practice, challenging nurses to develop nursing practice skills of "accessing, informing, guiding, teaching, counseling, typing, 
and linking” (Peter-O’Grady, 2001, p. 183). RNAO’s (2013), Developing and Sustaining Nursing Leadership Best Practice Guideline, encourages all nurses, including nursing educators, administrators, and clinicians, to develop leadership competencies to adapt to the growing pressures of cost savings and increasing productivity, while responding to the demands from the changing population and healthcare system. Regardless of the nurses' position or title, nurses are expected to utilize skills and competencies related to leadership to encourage innovation and adapt to these changes in healthcare and nursing (Heid, 2010).

Perioperative nursing has evolved alongside these population health changes and technological developments. Nurses in the OR must continually adapt to the evolving expectations and values that come with surgical advancements (Bull \& FitzGerald, 2006). Despite such changes, perioperative nurses still maintain "a strong identity as patient advocates and protectors" (Sax, 2012, p. 16). They have extensive experiences navigating through the policies and procedures that may cause conflict with other members of the OR team, who may have different motivations (Sax, 2012). Surgeons are driven to treat an illness or an injury. Anaesthetists are concerned with maintaining the patient's hemodynamic functioning while administering inherently toxic medications intraoperatively. OR teams are expected to function optimally to ensure that health goals are achieved (Sax, 2012). However, a social hierarchy in the OR exists, which dominates team relations (Gillespie, Wallis, \& Chaboyer, 2008). This may pose challenges for perioperative nurses in their role as patient advocates.

Perioperative nursing is an interesting field to study point-of-care nursing leadership because of the intricate team relations and the technological advancements that directly impact patient care. Leadership by perioperative nurses, within the context of multidisciplinary teams, is 
still unexplored. This Narrative Inquiry addresses this gap in the nursing leadership literature by adding to the understanding of leadership by clinical nurses in the perioperative space of the OR.

\section{Literature Review}

\section{General Leadership Theory and Research}

Leadership literature is vast and varied with multiple definitions of leadership, which can be categorized based on the variable that is emphasized: leader characteristics, follower characteristics, or situational characteristics (Yukl, 2010). Leadership is defined according to researchers' individual perspectives and the elements of the phenomenon that are of interest to them. Most leadership definitions reflect the assumption that leadership is a process that involves intentional influence exerted over others in a particular group or organization with a purpose of guiding and facilitating their actions, activities, and relationships (Yukl, 2010).

Early developments in leadership theory and research focused on studying the individual leaders in some large private-sector organizations. The initial leadership theories, such as trait or behavioural approaches, focused on the leader's traits, how they were chosen, and how well they functioned (Weberg, 2012). As time progressed along with the knowledge-driven economy, traditional models of leadership needed re-thinking and revising because of the increasing interdependence, creativity, and complexity of the knowledge and skills required to complete tasks (Pearce \& Barkus, 2004). As the leadership field evolved, there was a shift in focus to the followers, peers, culture, work setting/context, and supervisors (Avolio, Walumba, \& Weber, 2009). In doing so, leadership research expanded to include a broader range of individuals from private, public, and not-for-profit organizations (Avolio et al., 2009).

Leadership is no longer considered as an individual characteristic, but it is depicted as shared, relational, strategic, global, dyadic, and complex (Avolio et al., 2009). New models, such 
as shared leadership (Pearce \& Conger, 2003), transformational leadership (Avolio et al., 2009) and authentic leadership (Gardner, Avolio, Luthans, May, \& Walumba, 2005) have been developed to directly address leadership as a relational process that facilitates positive outcomes for teams and organizations. Nicolaides et al. (2014) demonstrate in their meta-analysis a moderately strong relationship between team effectiveness and shared leadership. Hoch (2012) also demonstrates a positive association between shared leadership and team performance. In a meta-analysis by Burke et al. (2006), transformational leadership behaviours, such as consideration and empowerment, are associated with perceived team effectiveness. Authentic leadership behaviours are associated with employee work engagement (Walumba, Wang, Wang, Shaubroeck, \& Avolio, 2010) and voice behaviours (Hsiung, 2012).

The above overview of the general leadership literature demonstrates how leadership theory and research continue to evolve synchronously with our knowledge-driven economy. Our current understanding of leadership, specifically in healthcare, also continues to grow, as more theories are being developed through various research undertakings, such as this Narrative Inquiry, which explores the particular aspect of this phenomenon, point-of-care leadership within the OR context.

\section{Leadership in Healthcare Research}

With its rising costs, limited resources, system inefficiencies, and increasing complexity, the healthcare landscape requires a new approach to leadership (Weberg, 2012). Healthcare workers are increasingly required to work in teams to support the patients' or clients' experiences, while maximizing their safety along the continuity of care. As a result, team-based approaches to leadership are warranted (Kunzle, Zala-Mezo, et al., 2010). Knowledge work that is complex, interdependent, and creative, has a greater need for shared leadership (Pearce \& 
Barkus, 2004). Shared leadership is an interactive influence process between individuals of a group whereby the objective is to lead one another towards achievement of group goals (Pearce $\&$ Conger, 2003). Shared leadership differs from traditional models because leadership is distributed amongst a group of individuals instead of being concentrated in the hands of one person (Pearce \& Conger, 2003). In a quasi-experimental study, Kunzle, Zala-Mezo, et al. (2010) demonstrate that high-performing teams in the OR have higher levels of shared leadership in comparison to low-performing teams, especially when task load, complexity, and interdependency are high. Anaesthesia residents who share leadership functions with anaesthesia nurses are more likely to accept the medical know-how of nurses. In high-performing teams, the members' strengths are used and the leadership functions are transferred appropriately between OR team members. Consequently, patient safety is supported (Kunzle, Zala-Mezo, et al., 2010). Effective communication is consistently being recognized as a facilitator of leadership in healthcare to promote safety for the givers and recipients of health care (Higgins et al., 2014; Kunzle, Kolbe, \& Grote, 2010; Kuo \& Robb, 2013). Failures in communication can result in team tension, resource waste, inefficiency, delay, procedural error, and patient inconvenience (Lingard et al., 2004). Hoch (2012) suggests that information sharing facilitates the positive association between shared leadership and team performance. Safe communication requires "transparent dialogue and effective teamwork" among healthcare team members to improve healthcare performance and safety outcomes (Kuo \& Robb, 2013). Leadership behaviours that are visible and unambiguous enhance team performance, thus ensuring patient safety (Kunzle, Kolbe, et al., 2010).

Leadership and collaboration between healthcare professionals foster the safest environments for patients (Kunzle, Kolbe, et al., 2010; Kuo \& Robb, 2013). Based on a literature 
review by Kuo and Robb (2013), surgical safety elements are identified in orthopedic surgery practice, which include communication, consent, checklists, confirmation, concentration, and collection. There is a need to shift the traditional authoritative role of surgeon to an effective communicator and collaborative member of the healthcare team. Anaesthetists also prefer nonhierarchical structures where leadership is shared between formal leaders and team members to safeguard patient safety (Kunzle, Kolbe, et al., 2010). This reflects the movement away from the autocratic approach to leadership towards one that is shared and situational, thus shifting the focus to the followers, peers, and work context.

Healthcare professionals recognize the need for collaborative or shared leadership in interprofessional teams (Higgins et al, 2014; Kunzle, Kolbe, et al., 2010; Kuo \& Robb, 2013). Bergman, Rentsch, Small, Davenport, and Bergman (2012) reveal in their quasi-experimental study that teams who share leadership functions amongst its members experience a full range of leadership behaviours, such as consideration, envisioning, and spanning. Teams with shared leadership experience more consensus, less conflict, and "higher intragroup trust and cohesion" (Bergman et al., 2012, p. 17).

Although health care professionals agree that shared leadership is essential to effective team performance and overall functioning, enactment of this type of leadership continues to be a challenge. In an ethnographic research by Lingard et al. (2012), physicians believe that there is a nonhierarchical functioning team, while other non-physician team members report the persistence of hierarchical behaviours. Tang, Chang, Zhou, and Liaw (2013) also suggest that physicians are more likely to rate the quality of collaboration higher than nurses. Although nurses contribute to the informal learning of doctors (Burford et al., 2013), nurses feel that there is unequal power and they do not feel respected or trusted by physicians, which has implications 
on the leadership processes that occur in healthcare teams (Tang et al., 2013). An individual's experience may carry authority regardless of one's position in the structural hierarchy. However, doctors and nurses continue to implicitly maintain the dominance of the medical profession in healthcare (Burford et al., 2013).

The extant healthcare literature suggests that effective communication and collaboration are facilitators of leadership. However, a structural hierarchy that pervades the healthcare system, continues to challenge the enactment of this shared leadership approach. These challenges require further exploration to ensure the leadership potential of healthcare professionals is actualized.

\section{Leadership in Nursing Research}

The future of nursing rests on leadership at every level of the system (O'Grady, 2011). Nurse clinicians, educators, managers, administrators, and researchers may engage in leadership practices of mentoring, coaching, challenging the process, questioning the status quo, and questioning treatments (RNAO, 2013). The nurses' position in the patient care arena predisposes them to facilitating, coordinating, and integrating team practices to maximize quality, value, and access to patient-centred care environment (O'Grady, 2011).

Nursing research, which examines the construct of leadership, suggests that nursing tends to concentrate on transformational leadership by nurses (RNAO, 2013). Transformational leadership is a leadership style whereby the leader motivates and supports its followers to work collaboratively towards achievement of shared aspirations (Rolfe, 2011). The followers are inspired and empowered to reach their full potential (Avolio, Zhu, Koh, \& Bhatia, 2004). Nursing research studies that examine transformational leadership have largely used quantitative research methodology and design, especially correlational research. Formal leadership roles 
carried out by upper level management, such as nurse managers, are of great interest to most of these nurse researchers. Transformational leadership is associated with positive patient outcomes. In a systematic review by Wong and Cummings (2007), they suggest that transformational nursing leadership is associated with patient satisfaction and reduction in patient adverse events. Transformational leadership is also associated with positive outcomes for nurses. Job satisfaction has been associated with relational leadership in a correlational study by Cummings et al. (2008) and a systematic review by Cummings et al. (2010). Nurses' role performance, through improvements in self-efficacy and work engagement, is positively related to transformational leadership of nurse supervisors in a correlational study by Salanova, Lorente, Chambel and Martinez (2011).

Current qualitative nursing research on transformational leadership also focuses highly on the leadership of nurses in formal leadership and managerial positions. Linton and Farrell (2009) identify five themes in their phenomenological study of intensive care unit (ICU) nurses' perceptions of nursing leadership: leading by example, "ability to think outside the management square", communication, knowing your staff, and "stepping up in times of crisis" (p. 67- 69). In another phenomenological study, Salmela, Eriksson, and Fagerstrom (2012) examine main tasks and roles of nurse leaders, such as head nurses and directors of nursing, as they go through a process of change. In one Narrative Inquiry, Adams (2010) examines one nurse leader's transformational leadership as she helps organize and build the first hospice in the United States of America. The nurse leader demonstrates behaviours of supporting and inspiring her hospice team by valuing contributions and raising their consciousness towards meaningful change.

Nursing research studies (Brown, 2010; Kallas, 2014; Patrick, 2010; Patrick, Laschinger, Wong, \& Finegan, 2011) have used Kouzes and Posner's (2007) Leadership Model to examine 
the exemplary leadership practices of nurses. Kouzes and Posner conceptualize exemplary leadership as an application of both transactional and transformational leadership styles. They identify five leadership practice domains: model the way, inspire a shared vision, challenge the process, enable others to act, and encourage the heart. By using a qualitative research design, Brown (2010) examines the positive effects of leaders' behaviours of shared decision-making and supportive behaviours on clinical nurses' satisfaction. In a non-experimental design study by Patrick (2010), results show that manager leadership behaviours influence staff nurse clinical leadership through an empowered work environment.

Nurse researchers have also used Kouzes and Posner's Leadership Practice Inventory (LPI) self-instrument to measure exemplary leadership practices of nurses, especially nurse managers. In an exploratory quantitative study, Kallas (2014) uses the LPI as a tool to measure and develop a profile of an excellent nurse manager. In a longitudinal outcomes research study, Krugman, Heggem, Kinney, and Frueh (2013) demonstrate significant improvements in LPI scores of charge nurses after participation in leadership educational initiatives. In a correlation study by Loke (2001), she demonstrates that nurse managers with higher LPI scores are associated with employee job satisfaction, organizational commitment, and productivity.

Based on these studies, nursing research has largely focused on leadership by nurses in formal leadership positions, more specifically nurse managers. This identifies a gap in the literature, which supports the need to examine storied experiences of leadership by nurses at the point-of-care.

\section{Point-of-care Nursing Leadership Theory and Research}

Definitional perspectives. Point-of-care nursing leadership is a complex construct with various names and definitions. The construct of point-of-care nursing leadership is addressed in 
literature using the terms clinical leadership (Cook, 2001; Patrick, 2010; Patrick et al., 2011) and staff nurse leadership (Heid, 2010). I have chosen the term point-of-care nursing leadership from the RNAO’s (2013), Developing and Sustaining Nursing Leadership Best Practice Guideline, who uses the term. Heid (2010), in her doctoral dissertation, defines staff nurse leadership as a multilevel construct that involves the leader, follower, and context, which has been adapted as a starting definition for point-of-care nursing leadership in this Narrative Inquiry. In this study, I use the term point-of-care nursing leadership because the term best captures the narrative view of experience. The term point-of-care nursing leadership aligns and emphasizes Narrative Inquiry's three commonplaces (sociality, temporality, and place) of human experience. The word care connotes the moral, affective, behavioural, and interpersonal dimensions of leadership, which are consistent with the commonplace of sociality. The word point refers to the time and place where leadership occurs, which comprise the commonplaces of temporality and place. Narrative Inquiry's three commonplaces (temporality, sociality, and place) are discussed in more detail in Chapter Four on methodology.

Point-of-care nursing leadership research. The healthcare system recognizes the significance of leadership by front line nurses in improving outcomes for patients, nurses, and other members of the healthcare team (RNAO, 2013). Research that examines point-of-care nursing leadership continues to grow and improve our understanding of the phenomenon (RNAO, 2013). In her doctoral dissertation, Heid (2010) uses a grounded theory research methodology to explore the process of nursing leadership at the staff nurse level. Three categories emerge, which include "recognizing the need to act, assessing responsibility, risks, and roadblocks, and making a choice" (Heid, 2010, p. 109). The attributes and experiences of 
clinical leadership are also explored in other studies using grounded theory methodology (Cook \& Leathard, 2004; Stanley, 2006).

The inclusion of nurse managers and front line clinical nurses in research studies can provide perspectives from both clinical and administration domains, which can be seen in the following qualitative research studies. In a phenomenological study by Burns (2009), the factors influencing the development of clinical leadership skills in general practice are identified, which include role development opportunities and organizational structure and culture. Sorensen, Iedema, and Severinsson (2008) use an ethnographic research approach in their study of nursing leadership and its contribution to the organization and management in health care, specifically the end-of-life care in ICU. The hierarchical nature of the decision-making process in the ICU that serve the status quo of medicine is highlighted as the nurse managers struggle to balance their administrative and clinical domains. The same medicine-focused status quo excludes clinical nurses in the decision-making process related to their patient care (Sorensen et al., 2008).

The effectiveness of leadership development programs on improving leadership behaviours of nurses have been evaluated by nurse researchers who study point-of-care nursing leadership. Alleyne and Jumaa (2007) utilize an action research methodology in their study to build capacity for clinical nursing leadership through management and leadership interventions, such as executive co-coaching and focused group clinical supervision. Dierckx de Casterle, Willemse, Vershuerren, and Milisen (2008) suggest that nurses experience improvements in communication with greater sense of responsibility towards the patient and problem resolutions on the ward after completing a leadership program. In a quasi-experimental study, George et al. (2002) demonstrate improvements in staff nurses' shared leadership behaviours as a result from a shared leadership concepts program. 
These studies provide evidence that validate the importance of informal form of leadership by point-of-care staff nurses in healthcare and nursing. Nurses at the point-of-care have clinical expertise that is valuable for enhancing the quality of patient care, as well as their work environments (Doran, Koh, Dick, Hayes, Van Wiechen, \& Yim, 2012). Leadership development programs also have the potential to increase nurses' leadership at point-of-care.

\section{Point-of-care Nursing Leadership and Person-Centred Care Research}

Staff nurses provide direct patient care at the clinical level. Their leadership behaviours are embedded in their nursing practice of patient care (Patrick, 2010). In her doctoral dissertation, Patrick explicates the clinical leadership behaviours of staff nurses through the enactment of Kouzes and Posner's (2007) five exemplary leadership practice domains. Nurses at the point-of-care demonstrate leadership behaviours of collaborating, coordinating, and influencing colleagues, patients, and families.

Commitment to patient-centred care is one of the leadership behaviors outlined in Patrick et al.'s (2011) model of clinical leadership. Person-centred care in nursing and healthcare has been largely explored in research. The effectiveness of adopting a person-centred care approach for patients with Alzheimer's (Hayajneh \& Shehadeh, 2014) and dementia has been examined (Jeon et al., 2012; Luscombe et al., 2012; Sjogren, Lindkvist, Sandman, Zingmark, \& Edvardssion, 2013; Smythe, Bentham, Jenkins, \& Oyebode, 2015). In a quasi-experimental study, Jeon et al. (2012) suggest that the implementation of person-centred care involves a whole systems approach from individualized care of patients/clients/residents to supportive interaction with staff. Healthcare staff members have reported increases in perceived support from management after an institutional implementation of person-centred care in residential aged care institutions. Person-centred care by healthcare providers has also been associated with higher 
levels of quality of life with improvements in abilities to carry out activities of daily living for residents in dementia care units (Sjorgen et al. 2013).

Person-centred care has also been explored in nursing and healthcare education (Currie et al., 2015; Schwind, Lindsay, Coffey, Morrison, \& Mildon, 2014; Schwind, Santa Mina, Metersky \& Patterson, 2015; Steenbergen, 2013). In an arts-informed Narrative Inquiry, Schwind et al. (2014) elucidate how nursing students and nurses co-construct their knowledge, skills, and competencies in person-centred care through "exploration of experience and dialogue" (p. 1170). They suggest that creative activities, such as of Narrative Reflective Process and cocreative art making, promote students', nurses', and other healthcare providers' engagement in critical reflection on their person-centred care. Thus, giving rise to new knowledge and possibilities in their professional practice. Devenny and Duffy (2014) also emphasizes the significance of critical reflection in healthcare education. They suggest that healthcare providers engage in reflective practice to explore the desires, wishes, values, and beliefs of patients, as well as their own. By embodying person-centredness in nursing practice, nurses can empower the persons in their care by mobilizing resources that respect human rights, values, and beliefs (McCance, McCormack, \& Dewing, 2011).

\section{The Need for Narratives of Point-of-care Nursing Leadership}

The review of the leadership literature suggests that there is a high concentration of qualitative and quantitative research studies that focus on leadership by nurses in formal leadership roles, such as upper level management. Previous studies (Alleyne \& Jumaa, 2007; Burns, 2009; Cook \& Leathard, 2004; Dierckx et al., 2008; Patrick, 2010; Stanley, 2006) have contributed to the growing body of empirical literature on point-of-care nursing leadership. Our 
understanding of point-of-care nursing leadership continues to grow with more research that examines the phenomenon (RNAO, 2013).

This literature review demonstrates the paucity of nursing studies, especially those using rigorous qualitative research, that examine nursing leadership at the point-of-care. Furthermore, research studies that investigate the leadership experiences of perioperative nurses in the OR is still lacking. By implementing Narrative Inquiry (Connelly \& Clandinin, 1990, 2006), I endeavor to remedy this gap by exploring, and thereby giving voice to nurses as they tell their experiences of point-of-care nursing leadership in the OR.

In the next chapter, I focus on the research methodology that I use in this inquiry. I explicate the philosophical and theoretical underpinnings of Narrative Inquiry (Connelly \& Clandinin, 1990, 2006).

After inquiring about my chosen mountain, I take out my empty backpack to fill it with the essentials for my journey. I review my list of required items making mental notes of where I can acquire them. 


\section{CHAPTER THREE \\ PACKING MY BACKPACK: \\ RESEARCH METHODOLOGY}

I strategically collect the necessary equipment for my hike. The basic essentials of food, water, and first aid kit help me prepare for the mental and the physical challenges of my journey. I anticipate that the mountain will quickly change to a rugged terrain with increasingly uncertain weather. Consequently, I bring waterproof and wind-resistant clothing, and hiking boots. As I excitedly imagine the textured and precarious landscape of glaciers that I will encounter closer to the summit, I also bring along the essential crampons (spikes for walking on glaciers).

After reviewing and synthesizing the literature, I move forward to describing the methodology I use in this inquiry. More specifically, I explicate the philosophical and the theoretical underpinnings of Connelly and Clandinin's $(1990,2006)$ Narrative Inquiry.

\section{Methodology}

In this chapter, I explicate the philosophical underpinnings of Narrative Inquiry, which are traced back to Dewey's theory of experience and pragmatic philosophy (Clandinin \& Connelly, 2000). The theoretical foundations of Narrative Inquiry as a research approach are further described by outlining its key concepts, such as the three commonplaces (temporality, sociality, and place), four directions of inquiry (backward, forward, inward, and outward), and the three justifications (personal, practical, and social) for studying a particular phenomenon, and later in the study as the analysis process (Clandinin \& Connelly, 2000). I conclude this chapter by describing the creative data collection tool, inspired by Narrative Inquiry, called Narrative Reflective Process (Schwind, Cameron, Franks, Graham, \& Robinson, 2011). 


\section{Story and Narrative}

Narrative Inquiry studies human experience by the means of a story (Connelly \& Clandinin, 1990). Within the context of Narrative Inquiry research, the terms story and narrative have distinct definitions. Participants live and tell stories of experience related to a particular phenomenon of interest. Upon observing, hearing, reading, and re-telling these lived and told stories, the narrative inquirer begins to interpret them to construct a cohesive story with a temporal sequence. The constructed story is negotiated with the participants and de-constructed through the Narrative Inquiry analysis process (J. K. Schwind, personal communication, April 30, 2014). New meaning and understanding about the human experience under study arises from the analysis (J. K. Schwind, personal communication, April 30, 2014), thus re-constructing the story to create the narratives of experience (Connelly \& Clandinin, 1990).

\section{Philosophical and Theoretical Underpinnings of Narrative Inquiry}

The intellectual roots of Narrative Inquiry research methodology can be traced back to the humanities and other fields in narratology, such as anthropology and philosophy, amongst others (Connelly \& Clandinin, 2006). Social science research began studying narratives of human experience in the late 1980s and early 1990s. Connelly and Clandinin published their first writings about Narrative Inquiry as a research approach in the field of education in 1990 (Clandinin, 2013; Clandinin \& Connelly, 2000; Clandinin, Pushor, \& Orr, 2007; Clandinin \& Rosiek, 2007). The development of Narrative Inquiry grew out of Connelly and Clandinin's interest in understanding experiential knowledge (Clandinin, 2013). Influenced by Dewey’s (1997) key concepts of experience and education, Connelly and Clandinin first understood Narrative Inquiry as a phenomenon and a method. However, they began to comprehend 
Narrative Inquiry as a methodology because of the interconnected "narrative ways of thinking about phenomena" (Clandinin, 2013, p. 11).

Narrative Inquiry is a way of thinking about human experience. This research approach takes on a narrative view of experience that is influenced by Dewey's theory of experience, which has its philosophical origins in pragmatic philosophy and Aristotle's conceptions of dualistic metaphysics (Clandinin \& Connelly, 2000; Clandinin \& Rosiek, 2007). Dewey (1997) asserts that the examination of experience is important for intelligently conducted education. Research, education, and life are interconnected. To study education is to study life (Clandinin \& Connelly, 2000).

Dewey's conception of experience situates the philosophical foundations of Narrative Inquiry (Clandinin, 2013; Clandinin \& Rosiek, 2007). According to Dewey, experience is where all inquiries begin. Experience is conceptualized as a continuous interaction between human thoughts and their personal, physical, and social environments. Things and events of the physical and social world enter the human context, transforming the objects and rendering the individual changed and improved (Clandinin, 2013). This Deweyan view of experience recognizes "the embodiment of the person living in the world", who shapes and is shaped by the social, institutional, and cultural narratives of the person's experiences (Clandinin \& Rosiek, 2007, p. 13). The influence of Dewey's pragmatic ontology is observed in Connelly and Clandinin's (2006) writings about the story as an ontological experience: "story, in the current idiom, is a portal through which a person enters the world and by which his or her experience of the world is interpreted and made personally meaningful" (p. 477). Story is a reflection of one's social reality, and therefore, it is the closest channel we have to that human experience (Clandinin \& Connelly, 2000; Clandinin \& Rosiek, 2007). 
Dewey's philosophy also proposes that experience is transactional with epistemological implications. Knowledge arises from experience. To validate our knowledge, we must return to our storied experiences, which can be studied by living alongside one another, observing, listening, writing, and interpreting texts (Clandinin \& Rosiek, 2007). When undertaking an inquiry using a pragmatic framework, narrative is the most suitable form to use to study experience. Narratives are considered the form of representation of human experience unfolding through time in particular place or places (Clandinin \& Rosiek, 2007). By studying narratives, we study the ways in which humans experience the world. It is through narratives that knowledge is made explicit (Connelly \& Clandinin, 1990).

\section{Three Commonplaces of Human Experience}

Connelly and Clandinin's (1990) Narrative Inquiry is the study of experience as a story. Humans live out storied lives, both individually and socially. According to these researchers, humans are storytellers by nature who live, tell, and retell their stories in words that enable them to reflect upon their life and clarify themselves to others in the present moment with the purpose of growth in the future. With this view, we are "engaged in the living, telling, retelling, and reliving" of stories (Connelly \& Clandinin, 2006, p. 4). To engage in inquiries that utilize Narrative Inquiry as a methodology, researchers must learn and think narratively as they frame their research puzzles, enter the field, and compose field texts, interim texts, and research texts (Clandinin \& Connelly, 2000).

To think narratively as inquirers, we must think about Dewey's philosophy of experience that identifies the criteria of continuity, interaction, and situation for every human experience. Dewey's pragmatic ontology is influential in the development of what Connelly and Clandinin (2006) call the three commonplaces: temporality, sociality, and place. Researchers attend to the 
interplay of all three commonplaces in the lived and told stories of experience throughout the entire Narrative Inquiry process (Clandinin \& Connelly, 2000).

Temporality. Dewey's (1997) first criterion of continuity of experience asserts that every experience grows out of past experiences, which then modifies the quality of future experiences. Based on this notion of continuity, Connelly and Clandinin (2006) have conceptualized the commonplace of temporality. As narrative inquirers, we examine the temporality of the objects, places, and events that occur in the experiences of our participants, as well as our own. Temporality is embodied in the person who is living or telling her/his life stories (Clandinin, 2013). By attending to the temporality, we are attending to the changes in our internal and external environment that occur over time. Throughout the research process, we travel with the participants across landscapes over time to know who we are in the present, where we have been in the past, and the directions for our future physical, intellectual, and moral growth (Clandinin, 2013). Upon completion of a Narrative Inquiry, the co-participants retell and relive their told stories by applying their newfound knowledge in future endeavours. The final research texts are also re-interpreted and applied by its readers across various landscapes, further supporting the continuity, and the transferability, of experiences.

Sociality. Dewey's (1997) second criterion of interaction asserts that all human experience is social. Humans live and tell storied experiences. The stories they live and tell are a convergence of the multiple social influences on their personal inner lives, environment, and history (Clandinin \& Rosiek, 2007). This informs, what Connelly and Clandinin (2006) call, the second commonplace of sociality. Experience is an interaction between the personal and the social conditions (Dewey, 1997). The personal conditions refer to the feelings, thoughts, hopes, desires, and moral dispositions of the participants and the narrative inquirer (Connelly \& 
Clandinin, 2006; Clandinin, 2013). The social conditions refer to the existential conditions that form the person's context, such as the "environment and surrounding factors and forces, [and] people" (Connelly \& Clandinin, 2006, p. 480). Clandinin (2013) also refers to such social conditions as the social, cultural, institutional, linguistic, and familial narratives that provide narrative contexts and landscapes.

Dewey's pragmatic philosophy of experience emphasizes "the social dimension of our inquiries and understanding" (Clandinin \& Rosiek, 2007, p. 11). In Narrative Inquiries, researchers are co-participants. They study human experience through a collaboration with participants over time in one or more places, constantly interacting socially with the world. Researchers form new relations with the participants and their personal, social, and physical environment, which can transform the researchers and participants by creating new ways of dealing with their environment and changing the experienced objects (Clandinin \& Rosiek, 2007). In other words, by studying the participants' stories of experience, the researcher and participants transform their experiences of their personal, physical, and social world to generate new knowledge and understanding that can be used in future experiences. This demonstrates the constructivist philosophical assumption related to epistemology that stipulates how knowledge is co-created between researchers and participants in Narrative Inquiry. Knowledge is coconstructed as the stories are shared, interpreted, and represented throughout this relational inquiry.

Place. The personal and social conditions together form what Dewey (1997) calls the situation, which has influenced what Connelly and Clandinin (2006) have conceptualized as the place. The third commonplace of place refers to "the specific concrete, physical, and topological boundaries of place [or a series of places] where the inquiry and events" transpire (Connelly \& 
Clandinin, 2006, p. 480-481). Narrative inquirers recognize the quality of the place/s where the human experience occurs and its influence on the study. The physical place is what Clandinin \& Connelly (2000) call the landscape, where the human experience, including the inquiry, unfolds. The inquirer must recognize that $\mathrm{s} / \mathrm{he}$ is part of the landscape and that $\mathrm{s} / \mathrm{he}$ also lives in relation with that inquiry, thereby, shaping and being shaped by it. The relationship and the landscapes are constantly changing over time, impacting how participants share their lived stories and how the inquirers interpret them (Clandinin, 2013).

\section{Four Directions of Narrative Inquiry}

The notions of continuity, interaction, and situation have also influenced what Connelly and Clandinin (1990) identify as the four directions of any inquiry: backward, forward, inward, and outward. Backward and forward refers to the temporality of experience, which is the past, present, and future. Inward direction refers to the personal conditions of an individual, such as feelings, moral dispositions, and hopes. Outward direction refers to the social or existential conditions, which is the environment (Clandinin \& Connelly, 2000).

During the iterative process of data collection and analysis, narrative inquirers coconstruct with their participants the field texts, interim field texts and research texts that delineate what has happened, what is happening now, and what is becoming while being situated in its spatial environment and the personal-social conditions (Clandinin \& Connelly, 2000). Narrative inquirers travel forward and backward in time while moving inward and outward to examine the personal and the social conditions that shape human experience under study. In this inquiry, I simultaneously explore temporality, sociality, and place, by moving in various directions, to develop a deeper understanding of perioperative nurses' experiences of point-ofcare leadership, and the meanings they ascribe to these experiences. 


\section{Three Levels of Justification}

At the outset of a Narrative Inquiry, researchers use the three levels of justification (personal, practical and social), to justify the reasons for their research and to ultimately answer the "So what?" and "Who cares?" questions (Clandinin et al., 2007, p. 25).

First level of justification: Personal. The personal justification asks why the current research study concerns us as individuals (personally and professionally). In this Narrative Inquiry I ask, why is it important for me, as a person and perioperative nurse, to study point-of-care nursing leadership experiences in the OR?

Second level of justification: Practical. The practical justification asks what research has been done and where the gaps may be within the professional field under study (Clandinin et al., 2007). In this inquiry I ask, what has been studied about point-of-care nursing leadership by perioperative nurses in the OR in the empirical and grey literature?

Third level of justification: Social. The social justification asks what research, beyond the professional field, has been done on the chosen phenomenon and further illuminates the gaps. For this Narrative Inquiry, I ask how does research about point-of-care nursing leadership experiences by perioperative nurses contribute to our understanding of leadership by clinical or front line staff within the broader context of health care.

The three levels of justifications are revisited once again at the data analysis stage, when the field texts transition to interim texts, to finally produce research texts. The Narrative Inquiry analysis process is described in more detail in Chapter Four.

\section{The Narrative Reflective Process}

Stories can be extracted through various modes of narrative self-expression, such as storytelling, photography, creative writing, drawing, and metaphors. The Narrative Reflective 
Process is a creative self-expression activity that stems from Narrative Inquiry and Dewey's theory of experience and pragmatic philosophy (Schwind, 2008). This creative process is a form of reciprocal storytelling that enables the researcher and her/his participants to express their storied experiences with the purpose of extracting meaning of these events (Schwind, 2008; Schwind et al., 2011). Through dialogue, metaphors, drawing, creative writing, and reflective conversations, researchers and participants co-create personal and professional knowing, which, in turn, expands individual and collective consciousness (Schwind et al., 2011).

In this inquiry, I utilize an adaptation of Narrative Reflective Process. I begin by engaging each of my participants in a narrative interview, where I ask them to tell me their stories of point-of-care nursing leadership in the OR. After the narrative interview, I invite them to choose a metaphor that best represents for them their point-of-care nursing leadership in the OR. Following, I ask my participants to draw their chosen metaphor and then to explain why they have chosen it and how it expands their understanding of point-of-care nursing leadership. Using the creative self-expression of Narrative Reflective Process facilitates a more complete story, which adds to the rigour of this inquiry by ensuring the narratives are explanatory. Schwind (2003) writes that drawing "is known to elicit the depths of our being unreachable by words" and that it "teases out, to a deeper level, the reflective process necessary for meaning making of life events" (p. 25). Additionally, metaphor, within Narrative Reflective Process, helps wring out the essence of the participants' experience through creativity and imagination, which may not have been immediately apparent (Schwind, 2009). In other words, Narrative Reflective Process enables my participants to understand more fully the meaning of their pointof-care nursing leadership experiences, thereby expanding their personal and professional knowing. 
There are, however, considerations to keep in mind when metaphor is used to elicit critical reflection that brings forth new knowledge into consciousness. The immediate relationship between the actual situation or subject and the chosen metaphor may not be immediately clear to the receiver of the message, thus causing potential misunderstanding. The effectiveness of metaphor is largely "contingent on the sender and receiver sharing similar contextual points of references" (Schwind, 2009, p. 16). Thus, the interpretation of a metaphor is subjective, intuitive, and contextual. Metaphor requires metaphorical imagination, a skill that involves bending one's world view, which may be difficult for persons who are logical and linear thinkers (Schwind, 2009). Because of its rich possibilities, metaphor has the potential to uncover multidimensional narratives of experiences, and for the same reasons, it has the potential for miscommunication. It is in this awareness that I, as a narrative inquirer, mindfully work with my participants as I engage them in Narrative Reflective Process.

\section{Narrative Inquiry and Point-of-care Nursing Leadership}

Point-of-care nursing leadership in the OR is a complex social influence process that renders change/s in the lives of patients, nurses, and other care providers involved in the care partnership. Narrative Inquiry`s narrative view of experience enables researchers to examine how space, time, and internal and external conditions interplay in every human experience. I am able examine the uniqueness and the depth of experience through this research approach. For this reason, I use Narrative Inquiry to answer my inquiry puzzle. The participants and I are able to move in four directions throughout the inquiry, to examine how the three commonplaces (temporality, place, and sociality) interact to co-create knowledge about the meaning of the lived and told stories of experience. Through this relational inquiry process, the meaning of point-of- 
care nursing leadership in the OR for the two participants are made visible, thus giving them voice as persons and professionals.

In the next chapter, I focus on the research design. I explicate the seven considerations of Narrative inquiry, as well this inquiry's rigour.

Having filled my backpack with the essential equipment, I head for my mountain hike. I begin to feel its weight. My anticipation begins to rise, as my backpack straps press against my shoulders. Yet, I feel my determination and vigor, which inspire me to move forward along my chosen path. I head towards the base of the mountain, eager to experience new landscapes and new discoveries. 


\section{CHAPTER FOUR}

\section{HIKING ALONG MY CHOSEN TRAIL: \\ INQUIRY DESIGN}

Guided by my map and compass, I locate the signpost that directs me to the entrance of my hiking trail. I take in fully the surrounding landscape, being aware that it changes rather quickly and the path becomes uncertain. In order to more fully benefit from my hiking experience I decide to connect with a couple of mountain guides who live on this mountain. I am hopeful that our encounters will help me reach the mountain summit, where I am able to have a better look at the lay of the surrounding landscape, locating my journey within this mountain range.

After explicating the research methodology of Narrative Inquiry in the previous chapter, I now move forward in my thesis journey to detail the inquiry design, which is based on Narrative Inquiry's seven considerations and the methodology's evaluative criteria. After designing this Narrative Inquiry and receiving ethics board approval, I recruit two participants.

\section{Study Design: Inquiry Process}

I start this chapter by outlining the seven considerations I used when designing this Narrative Inquiry, collecting field text, and composing research text, with the purpose of strengthening the rigour of this qualitative study (Connelly \& Clandinin, 2006). I also outline the Narrative Inquiry analysis process, and conclude the chapter by discussing how I integrate reflexivity throughout my thesis.

\section{Rigour}

When conceptualizing rigour in Narrative Inquiry, Clandinin and Connelly (2000) suggest asking the question, "What makes a good Narrative Inquiry?" (p. 185). Rigour in Narrative Inquiry involves the study of narratives that are sufficiently explanatory. In other 
words, narratives need to explore the past and present landscapes and how its internal and external conditions interplay and change over time to contribute to future experiences of the participants and researcher. Narratives also have an invitational quality that engages readers to reflect on their own experiences and potentially change their practice, thus contributing to the continuity of experiences (Clandinin \& Connelly, 2000). Narrative inquirers need to safeguard the authenticity of narratives by ensuring the representation and the interpretation are honest and faithful to the lived and told stories shared by the participants. Plausibility in Narrative Inquiry ensures that the narratives reflect truth and reason. That is to say, the reconstructed narratives logically reflect participants' storied experiences, as well as researcher's interpretations of these. Narratives also need to sufficiently capture the human experience under study to address the research puzzle and achieve the study purpose, which reflects the criterion of adequacy. Furthermore, Clandinin and Connelly (2000) emphasize the importance for narrative inquirers to establish a sense of wakefulness when they are in the field collecting field texts and composing research texts. It is only when we are awake to the interwoven commonplaces (temporality, sociality, and place) of human experience that we are able to achieve rigorous quality of narratives, which are explanatory, invitational, authentic, plausible, and adequate. This is explicated in more detail in the next section.

\section{Seven Considerations of a Narrative Inquiry}

\section{Imagining the Lifespace of the Research Puzzle}

In Narrative Inquiry, researchers and participants enter an inquiry lifespace, also called the field (Clandinin, 2013). Connelly and Clandinin (2000) refer to the field as the conversations between researchers and participants, whereby lived stories are told in a specific place or places. The construction of the research puzzle began with a self-examination of my professional 
experiences as a perioperative nurse in the OR; more specifically the challenges that I

experienced within that role. I imagined the inquiry lifespace to include perioperative Registered Nurses (RNs) as the main actors who cared for surgical patients. I also thought about patients and healthcare providers, such as surgeons, anaesthetists, respiratory therapists, and care assistants, who were also directly involved in the care partnership. I imagined how the healthcare institution and its narratives may influence the stories lived and told by the participants. By imagining this inquiry lifespace, I was able to fine-tune the research puzzle and design this Narrative Inquiry (Clandinin, 2013).

In the inquiry lifespace, also known as my field, I engaged the participants in narrative interviews and creative activities. I encouraged them to tell stories of their leadership experiences as staff nurses who cared for patients in the OR. I collected my field notes, told stories, metaphor drawings, and journal entries, through my meetings with the participants.

\section{Methods: A Telling Inquiry}

Participant recruitment. Purposeful sample of two perioperative RNs working in an urban hospital in Ontario, Canada were recruited for: narrative interview, creative reflective activity, and follow-up telephone interview. I recruited participants who read, spoke, and understood English. The participants were recruited from a hospital where I did not hold an employment position as a perioperative $\mathrm{RN}$.

The purpose of Narrative Inquiry is to honour the experiences of its participants instead of adopting a reductionistic purpose of creating generalizations based on the participants' narratives (Clandinin \& Connelly, 2000). Narrative research, more specifically Narrative Inquiry, is an in-depth study of human experience that usually involves one to five participants (Aksenchuk, 2013; Creswell, 2013; Lindsay, 2006; Schwind, 2003; Walji, 2014). Schwind 
(2003) explores the illness experience of two nurse-teachers in her Narrative Inquiry for her doctoral dissertation. In this inquiry, I focus on the experiences of perioperative OR nurses, in order to conduct an in-depth exploration through storytelling, metaphor, and drawing and coconstruct meaning of their point-of-care nursing leadership. In this way, I am able to articulate the richness of these nurses' experiences, which gives them voice and thus makes them visible within the healthcare landscape as whole persons.

As a recruitment strategy, an email invitation (Appendix A) for study participation was sent to the OR department ward clerk, who was asked to forward the invitations to the perioperative nurses email listserv. I placed two recruitment posters (Appendix B) in the OR nursing lounge located in the selected hospital to recruit participants. The content of the recruitment poster was the same as the recruitment email. The posters were displayed until the desired number of participants was reached.

Collection of field text: Telling of lived stories. Stories are embedded in the field texts that is created by the encounter between the participants and the inquirer. Field texts represent some aspect of reality (Clandinin \& Connelly, 2000). Field text may change upon its telling and re-telling. Therefore, as a narrative inquirer, I am very attentive to how the participants and I are positioned temporally, spatially, and in terms of the personal-social when collecting and composing the field text, and throughout the entire research process (Clandinin \& Connelly, 2000).

This inquiry began when I entered the field where I engaged each participant in an individual narrative interview, as well as the creative self-expression activity, Narrative Reflective Process (Schwind, 2008; 2015). Sandy's interview lasted one hour. Alaia's interview lasted one hour and 45 minutes. The face-to-face meeting with the first participant, Sandy, took 
place in a private lounge in the nearby university, as per our mutual agreement. Based on the second participant, Alaia's recommendation, the face-to-face meeting took place in a private lounge in the hospital where Alaia works.

The starting point for collecting field text focused on participants telling their lived stories of point-of-care nursing leadership in the OR. The semi-structured narrative interviews were guided by the following questions:

- Tell me about your choice to be a perioperative nurse.

- How do you understand leadership when you are taking care of your patients in your current nursing practice as a perioperative nurse?

- How would you define, using your own words, nursing leadership at the point-ofcare?

- Can you please describe your experiences/feelings of nursing leadership at the pointof-care, as you provide nursing care to your patients and work together within an interdisciplinary team in the OR?

- How is your leadership experience different now, as compared to when you first started your nursing practice as a perioperative nurse?

- What kind of internal or external challenges did you face in your experiences of point-of-care nursing leadership in the OR?

The nature of the narrative interview was intended to be conversational and fluid. As the interview progressed, new questions emerged and the listed questions were modified, based on the participant's responses. Interviews were audio-recorded and transcribed verbatim.

I used an adaptation of the Narrative Reflective Process (Schwind, 2008; Schwind et al., 2011), a creative data collection tool to assist the perioperative nurses in drawing out 
multidimensional narratives of their point-of-care nursing leadership experiences. Participants were given time to select a metaphor or symbolic image that best represent their experiences of point-of-care nursing leadership during their current practice as perioperative nurses. Participants were asked to compose a drawing of the metaphor using paper, pencils, and coloured crayons. At the completion of the drawing composition, participants provided a verbal description of the reasons for their chosen metaphor. Through creative self-expression, participants expressed their feelings, thoughts, and experiences, which brought to the surface tacit knowing of their experiences of point-of-care nursing leadership that may not have been accessible through traditional interviews alone (Schwind, Zanchetta, Aksenchuk \& Gorospe, 2013).

After the interview with each participant, I wrote field notes to identify existential conditions that provide details not normally captured on tape recordings. These details include my observations of non-verbal communication, such as silences, pauses, facial expressions, and changes in body positions. Existential outward events are recorded as field notes to supplement the narrative interview (Clandinin \& Connelly, 2000).

Through the relational inquiry process of Narrative Inquiry, the participants and I work within the three commonplaces to collect and compose field text. Field notes and journal-style reflection enable me, as narrative inquirer, to move back and forth between full involvement and distance from the participants. The tension between maintaining professional and ethical boundaries and forming close relationships with participants is always present in Narrative Inquiry. Through diligent and day by day composition of field text, I was able to address this ongoing tension all along the inquiry process (Clandinin, 2013; Clandinin \& Connelly, 2000). After the narrative interview and Narrative Reflective Process activity with each participant, I listened to the audio-recordings once before transcription. During the process of 
transcription, I made notes of audible changes in the tone, volume, and/or pitch of the participants' voice, such laughter, pauses, or sighs, which may suggest emotions of happiness, sadness, concern, indifference, or excitement. I listened to the audio-recordings of the narrative interviews and Narrative Reflective Process for a minimum of three times to ensure accurate transcription of field notes into field text. The narrative interview transcripts, the Narrative Reflective Process creative activities, and my field notes make up the field text.

The stories that people live and tell do not follow a linear chronological sequence (hooks, 1998). To verify the chronological account of participants' stories, I read and reread each participant's story several times. Based on the field text, I constructed each participant's individual story, which makes up the interim research text (Clandinin, 2013). Clandinin defines interim research texts as partial texts that are open to support the "participants and researchers to further co-compose storied interpretations and to negotiate the multiplicity of possible meanings" (p. 47).

Interim research text was negotiated or co-composed with each of the participants for the purpose of ensuring the text was authentic and plausible. Therefore, the interim text was brought back to the participants to engage them in further negotiations with their co-constructed stories, before engaging in the three levels of justification: personal, practical and social. So, two to three weeks following the initial narrative interview and Narrative Reflective Process, I emailed the first participant, Sandy, her constructed story. One week following the email, I conducted a follow-up telephone interview with Sandy, for the purpose of validating the accuracy of her lived and told stories. I emailed the second participant, Alaia, her constructed story two months after the initial narrative interview and Narrative Reflective Process activity because I first focused on the construction and interpretation of Sandy's story. The follow-up telephone interview with 
Alaia was conducted one week following the email. Each telephone interview, which was audiorecorded, took approximately 30 minutes in duration. I asked each participant if her constructed story accurately reflected her told experience of point-of-care nursing leadership in the OR (Streubert \& Carpenter, 2011). Based on the participants' feedback, there were no revisions to the story. I then analyzed the narratives through the three levels of justification of Narrative Inquiry (Clandinin et al., 2007).

Data analysis and interpretation. Connelly and Clandinin's (2006) Narrative Inquiry is used to analyze the participants' stories as expressed through drawing, writing, and conversations. As I move from field text to research text, the field text are situated within the three commonplaces, which reflect the Narrative Inquiry three-dimensional analysis process (Connelly \& Clandinin, 2006). At any given moment during each of the narrative interviews, I am cognizant of where the participants and I are placed spatially, temporally, and within the personal-social relationship, to ensure that the narratives have an explanatory quality (Clandinin \& Connelly, 2000; Connelly \& Clandinin, 2006). I reflect backward and forward to identify the storied moments of space and time. I look inward and outward to identify how the personal intersects with the social dimensions of the point-of-care nursing leadership stories of perioperative nurses (Clandinin \& Connelly, 2000). The three commonplaces within the inquiry lifespace are open and boundless. All three commonplaces are explored simultaneously throughout the collection, analysis, and re-presentation of stories.

During this process of analysis and interpretation, the field texts are "woven into the development of research texts" (Clandinin \& Connelly, 2000, p. 119). This inquiry's field text are read and reread to search for patterns, threads, and tensions embedded in participants' experiences and overall social setting (Clandinin \& Connelly, 2000). I ask questions related to 
the meaning, purpose, and significance of the study (Clandinin et al., 2007). As I compose the research text, I continue to live within the three commonplaces (temporality, sociality, and space) of Narrative Inquiry to develop a deeper understanding of the interconnections and complexity of the multiple meanings of experiences relevant to the research puzzle (Clandinin, 2013; Clandinin \& Connelly, 2000). Final research text are created after the stories are analyzed using the three levels of justification, consisting of the personal, practical, and social (Clandinin et al., 2007). In doing so, I ensure that the narratives address the inquiry puzzle and attain the study purpose, thus meeting the criterion of adequacy.

Personal justification. Narrative inquirers need to start with personal justifications, which involve justifying their inquiries in the context of their life experiences, tensions, and research puzzles (Clandinin, 2013). In Chapter Five and Six, I situate myself as a narrative inquirer in the constructed stories of the two participants, Sandy and Alaia. I read and reread the narrative interview transcripts, field notes, journal entries, and metaphor drawings, while paying attention to my own reactions to the words of the participants. As I read and listen to the participants' words, I make personal interjections, based on my life experiences, as well as my observations, thoughts, and feelings, to gain insight into my relationship and interest in the inquiry (Clandinin et al., 2007). This dynamic process is reflected in Chapters Five and Six, where I present my participants’ accounts.

Throughout my personal justification, I question how I see my being and becoming as a co-participant within the inquiry. I explore what I bring into each researcher-participant relationship. As I make my personal interjections, I become mindful of the stories that I live and tell within the relationship. As a result, I am able to recognize my own contributions. I am clear regarding who I am as a co-participant within the inquiry. 
Practical justification. The second level of justification is the practical justification. During this level of analysis, I look at the field text in terms of how they can change my own practices and those of my colleagues (Clandinin et al., 2007). At this point, I explore and analyze, using relevant literature, the significant concepts raised by the participants.

Theoretical frameworks can be used to give "meaning to the inquiry and its outcomes" (Clandinin \& Connelly, 2000, p. 121). I use Leadership Model by Kouzes and Posner (2011) and Person-Centred Nursing by McCormack and McCance (2010) as the theoretical lenses through which I examine participants' stories of point-of-care nursing leadership. I deconstruct and critically consider, using the Narrative Inquiry three-dimensional commonplaces: temporality, sociality, and place, all collected field text, which include the participants' stories, metaphors, drawings, and my journal entries. I also find myself moving back and forth between the field text and interim field text, also known as constructed stories. Through this process, I am able to gain a deeper insight into participants' stories to identify narrative patterns and key narrative threads. I introduce relevant literature throughout this analysis process. By doing this, I bring new awareness, meaning, and ideas to the current knowledge related to human experience under study, which in this inquiry is the point-of-care nursing leadership in the OR.

Social justification. The third level of the Narrative Inquiry analytical process is the social justification, which involves asking the questions "so what?" and "who cares?" (Clandinin et al., 2007, p. 25). At this point, I examine the narrative threads in terms of how they fit within the larger social context. I am attentive to political, social, cultural, economic, and institutional narratives that shape the lives and identities of the participants (Clandinin et al., 2007). The significance and the implications of the perioperative nurses' narratives of point-of-care nursing 
leadership to the broader scale of the healthcare system and the society at large are presented at this stage of justification.

The research texts that are produced from the personal, practical, and social justifications do not provide final answers (Clandinin, 2013). Instead, these texts are meant to engage audiences to reflect and reimagine alternate possibilities or new ways of thinking, doing, and relating with others, both as persons and as professionals (Clandinin, 2013). Through the free verse poems in Chapter Eight, I re-present the participants' stories to engage the readers to reflect on their own experiences of point of care nursing leadership, and potentiate personal and/or social changes in the future. In doing so, the criterion of invitational quality is met to achieve rigour.

\section{Balancing the Three Commonplaces}

Narrative Inquiry identifies three commonplaces, named temporality, sociality, and place, which signify the three dimensions of an inquiry lifespace (Clandinin et al., 2007; Clandinin \& Connelly, 2000; Connelly \& Clandinin, 2006). Throughout the inquiry I need to think narratively. I examine and describe how the three commonplaces are built into the study, which can be seen throughout this thesis. Earlier in this chapter, I specified the questions I used in the semi-structured narrative interview that were guided by Clandinin and Connelly's (2000) four directions of an inquiry: backward, forward, inward, and outward. It is through these directional movements that the participants and I explore the interplay of the three commonplaces in the participants' storied experiences of leadership. In Chapters Five, Six, Seven, and Eight, I describe how I travel backward and forward in time while analyzing the internal and existential conditions that shape the lived stories of the two participants, Sandy and Alaia. In this inquiry space, I analyze how the dimension of time along with the physical, social, economic, and 
political environmental factors facilitate or challenge the leadership experiences of Sandy and Alaia, as well as my own. As a narrative inquirer, I am part of the research, to a greater or lesser extent, and so my stories of experience are also scrutinized through the three dimensional narrative space. This demonstrates how I ensure the narratives have an explanatory quality, which explores and balances the three commonplaces of temporality, sociality, and place throughout this inquiry.

\section{Investment of the Self}

I have started this study as a telling inquiry where two participants, Sandy and Alaia, share with me their lived stories of leadership as perioperative nurses in the OR. However, as a narrative inquirer, I am part of the inquiry where I co-create knowledge with Sandy and Alaia. I share with them my past and present experiences of being a perioperative nurse. This relational component of Narrative Inquiry impacts the nature of our researcher-participant relationship and the co-created knowledge.

Since the inception of the inquiry, I have been aware of the potential for developing intimate connections with the participants, field text, and research text. I entered the researcherparticipant relationship with prior knowledge and experiences related to the phenomenon under study. I am cognizant of how I contribute to the study as a co-participant, from the questions that I asked in the narrative interview and Narrative Reflective Process, and all the way to the interpretation of the field text and the research text. Through field notes and reflexive journaling, I have developed an awareness of how I made research-related decisions. Furthermore, I have been able to gain insight into how I interpret the field text and research text during the collection and analysis of stories. 
Through storytelling, our shared stories of point-of-care nursing leadership intertwined to develop a deep sense of awareness and understanding of our experiences and the meanings we ascribed to them, which is the purpose of Narrative Inquiry (Connelly \& Clandinin, 1990). I nurtured the connections with the participants because these connections enable me to develop a rich understanding of their experiences and meanings. However, I am also self-conscious of the potential for tensions between maintaining ethical and professional boundaries and forming close researcher-participant relationships. Through reflexive journaling I addressed this tension where I have been able to move back and forth between full involvement and distance from the participants.

\section{Researcher-Participant Relationship}

Narrative Inquiries may vary in terms of intensity and intimacy of the relations that develop between researchers and participants (Connelly \& Clandinin, 2006). Although this is an interview study where the researcher-participant relationships are short-term, our shared experiences as early career nurses and perioperative nurses has enabled us to develop close relationships, characterized by mutual respect and empathy. As discussed previously, I engaged in reflexive journaling to facilitate movements between full involvement and distance from the participants. Ethical relations between the researcher and participants are respected throughout this Narrative Inquiry (Clandinin et al., 2007; Connelly \& Clandinin, 2006).

\section{Study Duration}

The design and implementation of this study are based on the inquiry's starting point of telling stories and the Master of Nursing (MN) program restrictions. Designing and engaging in a participatory study, where researchers live alongside the participants in the field, is not realistic due to the MN program's time constraints. Instead, I have developed a telling inquiry, also 
known as an interview study. The focus of this inquiry is on the telling of lived stories and on the interpretation of field text. The majority of my time was spent on data analysis and interpretation to produce the narrative patterns and threads and to share the social significance of the study findings to the broader nursing community. This Narrative Inquiry has lasted eight months from the time of participant recruitment to thesis completion.

\section{Ethical Considerations}

Ethical considerations make up the seventh consideration of this study (Connelly \& Clandinin, 2006; Clandinin et al., 2007). Narrative Inquiry is a life study where the researchers and participants live and tell stories in relation (Connelly \& Clandinin, 2006). We need to be mindful of the relational ethical responsibilities we have to the participants both during and following the research (Clandinin, 2013). From the start of participant recruitment to the presentation of research texts, ethical problems may arise (Connelly \& Clandinin, 2006).

Research ethics board approval. Research with humans require ethical reviews (Connelly \& Clandinin, 2006), therefore, this inquiry commenced upon attainment of approval from the Research Ethics Board at Ryerson University and the selected hospital (Appendix C).

Autonomy. To support the ethical principle of autotomy, I obtained written informed consent (Appendix D) at the beginning of the research process. At the start of the researcherparticipant relationship, each participant was informed of her right to pause temporarily or withdraw permanently from the study without any penalty or loss of benefits. There was no coercion or deception of the participants involved throughout the study.

Respect for participants. Respect for participants is achieved through numerous measures, which is explicated throughout this section on Ethical Considerations. The participants 
were treated with respect and dignity throughout every stage of the research process, and their requests were honoured within the study parameters.

Benefits. There are benefits experienced by participants from study participation. Through this Narrative Inquiry, participants' stories give voice to their experiences, which can also be seen in other studies (Clandinin \& Connelly, 2000; Schwind, 2003). Participation in this study also positively contributed to participants' self-reflective practice and annual College of Nurses of Ontario's (CNO) Reflective Practice mandate.

Risk for harm. This study has foreseeable minimal psychological and emotional risk of harm for its participants. The participants did not express psychological or emotional harm during the conduct of the study. However, I minimized the foreseeable psychological and emotional risks by ensuring that I was prepared to provide the participants with emotional support, especially in the event that emotional discomfort surfaced from the interview questioning. I was prepared to end the interview or provide the participant with information about resources available, such as Employee Assistance Programs and existing personal networks.

Confidentiality. Within the context of research, confidentiality refers to the researcher's duty to prevent the public reporting of information that may identify the research participants (Streubert \& Carpenter, 2011). I have maintained participants' confidentiality by ensuring that the identified research data with participant identifiers are accessible only to me and my thesis supervisor. The consent forms are the only documents containing participant identifiers, which are stored separately from all the electronic and hard copies of the research data. I have ensured anonymity of the participants by using pseuodonyms throughout the research process, including data storage and future research publications. 
Electronic research files of the narrative interviews, journal entries, and metaphor drawings are saved as password protected Word documents in a biometric-encrypted USB memory card. These electronic research files contain de-identified data, which are transferred to my thesis supervisor. I emailed the electronic research files to my thesis supervisor's Ryerson email through the hospital's file portal to maintain the participants' privacy and confidentiality. Research files in a hard copy format are stored in a double locked filing cabinet in my home from the time of participant recruitment to research dissemination to ensure confidentiality.

The consent forms are stored in a locked filing cabinet in the thesis supervisor's locked office, separate from the research data to maintain the anonymity and confidentiality of the participants. The original metaphor drawings were given back to the participants at the completion of data collection. The electronic and hard copy files of the de-identified research data, including the photocopies of the metaphor drawings, will be stored in a double locked filing cabinet at Ryerson University for five years from the time of research dissemination. Should there be a breach of confidentiality, the university and hospital's Research Ethics Boards and Privacy Office would be notified to obtain instructions on how to contain the problem.

Privacy. The ethical principle of privacy refers to a person's right to be free from unreasonable or unauthorized interruption or intrusion by others (Government of Canada, 2015). I protected participants' privacy by having ensured that the interviews were conducted in mutually agreed upon rooms, away from their respective OR departments. I used an audiorecording device to document the interviews with consent from the participants. I triangulated methods of field text collections, such as narrative interview and Narrative Reflective Process, to ensure accurate representation of participants' lived stories in the field texts. 
After I developed the interim research text, also known as constructed stories, I negotiated a time with Sandy and Alaia for an individual telephone interview for the purpose of negotiations, elsewhere referred to as 'member checking'. I conducted the individual follow-up telephone interview during a time and place that was most suitable for each participant. Although I was prepared to negotiate any adjustments to the interim field text, both participants are satisfied with their constructed stories.

Throughout the face-to-face and telephone interviews with Sandy and Alaia, I was mindful of how I asked my questions. I continuously assessed their comfort level with each interview question. I was prepared to provide comfort measures, bypass the question, and/or end the interview should the participants perceive the questions to be intrusive. Through these respectful and ethical measures, I safeguard Sandy and Alaia's privacy throughout this Narrative Inquiry.

Communication. As a researcher, I am the main point of contact for the participants. To protect myself from harm, I have utilized a temporary ghostline telephone number, strictly for communication with participants, which is set up by Ryerson University's Computing and Communication Services (CCS) department. The recruitment poster explicated that the telephone number provided was a temporary number used only for study purposes.

\section{Reflexivity}

I engaged in self-reflective practice throughout the research process. I reflected on my personal and professional experiences related to point-of-care nursing leadership as a person who received perioperative nursing care and a perioperative nurse who delivered nursing care. I reflected and looked inward into my internal conditions. My thoughts and feelings related to the participants' stories were recorded in a journal with the intention of interpreting and making 
sense of them. These journal entries made up part of the field text that were used during the data analysis stage of this Narrative Inquiry.

In this chapter, I have outlined the seven considerations used by narrative inquirers when designing a Narrative Inquiry. I have also explicated how I apply these in my inquiry. In the next chapter we meet Sandy, a perioperative nurse, who shares her stories of point-of-care nursing leadership.

As I continue my hike, I stop at a look-out point near a village to enjoy the sights and the sounds of a mountain river. I look ahead to see a local guide who can provide me information about the mountain path ahead. Our eyes meet and I walk towards her to engage in a conversation about the mountain conditions I may encounter along my way. 


\section{CHAPTER FIVE}

\section{MEETING MY FIRST LOCAL MOUNTAIN GUIDE: PERSONAL JUSTIFICATION}

As I reach the look-out point, I meet Sandy, a local guide, who is also an experienced hiker in the area. She provides me with information about the mountain path that lies ahead. I listen closely to Sandy's words, making mental notes of the significant conditions that I may encounter.

The first participant is Sandy who is a perioperative RN. During our narrative interview and creative self-expression activity, she tells me her story of point-of-care nursing leadership. I then situate myself, as an inquirer, by making personal interjections throughout Sandy's story. This is the first level justification analysis in Narrative Inquiry, the personal.

\section{A Perioperative Nurse as a Teddy bear}

Date: December 23, 2014, Duration: 1630-1730, Location: university lounge

It is Tuesday evening. I make my way to the cold lobby of a busy urban hospital to meet Sandy. My mind is filled with stories of my workday in the OR, collaboration, teaching, multitasking, problem-solving, decision-making, and most importantly patient care. Our gazes meet and we exchange greetings. Sandy is also coming from working a day in the OR. I am concerned that she is too tired to engage in the interview, but she assures me that she is well enough to go ahead. We make our way to a nearby university. It is raining. The streets are bustling with activities from shoppers getting ready for the upcoming Christmas festivities. We settle inside a quiet, private, and well-lit room, away from the bright Christmas lights and clatter of downtown. 
Sandy's story is represented using Bradley Hand IT, font size 12, to provide a visual expression of her story of point-of-care nursing leadership experience in the OR. Sandy chooses the font because she considers it to be fun. I interpret the font's blending of cursive and print styles as a reflection of Sandy's outgoing and warm personality mixed with her proficiency in her chosen career as a perioperative nurse in the OR. Throughout Sandy's story I use Times New Roman, font size 12 , to represent my personal interjections as a narrative inquirer to gain insight into my relationship and interest in this inquiry. This is the stage of personal justification.

First Level of Analysis: Personal Justification

\section{Narrative Interview: Sandy’s Story}

I have been a perioperative nurse in the OR for five years, specializing in orthopedic surgery. Being a perioperative nurse in the OR was not my first choice out of nursing school. 1 really wanted to be in Labour and Delivery, but at the time it was hard to find a job. So, I decided to take the perioperative certificate because, in Labour and Delivery, you do c-sections and the perioperative certificate was one of the requirements. During the clinical component of the perioperative certificate, I was placed in a hospital, and after that, I just decided to stay there. My mom is also an OR nurse and I would hear a lot of stories about her day.

Sandy's words take me back to my own beginnings as an RN and the struggles I had in my first job on a busy cardiovascular unit. I feel an emotional connection with her. Neither of us planned to be perioperative nurses so early in our nursing careers.

$$
\text { My point-of-care leadership experiences in the or involve being an advocate for my }
$$

patients. Your patients may have general anaesthesia and they can't speak for themselves during surgery. Obviously, it's not only in nursing. It is a collaborative effort when it comes 
to patient care, because when you're in the OR you have anaesthetists, surgeons, nurses, and maybe even others, depending on the surgery. It is every team member's role to ensure the patient is safe and we do not do anything that would harm her.

I feel the vulnerability of the OR patients, anaesthetized while their mouths taped with endotracheal tubes in situ. Sandy emphasizes the nurse's role as being the patient's voice intraoperatively, their advocate during surgery. Who does she have to protect them from, when the whole team is expected to protect the patient from harm? I wonder if Sandy thinks patient care and patient advocacy are mutually exclusive.

There are many point-of-care nursing leadership activities in the OR. I ensure that the consent form is correct. I make sure that a briefing, time-out, and debriefing are conducted. It is important to make sure that the patient does not have any more questions before going to sleep. I ensure that the patient is positioned properly while being covered appropriately to show respect for the patient and maintain her body temperature. I would want someone to do that for me or the people I love if I was in that situation. I treat every patient equally. It is the way I would want for myself or my family members to be treated.

I begin to think about Sandy's ethic of care. When I hear her words, "I treat every patient equally", I sense that Sandy is guided by the value of fairness, which also guides my own nursing practice. I wonder if other perioperative nurses share this value. What are some other values that guide perioperative nurses in their practice? Your focus is on the patient. You are there for the patient's surgery. The vision of patient health and safety is the focus throughout the surgery. 
I recognize that Sandy has clarity in her purpose as a perioperative nurse, and ask her about other ways in which her vision is manifested in her nursing practice.

Point-of-care nursing leadership is about taking initiative. Let's say for example, your instrumentation. You have four cases during the day. Instead of waiting to find out what the surgeon needs for the fourth case, you would ask them in the beginning. You can give yourself time to get it organized for the fourth case and there won't be a delay, just in case the surgeon's instrumentation is not available.

I feel a hint of tension when Sandy mentions the word, "delay". I begin to think deeply about concept of time in the OR. I think about an image of a clock and the rigidity of its encasing. I recognize that, as humans, we cannot transcend time, but Sandy's words remind me that we can take initiative to effectively work within the boundaries of time. I wonder if other team members experience similarly time limitations in the OR. How do they deal with the pressures posed by time? Is it always the nurse who is charged with keeping time? Point-of-care nursing leadership also involves mentoring others or preceptorship. obviously you are not going to be there forever. You have to pass on the torch to the new people. It is like being a role model; guiding them and assisting them in terms of what you know and what they should know and what they should do. It is like with any job; you have an idea of what it is, but you don't really know what it actually entails until you're in that situation and you actually do it.

I sense Sandy's concern for the greater nursing profession. I am curious. Does this compel her to continue leading through teaching? 
I'm sure a lot of people would think that working in the OR involves passing

instruments to the surgeon, but what they really don't know is that it's so much more than

that. It is not your only job. I have to guide new students or new staff on how to organize

themselves or check-in a patient. The OR is just very different than if you were to work on the floor.

I feel Sandy's frustration when she discusses others' assumptions about nursing in the OR.

The words "passing instruments to the surgeon" take me back to past interactions with other people, including nurses, who unintentionally undermined the comprehensiveness of my perioperative nursing practice. I am curious to learn how others' assumptions about perioperative nursing impact nurse's ability to lead in the OR.

Role modeling and supporting them involves trying to give them an example of how to do things, but at the same time, it doesn't necessarily mean that's the only way to do it. You could show them one way, but you could tell them, "Okay, once you've developed your practice, you could do it the way you want to do it. I'm just showing you how to do it." Part of leadership is supporting and helping them see the big picture.

The words "role modeling", "supporting", and "big picture" enter my ears and I see a clearer image of Sandy as a nurse teacher. Sandy’s story reminds me of my recent teaching experience that has made me acutely aware of the multiple realities and truths. As my attention travels back to Sandy, I perceive her to have a sense of openness to multiple ways of knowing and doing, which I admire. I wonder, do we need to have the value of openness to effectively teach and lead at the point-of-care in the OR? 
Point-of-care nursing leadership entails a motivational aspect. You have to cheer up nursing students or new nursing staff. There are times, like any job, when you're having a bad day. When someone is having a bad day, you can say, "don't worry about it." sometimes you won't know until you're in that situation and you just have to use it as a learning opportunity. Put it in the books and learn from it. I'm still learning every day and I will make mistakes. There's always something new; new surgeries and equipment.

Nurses, anaesthetists, and surgeons also need support and motivation. It depends on who it is, especially the surgeons. There are some surgeons who are approachable and you can joke around them. There are some surgeons who are "professional".

I connect with Sandy's words that capture the realities of perioperative nursing practice and leadership. I think about the inevitability of challenges and mistakes that make up learning experiences in the OR. I recall stories of working with nurses, anaesthetists, OR assistants, and surgeons whose attitudes and behaviours challenged my ability to lead. My thoughts return to Sandy, and I am curious how her leadership experiences have changed over time in the OR.

When I first started in the OR I was shy. When you're new you're still so unsure of yourself and unfamiliar with the environment. I wasn't as vocal as I am now. For example, When I first started I would just cover the patient myself. Now, I would ask someone, "Can you do this? can you make sure this is done?" I'm more comfortable in speaking ont now because I've been there for a few years now. I feel more comfortable in terms of my environment. My confidence has increased. I'm able to voice out more. 
My relationships with my nursing, anaesthetist, and surgeon colleagues have also changed because I know them a lot better now. The more you work with them, the more you get to know them and their personalities. When I first started, my colleagues may have perceived my remarks or requests as negative or offensive. But now that we've worked together for a while, they wouldn't take offense or they wouldn't think I'm telling them what to do. They would perceive me asking in an innocent way, "can you do this?"

My heart and mind connect with Sandy's as she tells the story of her development as a nurse in the OR. The words "unfamiliar with the environment" and "unsure of yourself" remind me of my own beginnings in the OR. I recollect my early days when I felt shy. I limited my communication with anaesthetists and surgeons to simple nodding. As Sandy's stories shift from a shy novice to a more vocal and confident perioperative nurse, I see my own trajectory of evolution in the OR.

I have faced many internal and external challenges in my experiences of point-of-care nursing leadership in the OR. It has been discouraging for me when we are pressured from hospital management to be faster. The more surgeries we do the more money the hospital gets. Right now, they're asking us to be faster, but be safe. They implement certain policies or certain rules, but they don't really know what it's like, even though they have worked in the OR before. I feel like the managers or patient care coordinators (PCCS) have forgotten what it's like to do all these cases in a short period of time. You have to be faster and your turnover has to be faster, but at the same time you have to keep the patient safe. When you are doing 11 scopes in a day, in an eight hour period, how much faster can you get? I feel like I'm fast 
enough. I don't think I can go faster than this. When you're not meeting the expectations set out for you, not that it makes me not care about my job, it makes me enjoy it less.

1 feel pressured from OR team members as well. Anaesthetists would usually rush you because they don't want to be blamed for the delay because surgeons usually blame them for the delay. Even though you don't have anything opened, the anaesthetists would ask, "can we bring the patient in? can we bring the patient in?" Some surgeons rush you, but I think that's usually only if they're late. You see them and they would start helping you open stuff. Then you know that they're rushing in a subtle way.

When I'm being rushed, I either say, "yes, we're going" or "you can come and help me open things." When you're setting up there's usually just two of you. I would say, "the patient can't come in because once the patient comes in, I have to be with the patient." There's residents and anaesthetists, but I will have to be with the patient because ultimately the patient is my responsibility once they walk through the door. If anything happens to the patient, it's on me. If I still have to finish opening packages for the nurse then I can't do that. So, you just have to say no. If they want it faster, they have to help out. There has to be teamwork. Being able to say that to a surgeon or anaesthetist comes with time. If you just started, I'm pretty sure you wouldn't be able to say that. It depends on who it is as well. You've developed relationships with them. There are certain ones that you could tell them whatever and they don't really care.

Sandy's story awakens me to the borders of time and patient safety that can be rigid in the OR. I sense Sandy's frustrations with management, surgeons, and anaesthetists who impose time pressures on her perioperative nursing practice. I feel empathy when I listen to 
Sandy and her concern for safety when patient care is rushed. My mind fills with images of patients being given the wrong antibiotic or anticoagulant therapy preoperatively. I think about errors related to surgical counts and foreign body misplacement. Although the patient is treated by the whole OR team, it often seems like it is the perioperative nurse who is the closest to the patient. The nurse has a strong sense of accountability to the patient, ensuring that the patient is safe and necessary care is provided. I am impressed with Sandy and her ability to provide nursing care while taking charge of the OR and eliciting assistance from different team members in order to deal with the time pressures of the OR suite.

unfamiliarity with other surgical services is an internal challenge for me during my leadership experiences in the OR. When you're on the day shift you stick to your service and that's basically all that you do. On the weekend or on shift, you do whatever comes along. And for me, neuro I can get by. But it's spine that I have difficulty with just because there are so many different trays and I don't know the step-by-step order. I'm unfamiliar and I feel uncomfortable. You know l always get nervous. To deal with this challenge of unfamiliarity with other services, I usually check my assignment the day before. If it's something that I'm not familiar with, then I usually just research it. They have a hospital website for us where it has the list of different surgeries. If the surgery happens on shift, I would usually tell the fellow or surgeon, that I'm not from the service, just so I could give them a head's up. At least they don't assume that I know and they don't get disappointed. I wouldn't describe this as being a leader. Maybe it's taking initiative, in the sense of learning. In my personal opinion, 
researching beforehand or putting a disclaimer for the fellow or surgeon does not constitute being a leader.

I identify with Sandy's discomfort and anxiety with other surgical services. I think about robotic-assisted surgical procedures, where I feel I lack in expertise. I get anxious when I have to assist in these procedures. But, I am determined to learn and to succeed, so I ask for help from my colleagues. I reflect on how Sandy and I live by stories of persistence and asking for help from others, when necessary, to overcome this internal challenge of surgical service unfamiliarity. I wonder why Sandy does not interpret researching procedures or eliciting help as leadership behaviours.

An external challenge for me, during my leadership experiences, may involve the people that I work with. You work as a team in the OR. If one person slacks off, you have to pick up that slack. There are some people who just come to work and they don't care anymore. They come to work for the sake of coming to work and getting paid. If they don't care anymore then how would you know that they made sure that the patient's okay? Maybe they're doing the bare minimum. In terms of safety, it also puts the pressure on you because if they're not doing what is required of them then that means you have to do their share of the work as well. It's pretty much everybody, some who are nurses and then some who are attendants. You kind of know who's more attentive and willing. Sometimes they see you transferring a patient and they just watch and do nothing. I speak up and ask them to help. It doesn't always work. There are some people, let's say nurses, who are just the way they are. You just work around it. You just try your best, I guess. A lot of surgeons know who are less attentive compared to others. 
I sense Sandy's frustrations with colleagues who hinder her point-of-care nursing leadership experiences. I feel annoyed and disturbed when I listen to Sandy's stories about colleagues who are less attentive and unwilling to assist because I also have similar stories of conflict, tension, and struggle. I recall a situation with an OR assistant who refused to assist the team during a patient transfer, which of course, increased everyone's risk for injury. Sandy's earlier story about her professional relationships within the OR makes me think how our peers can both hinder and facilitate our leadership experiences. The value of teamwork and collaboration enter my consciousness as I think about the colleagues who help me bring out the voice of my leadership.

The physical environment can create an external challenge for me in my leadership

experiences in the OR. Our main OR is on the third floor. We have four ORs on the fifth floor for dentistry. Because we have so many cases now, they're trying to use the fifth floor for other cases, like hands or smaller orthopedic cases. A lot of the stuff we need for hands and ortho cases are not in the fifth floor ORs. They have a Pyxsis machine that has common stuff that we need, but a lot of times the Pyxsis machine is not filled or they do not fill it until 1000. Also, if we need instruments, it has to come all the way from the basement, so it takes longer to come up. The Pyxsis machine is at the end of the hallway, as opposed to being in your room, so there's a lot of back and forth and back and forth. If you don't work upstairs that often, you wouldn't know what's up there and what's not up there. I guess, the main challenge is not having the supplies or instruments that you need right away. It takes up more time. It delays the surgery. The surgeons get frustrated at 
you. You're frustrated and you're tired because you're going back and forth. It's not a good place to be.

To solve this problem in the fifth floor ORS, I would speak with the resource nurse about stocking common things we need that are not stocked upstairs in the fifth floor ORs. If I work with certain surgeons that need something, for example instruments, from the main ORs, I would get them before 1 go up to the fifth floor ORs. I also complained to the PCC about stocking the ORS earlier. It really does not do me good when the stocker comes at 1000 and I need it at 0730 . This is all part of taking initiative and being a leader. You do that so that the next time when you're there you don't have to struggle so much. It's the same for other people; so you know that it's there for them.

I feel a sense of satisfaction and joy for Sandy as I listen to her resolve. I recognize that Sandy turns the geographical barrier of the fifth floor ORs into an opportunity to carry out other nursing leadership activities. I think about my own challenges in the OR and what I have done to overcome them. I remember a time when my own supervisor failed to communicate pertinent information along with the resources required for a unique surgical procedure. To solve that problem, I spoke with the surgeon and supervisor, and then developed a preference card as a resource for my fellow nurses. Sandy's story validates my own experiences, which motivates me to continue to do the same personally and professionally. 


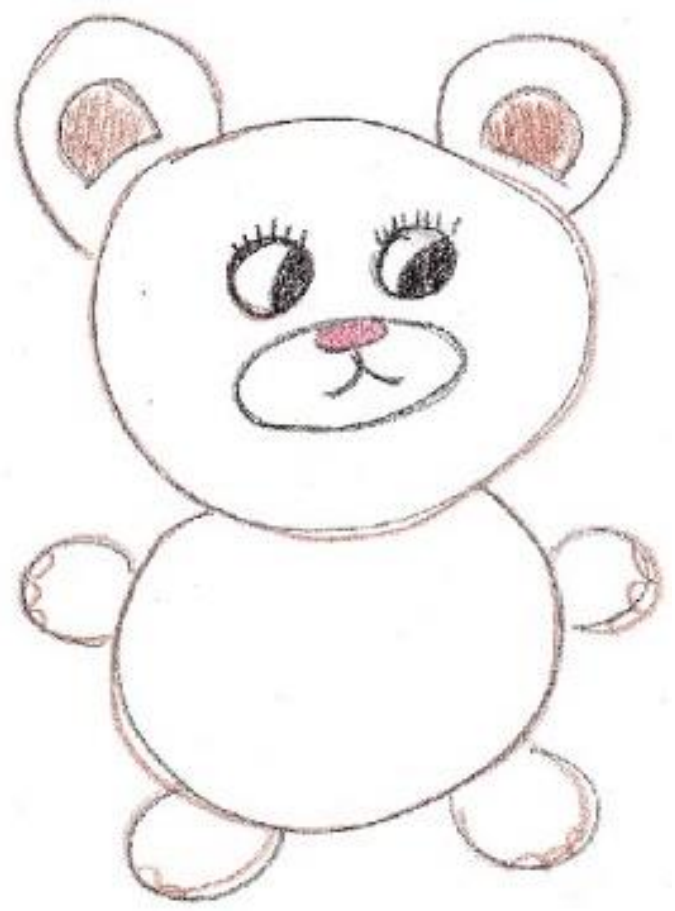

\section{Figure 1. Sandy's Metaphor of Point-of-care Nursing Leadership: A Teddy Bear}

I have selected and drawn a medium-sized teddy bear because I want to be almost like a teddy bear. I want to be huggable and approachable. A lot of patients are nervous and scared. I guess I use a teddy bear to calm them down and help them to minimize their fear. 1 just want to make them feel better, so they're not as nervous. I also thought about mama bears with their cubs. Mama bears are warm, motherly, and nurturing with their cubs, but when somebody attacks their cubs they go crazy with their protective instinct. I was thinking it was the same with me. When somebody is not doing or thinking about the patient's wellbeing, maybe just unintentionally, then 1 go all mama bear and tell that person not to do that and do this instead.

Sandy's teddy bear helps me to understand the balance that perioperative nurses must achieve in order to lead at the point-of-care. I think about my own nursing practice, where I 
strive to be open, approachable, encouraging, nurturing, honest, and trustworthy, while maintaining my confidence, courage, and assertiveness, especially when the patient's wellbeing is at risk. I think of Sandy's earlier story of her sense of responsibility and closeness to her patients. I now envision patient health and safety through her metaphor. Not only do I advocate for my patients, I also advocate for my colleagues, including students. I remember that time when I had my first student. I did not know anything about teaching somebody, but I was trying. At the same time I was still learning. A colleague of mine always wanted my student to do everything. I was okay with that because she had to learn, but certain things, like draping the c-arm, were already learned. I wanted her to do something that she hadn't done before because, as her preceptor, I felt that it would be more beneficial for her. My colleague would also ask her random questions. I don't think it was him trying to imply he knew more than me. I think it just was his way of teaching. He was always telling her what to do.

I was very protective of my student. When you're starting out, you do what people tell you to do because you don't know how to say no. To me, I felt that I had to protect her because I didn't think that certain things he wanted her to do was beneficial for her, at the time. I guess that's what the bear thing is: you can be approachable, cuddly, warm, and inviting. When a situation turns sour, you can go the opposite side of you, and be very protective.

I feel a sense of exultation as I listen to Sandy's story of advocacy with her first student. However, I also feel a sense of guilt because I am reminded of my own students. I recall moments when the acuity of the patients' health and the urgency of the OR team members' needs overwhelm and hinder my ability to teach students effectively when I am in the OR 
space. Sandy's story awakens me to the stories of teaching in the OR. I feel inspired by Sandy's story to become a better advocate for my own students in the OR.

As I finish my conversation with Sandy, I resume my hike. I reflect on the look-out point I just enjoyed. I feel more informed and excited about my hiking trail. I look forward to meeting my next local guide, Alaia. We are to meet at the next rest area a distance up the mountain side. 


\section{CHAPTER SIX}

\section{MEETING MY SECOND LOCAL MOUNTAIN GUIDE:}

\section{PERSONAL JUSTIFICATION}

As I arrive to the rest area, I notice the beauty of the now sparse botanical landscape. I sit down for a few minutes to wait for my second local guide, Alaia. Today, she is coming down from the mountain summit. She will be able to tell me more about the current conditions of the last leg of my mountain climb.

I meet my second participant, Alaia. She is also a perioperative RN. In this chapter, Alaia shares her story of point-of-care nursing leadership in the OR. I continue the first level of justification analysis, the personal, by making personal interjections throughout Alaia's story. This way of presenting Alaia's, and Sandy's, stories, demonstrates the relational aspect of Narrative Inquiry, which was earlier (Chapter Three) identified as the three-dimensional commonplace, sociality.

\section{A Perioperative Nurse with a Funnel Perspective}

Date: January 26, 2015, Duration: 1600-1745, Location: private hospital lounge

After teaching a clinical skills lab in a nearby college I make my way to the hospital. I arrive at the hospital lobby where I wait for Alaia. I can smell the fresh pastries along with the coffee brewing from the nearby café. With the notes in my hand, I repeatedly recite the questions in my head before I see Alaia's figure come into my view. I see Alaia approach, holding a backpack in her hand, and a big smile on her face. I have reserved a private room for the meeting, but Alaia suggests that we hold the interview in a quiet and private lounge in the hospital. We make our way to the lounge where we settle on two single sofas across from one 
another. The lounge is empty and quiet with very minimal lighting. I turn my recorder on. Alaia begins sharing her stories of leadership in the OR.

Alaia’s story is represented using Century Gothic, font size 10, to provide a visual expression of her story of point-of-care nursing leadership experience in the OR. She feels that the font is wider, rounder, and welcoming, which facilitates the perception of less judgment and greater openness. Throughout Alaia's story I use Times New Roman, font size 12, to represent my interjections as a narrative inquirer.

\section{First Level of Analysis: Personal Justification}

\section{Narrative Interview: Alaia’s Story}

During my undergrad I thought I was going to go into pediatric nursing. Kids are so much fun. They are always going to get better. They'll come in and we'll fix them. So, that's why I wanted to have a surgery clinical placement. I went to see Dr. James (pseudonym) on a scoliosis case in the OR during my undergraduate observation. There was music playing. People were just hanging out, and I saw the scrub nurse. The whole time that they were doing the case you didn't hear Dr. James. They were having a conversation about Vegas. The room was ready and they just kind of knew what was going on. It was just like a relaxed environment with all their toys. It was a pretty sweet place and everybody was happy.

When I graduated I did some travelling. I then worked as part of a nursing resource team. Medicine is good to have, but you need to build something else. You get bored. It's either you go to the OR, ICU, or NICU, so I applied for the OR course.

I remember my own observation day in the OR as an undergraduate student. I spent the day following a circulating nurse during a radical prostatectomy surgical procedure. Similar to Alaia, I liked the work environment because of the professionalism and teamwork 
displayed by the members of the team. Working in the OR seemed easy, fun, effortless, and fluid. My OR observation experience also inspired my path into perioperative nursing. When it comes to leadership, it's not so much about the person who takes charge. It's a matter of communicating. It's the way you say something and that is what makes up leadership. People might have something to add. Let's say you're new and I notice that you did this. I may think, "Hey, I think it may be more efficient if you actually did this instead." At the end of that, you can ask, "What do you think of that?" You can also ask, "Is there anything that you might want to add that we should always get ready at the beginning?" It is about sharing those suggestions.

My attention is drawn to the interpersonal exchanges between OR team members described by Alaia. I agree with Alaia that leadership is about communication and reciprocal exchanges of recommendations between professionals, such as nurses and students. I think about interactions between senior nurses and less experienced nurses, which is often characterized as a unidirectional process with senior nurses only making suggestions to novice nurses. I seldom witness nurses request feedback from students. How do we improve if we do not seek feedback from others, even from neophytes? Leadership is also about helping others, especially new staff or students. Just because someone is new does not mean you need to hold their hand. They may be trying to figure it out. You can just ask, "Do you need help?" If you see someone struggling, you can help them. There's so much circulating stuff to do and that's why the nurses decide to scrub. Sometimes, we pull people aside and we ask them why they're having a hard time circulating. We make suggestions to try this or that.

Alaia continues to look at leadership from the context of intraprofessional collaboration. I hold the same views as Alaia: leadership at the point-of-care involves mutual giving and 
receiving of support from other perioperative nurses. How can we perform our jobs safely and effectively without assistance from other nurses?

When you say nursing leadership, I think of it as being an example. For instance, if I was scrubbed to set up my table and I noticed that someone was struggling to circulate, I would unscrub to help. After a while I noticed people started following what I did. They would quickly set up the table and take off their sterile gown and gloves to help the team members. The more people see that change in practice, the more they start doing it. We help each other and that works better. Once you change that practice, you change the whole culture.

Alaia reminds me that role modeling can be a very powerful tool for change, to the point where it can even impact the culture of a surgical department. I think about the nurses I have encountered in my own career, who have modeled admirable values and behaviours that have shaped my nursing practice. I fondly recall one nurse colleague remove her sterile gown and gloves to help me reposition a patient before surgery. She was also the same nurse who taught me how to use humour in communication with my colleagues. As a perioperative nurse, I always appreciate help from other colleagues, especially if I am struggling. I wonder about the environmental impact and the financial costs related to using multiple sets of sterile gowns and gloves. Do the immediate needs of patients and the healthcare team outweigh the long-term consequences of multiple gowns and gloves wasted?

Every service has a different culture. In neurosurgery the culture has changed. Before there were mostly senior nurses and if you were new, you really didn't have a say. A lot of the neuro nurses would say, "A good nurse wouldn't do this. You should do this instead." They never realized that they were actually criticizing you in front of others. People would think that you were not good. It makes you feel awful. 
I could not help but feel mortified for the actions of some of my fellow perioperative nurses. Humiliating a colleague, especially someone who is still learning, is distressing for everyone involved. My thoughts travel to a recent interaction I had with another perioperative nurse. I decided to place the cautery pads vertically, instead of horizontally. In front of the whole team, she criticized my placement of these pads. Although I had logical reasons for my chosen placement for the cautery pads, I did not respond. I judged the time and the place for further discussion, or potential altercation, to be wrong. I simply accepted her recommendation. I felt embarrassed, misunderstood, and dejected. I do not wish others to feel similar emotions. Importantly, the patient was safe and unharmed. However, I continue to have lingering questions about this experience. Did I do the right thing by letting my truth remain unspoken? What could I have done differently? We are there to help each other as nurses. So, why do we continue to implicitly and/or explicitly alienate each other?

Ever since I started they have hired new nurses. The culture is different now. The surgeons have noticed the change. They never used to socialize with the nurses. Before, Dr. Ben (pseudonym) would just say, in a very professional manner, "I need this." Now Dr. Ben likes to hang out. He has noticed that people are really working hard to make the room work, because they are all new people. It is just like being a student or a new person. When you're new you know all the hard things and all the struggles. We all share that. I don't know if it's just communication or the fact that we are all on the same stage.

Alaia's surgical service has received an influx of new and younger nurses, which has changed the workplace culture. I wonder if Dr. Ben is socializing with the nurses more frequently because they are younger, or because he is simply appreciating everyone's hard work. 
The struggles that are experienced by new nurses in Alaia's surgical department validate the stories that I have lived from my own beginnings as a nurse in the OR. I recollect my own struggles related to time management when I first started. I remember thinking, how do I count all the instruments on my sterile table set-up within the 10-minute time frame given to me? How do I help the scrub nurse set up for the case, while helping the anaesthetist when the patient is being prepared for intubation? I appreciate how Alaia reconceptualizes the struggles as opportunities to change the culture in her neurosurgery department. I can see how the collective struggle and hard work of her OR team has helped them build a collective consciousness, which has benefited them as a team.

I feel like we have the same goal. We help each other out and then we become a really good team. For instance, if I'm better at breaking ampules, l'll break them all for today. If you're good at suction then you'll do that. We're also like each other's friends. We automatically see each other and we just know.

We support and motivate each other. Everyone is pretty open and they just want to come and do the work. Nobody is really lazy. We're all kind of easygoing. For people who never used to do this and that, they had to change. Some people, who didn't normally do certain things, had to step it up and do them.

I think we openly appreciate each other. We learn from one another. One day I see somebody do something and I then add it to my practice. You pick up from each other because there's always a different way to do it.

As I listen to the words, "support", "motivate", "appreciate", and "learn from one another", to describe Alaia's professional team relationships, I sense the spirit of community that has developed between Alaia and her colleagues. They seem to have a clear sense of purpose, which has facilitated their commitment to each other and their work. 
I recognize how the notion of openness plays out when Alaia talks about the team's ability to learn from one another. Within this OR team context, I understand openness as a value that guides the team members to be transparent and objective, especially with respect to past and new experiences. I think people who value openness are receptive to new experiences for the purpose of learning, changing, and, ultimately, growing personally and professionally. I wonder if a sense of community and value of openness are prerequisites for nurses to effectively lead positive changes in the OR.

Another big aspect of leadership is just speaking for a patient. I think it speaks volumes that even though it is everybody's responsibility, it's mostly nurses who initiate the briefing, time out, or debriefing. There are certain surgeons who just have a habit of coming in later and asking, "Did you guys do the briefing?" I'm going to say $95 \%$ to $99 \%$ of the time the nurses call the time out and I really like it when they do it.

Last week there was a 35 year-old patient who was developmentally delayed. They wanted to know if we were okay with a parent coming into the OR to help him calm down and relax for the intubation. Some people were like, "We never do this." He was developmentally delayed and I honestly thought it was helpful that the mom was there. It was really nice because there was somebody here who was present for the briefing. If this patient couldn't sign the consent, shouldn't we technically have a family member for everybody who is confused? Half of the room was seniors who were saying, "We don't do that. We haven't done that before." What harm did it really do? I had to stand up for what I believed in. We're not doing this for every patient. This is a special case. Not all of our patients are developmentally delayed. We're not always going to do it, but if it makes sense that we should do it. I hope they wake up. This is a good thing and we should move towards it.

After focusing so heavily on leadership from a team perspective, Alaia now focuses her attention to the patient. I feel Alaia's passion, as she tells her story of patient advocacy. 
The words "speaking for the patient" describe the reality that I live at work when I have mechanically ventilate patients whose mouths are physically taped for surgery. In Alaia's story, I see how, even if a patient can speak, nurses still need to lead by treating patients fairly and by facilitating accessibility for patients and their families. I think back to Sandy's story and the value she places on fairness and the importance of nurse's voice. Alaia's story does introduce potentially contentious notion of who could be allowed into the OR. Why are some nurses or doctors so rigid, even when it comes to patient care? I wonder what we can do as nurses to change practices and policies to facilitate family members' access to patients, especially if it is essential to the patient's safety. I think leadership is also about times when you have to question how we've always been doing our job. It's not about going against what someone said. Maybe we should consider other things. As a hospital, we're more patient-centred care, but patient- and family-centred care is the same thing. It's about the patient. I also understand that there are things that you can't change. You just have to adapt.

Alaia continues to emphasize the value of openness to effectively care for patients and lead in the OR. My thoughts travel to Sandy and her open approach to teaching and learning. Although Alaia and Sandy strive to be open to different perspectives, they are guided by their sense of purpose, which is quality patient care. I think about my own nursing practice. I endeavor to be open for the purpose of ensuring the persons in my care are healthy and safe. I also try to be open by learning from others to avoid stagnation both personally and professionally.

When I was new, I remember how I didn't know there was a separate consent for tissue for research. I forgot to check the research consent. Another nurse said, "How could you do that? We always do tissue consent!" Every time I work with that nurse she tells me that I should do this 
and that. I see other people who would do as the nurse had suggested for the purpose of securing the nurse's approval. Others have to remember that they're doing their job because it is the right thing to do, not to gain another's approval. At some point you guys will butt heads. If you're right, you're going to have to stand up for it.

Leadership involves standing up for yourself and each other. Let's say for example, your circulating nurse is running around, trying to hook things up, or calling for a replacement of an item. We would say to a complaining surgeon, "It's not her fault. So will you relax?" People do their best and people need to appreciate that. A functioning team is good for a patient. In nursing, we stand up for each other and help each other out.

Alaia's story emphasizes that leading is also about caring for self and for others who are involved in the care of patients. I am delighted to see a nurse stand up for herself and her colleagues in times of adversity. However, I feel guilty for my own lack of moral courage. I feel that I do not stand up enough for myself or my colleagues. I have no difficulty standing up for what is right for the patient, but I still find it hard to care for my colleagues in the form of defending or advocating for them. Sometimes I can be overwhelmed by the required tasks of the moment that I do not have the time or courage to stand up for myself or my colleagues. Alaia brings to light my own experiences of point-of-care leadership failures, which is insightful for me as it provides me with the inspiration for future selfdevelopment.

For patients, I think the only time you really get to interact with them is during the introduction. The best thing you can come up with is, "Do you have any other questions?" I don't think most people ask that. They rush through all the questions. They say "thank you" and they're out of there. I totally understand that there are rooms that are running or carpal tunnels that need to be done. You can just ask, "So, do you have any other questions with that?" Most 
people do not spend that much time. Despite time limitations, it is a really good thing to ask the patients if they have any questions and assure them that the team will be there for them.

Alaia echoes Sandy's perceptions of time pressures placed on perioperative nurses in the OR. I think about the patients and families that I cared for as a perioperative nurse. I question my own nursing care. Do I rush through my introduction or preoperative patient assessment? Do I share meaningful moments with patients, even during the brief preparation for anaesthesia induction? I recall the time when I was a patient and required surgery. I constantly turned in my mind the potential complications, which increased my anxiety. This patient experience informs my daily practice. I constantly ask myself: Am I present in the moment with my patients to hear their fears and concerns?

I provide indirect care to patients, as part of my leadership activities. For instance, case usage where we are accounting for surgical items that are used per case, such as suctions, green, or white gloves. It affects everybody, including the budget and even your taxes.

I am reminded of the significance of healthcare system's sustainability and the role that nurses play within it. I think about the copious amounts of supplies that are used and wasted in the OR, including disposable drapes, gloves, gowns, vascular grafts, and other surgical supplies. How do all these disposable instruments and drapes, although safer for patients, impact the environment? As part of our role as leaders at the point-of-care, how can nurses reduce unnecessary wastage in the OR?

Other indirect things that we do to support leadership would be writing the incident reports. I think it's also leadership when you're writing stuff out when things are missing or when you're running low. You don't have to wait for the cords to be completely broken to write a report. Just take it out of circulation before something goes wrong. There are shaving boxes that 
only work sometimes. I remember talking to my manager before. Your mom could be the next person coming in and would you want that box in there? No, okay? So we should take it out. Alaia's words about caring for patients as family, remind me of Sandy's ethic of care: we should treat patients as we would like ourselves and our family to be treated. In my own practice I have followed the same ethic of care since the inception of my own nursing career. How, where and when did Alaia, Sandy, and I learn these values?

There are a lot of challenges in the beginning of your career in the OR. There's a lot of stuff you don't know. There is always that novelty. Once you get more experience, you have other challenges, like I don't know if certain people are going to blow up today. We all have our bad days. If I'm also having a bad day, I will probably say something. Sometimes an anaesthetist is inserting a central line. It's highly stressful. They may ask you not to touch a patient. We snap at each other, especially when you're on shift. It still happens. Sometimes you let it pass and think that it's just him. That's just how he is. Sometimes they do say sorry.

I empathize with Alaia and the challenges she experienced early in her career. I remember the novelty of the OR and its physical, social, and political environment when I first started as a perioperative nurse. I feel that the novelty subsides over time. With more experience, Alaia's challenges shift predominantly to the social environment, which I can relate to. Alaia's story of conflict with her anaesthetist colleague brings to light the unique high pressure environment of the OR where colleagues work so closely together. I could feel the tension as Alaia discloses how some colleagues "blow up". I recall my past experiences with colleagues “snapping at each other” especially during emergency surgeries. My consciousness is filled with thoughts about my own fear of working with certain colleagues who make me feel like I am walking on metaphoric pins and needles during our 
professional encounters. Is it healthy for us to possess these fears? What implications do these fears have on our nursing care and leadership practices?

A lot of people are very serious. So, if you use humour, I think it really serves you to get the point across. Sometimes, humour actually works. Other times, people may not find it funny. They don't hear it.

I remember moments of clarity when humour was used to communicate potentially upsetting messages, which I think is an important leadership skill. Much like Alaia, I use humour in the form of funny comments to connect with my colleagues, especially when tensions are high. I agree with Alaia that humour must be used with caution, especially with patients, family members, and colleagues. I am curious. How do we learn to use humour? How do we know when to use it? How do we determine who would be receptive to funny messages, comments, or anecdotes? How do we learn about these unspoken boundaries to effectively care for patients and influence others?

The physical arrangements can inhibit my ability to be a leader. All the rooms are arranged differently. Some rooms have the nursing and anaesthesia desks closer together. That makes it easier for us to communicate with the anaesthetists. The distance between the nurses and surgical team is also important because it can affect the visibility of the surgical site. If I come back from break, I probably would not know which items were opened when I was out of the OR. If you cannot see the tables when you're circulating, you would not know what was opened by another circulating nurse and scrub nurse during your break.

I can relate to Alaia's concerns about the geographical boundaries that perioperative nurses must work within. I think about the time pressures that perioperative nurses constantly face when taking care of their patients and the OR team as a whole. I see a connection between physical distances and the amount of time that it takes away from the perioperative nurses 
in the OR. I recall Sandy's own trepidations about her physical environment, more specifically the location of the OR theatre from the required surgical instrumentation. I think there is a rift between nurses and attendants. There needs to be better communication between them. People hold grudges against each other. We can never find attendants. Some people refuse to tie the garbage. Some attendants sit there, do nothing, and watch us work. Sometimes they don't listen.

I think there is a social hierarchy between RNs, RPNs, doctors, and attendants. It depends on who is working. A lot of surgeons and anaesthetists feel like they need to be handed all the surgical and medical supplies by nurses. It's like they are not capable and they need nurses to hand them the supplies. Some nurses think that nurses should never clean because that is an attendant's job. Some will even refuse to put pillowcases on pillows. You have a degree. I'm pretty sure you know how to put a pillowcase on. There are surgeons who will clean the floor. There's no protocol that says you can't clean the floor because you need training.

RPNs have a lot of experience and they know a lot of our trays. I asked one of the RPNs to check the case cart for a revision. Someone asked me, "Is that his job? That's a circulating nurse's job." Does that even matter? I have no idea which trays we need. If the RPN goes to check, he actually knows which trays we need. He has knowledge and you have to appreciate that. Ever since then, some of the RPNs are just more easygoing. The younger people recognize their expertise and we ask them questions. It validates their knowledge.

As Alaia talks about her concerns related to the flexibility of other nurses and OR team members, I sense her rising tensions once again. Alaia underscores the juxtaposition of the OR team's professional roles and practices in the OR. Alaia suggests the presence of a social hierarchy that can hinder collaboration. However, she also stresses the interdependence of the OR team members in carrying out multiple functions that safeguard the patient's well-being. This lack of flexibility in the attitudes and behaviours adopted by 
colleagues is disappointing and embarrassing for me to hear. What kind of image does that portray to others about nurses?

The PCCs, educators, and other administrative nursing staff do come into the room sometimes and they will tell you to do certain things, but they are very small things. They may tell you to put the trays or organize the table set-up a certain way. Operating Room Nurses Association of Canada Standards (ORNAC) do not tell you whether a tray should be vertical or horizontal. I get it if I had a blade that wasn't protected lying around, but they just come into the OR and have billions of comments. Sometimes, the PCCs, educators, or other people interrupt your room in the middle of something important, like intubation. As they walk out of the room, the surgeon's and anaesthetist's shoulders relax. Even though the administrative nursing staff members are picking on the nurses, I think a lot of people, even the surgeons, are irritated. The administrative nursing staff members also pick on the surgeons too. Why come into to the room and criticize somebody, like they're perfect? Sometimes, I feel like I have to walk away from this and just breathe.

Our nurses have a voice. I get that I should always be this person who speaks out. When you're speaking out it doesn't mean you have to be the loudest voice. It doesn't mean you have to be stern and make people look bad. That's not really speaking up. That's promoting a culture that's actually unsafe. It reduces communication between team members. I think the administrative nursing staff would probably be more supportive if they had a more open attitude.

I sense Alaia's frustrations with administrative nursing staff, who criticize the work of the OR team. I see how their comments may potentially demean the OR team members. What does Alaia mean when she mentions "promoting a culture that's actually unsafe"? To Alaia, leadership encompasses support with an open attitude. In her story she often uses the 
word open and openness to describe qualities of effective point-of-care leadership. What exactly does she mean when she uses the term "open attitude"?

One of the internal challenges during my leadership experiences is the stress I feel from dealing with other people. The challenge I experience relates to whether I release the anger or hold it in. Some days I feel like letting you have it. Some days you're not worth it. I definitely don't want to take the anger home. I also don't want to take it out on other people. I know we're all here as a team and you cannot speak to people like that. I know that you can't change people. You just work around them. You could just say certain things and it lightens the room. I think about the role of nurse leaders in creating change. Alaia points out, everything and everyone cannot be changed. If we cannot change the attitudes and behaviours of others, how do we cope with it? If we cannot change our physical, social, economic, or physical environment, how do we continue to care for ourselves and others, including patients, family, and colleagues? Alaia's suggestion that we can strive to change ourselves, by changing how we cope with the environment, including the people we work with, gives me hope. I find it empowering that there is something I can do. Yet, I wonder what working around people would look like. What do you say? What do you do? How can we use humour most effectively? Does power have anything to do with it?

You've been there for a while, so they trust you more. I think you have to earn that trust. When you're new, they won't know whether you understand or do certain things. I think once they've seen you do it, they actually stop watching you. I see that she doesn't contaminate herself. I'm going to just leave her. With more time and experience, you will feel more relaxed. If something goes wrong, you kind of feel like you can take on anything. You totally have that confidence. 
I centre my attention on the words "trust", "time", "experience", and "confidence". Alaia suggests that self-confidence is a function of time, experience, and trust from colleagues. I relate to Alaia's story. Once I gain self-confidence, I feel that I can take on anything. I feel that I can care for patients and support positive changes in the OR as a perioperative nurse. How can we make this more accessible to the new nurses, who are just learning their OR role?

My surgical service is different now with well-functioning go-getters. They take initiative. The senior nurses are distributed now. You don't have to yell at each other to make things work. You have surgeons who joke around and they're like your friends. Our PCC the other day commented on our relationships. We actually like each other and not just pretending. We're really friends.

I sense Alaia's pride in her team. I feel her genuine happiness and affection for the people she works with. I think about the value of professional collaboration on the well-being of patients and the professionals involved in the care. 


\section{Figure 2. Alaia's Metaphor of Point-of-care Nursing Leadership: A Funnel}

I have chosen to draw a funnel because I used a funnel today. I think when you start it's very narrow with darker colours. When you start, you're learning. As you become more of a leader, you see more of how you would want other people to be treated and how you would want to be treated. I think it opens up to other possibilities and it clears your way. You have a much more relaxed and comfortable environment and it helps you see things from different perspectives. Yellow is the colour for hope and happiness. Yellow represents the many possibilities. Things don't have to be so narrow and dark. It doesn't need to be a one-way thing. The funnel points towards the right to follow the creative right side of the brain, which helps you to get further and emphasize that we have to be open to different ideas and different ways of thinking related to patient care.

It becomes clear to me Alaia's ethic of care, which is the inspiration for her approach to point-of-care nursing leadership. Alaia values openness, creativity, and multiple perspectives in her nursing practice. I see Alaia's funnel as her journey of care, leadership, and overall satisfaction. I sense that Alaia is still hopeful that she will continue with her journey in her chosen career as a perioperative nurse. 
In this chapter, I revealed the personal justification to situate myself, as a narrative inquirer, in Alaia's story. My relationship and interest in this inquiry are revealed throughout my personal interjections. In the next chapter, I discuss how I use Narrative Inquiry and integrate the theoretical frameworks of Leadership Model and Person-Centred Nursing to analyze and interpret Sandy's and Alaia's stories during the second level of practical justification.

$\S$

As I bid farewell to Alaia, I resume my hike with the full understanding that I will soon encounter the glacier field, which lies just below the mountain summit. Before I set off, I look back towards the valley below. The houses in the village are now almost too small to be visible with the naked eye. I turn to look up the mountain and imagine that from the higher vantage point I will be able to have a broader perspective on the vast landscape that surrounds me. 


\section{CHAPTER SEVEN}

\section{CLIMBING HIGHER ON AN ICE-LADEN PATH: THEORETICAL FRAMEWORKS}

I take my first step onto the edge of the glacier and feel the spikes of my crampons pierce through the frozen surface. Wanting to avoid the deep crevasses, I consider each step carefully before moving forward. The winds have picked up. I brave the strong winds and slippery glacier surface, as I make my way up toward the mountain top.

It is at this stage of the thesis process that I feel the most challenged. I have heard the stories and engaged with them through my own reflexive responses. And now, I move to the second level of justification, the practical, where I draw in the theoretical frameworks and other relevant research that assist me in situating my own inquiry. In this chapter I present the two theoretical frameworks and my reasons for choosing the two.

\section{Theoretical Frameworks}

In this chapter, I explicate the two theoretical frameworks, Leadership Model by Kouzes and Posner (2007) and Person-Centred Nursing by McCormack and McCance (2010), which elucidate the second level of justification, the practical, of the participants' lived and told stories of point-of-care nursing leadership in the OR. I implement these two complementary theoretical frameworks for two reasons. Firstly, Sandy and Alaia describe their enactment of leadership behaviours, which are congruent with Kouzes and Posner's (2007) leadership practices. Therefore, I situate their stories within the context of point-of-care nursing leadership by using Leadership Model. Secondly, Sandy's and Alaia's stories reveal how their leadership behaviours are embedded in their enactment of person-centred care. They practice person-centred care for persons of the OR team, which includes the patient, nurses, surgeons, anaesthetists, and other 
care providers, to strengthen their leadership practices at the point-of-care. For these reasons, I use Person-Centred Nursing framework to deepen my understanding of point-of-care leadership in the OR. What follows here is the explication of each of the two theoretical frameworks.

\section{Leadership Model}

As Sandy's and Alaia's stories unfold, I begin to recognize how they interpret point-ofcare nursing leadership. They describe their informal leadership practices in the OR as taking initiative, supporting, motivating, role modeling, communicating, and recognizing others' contributions. These practices align closely with Kouzes and Posner's (2007) Leadership Model.

Leadership Model was developed from a series of self-reports about personal-best leadership experiences from public and private organizations' middle and upper level managers in the business discipline (Kouzes \& Posner, 2007). This model has since been adopted and adapted in healthcare (Brown, 2010; Kallas, 2014; Patrick, 2010). According to Patrick (2010), Kouzes and Posner integrate transactional and transformational leadership concepts throughout the five leadership practice domains (discussed below) in the Leadership Model. Transactional leadership is a leadership style based on a contingent rewards system that occurs in a leaderfollower relationship (Rolfe, 2013). The follower and the leader begin a relationship with a process of negotiating what is being exchanged. The leader offers benefits or rewards for followers in return for compliance (Rolfe, 2013). For example, if the follower performs a particular task, a reward is given to meet her/his needs (Bass, 1996). A transactional leadership style is more task-oriented and it may be effective for meeting deadlines or emergencies (Rolfe, 2013). Transactional leadership achieves lower order or basic needs, such as physiological or safety changes, which is based on Maslow's hierarchy of needs (Bass, 1996). 
Transformational leadership concepts are also incorporated in Kouzes and Posner's (2007) Leadership Model. Transformational leadership is a leadership style characterized by a reciprocal and interdependent relationship, whereby the leader motivates and supports its followers to work together towards achievement of a shared vision (Rolfe, 2013). The followers are inspired by their leader to "transcend their own self-interest" and do more than is expected of them (Yukl, 2010, p. 277). Transformational leadership involves the empowerment of its followers along with the transformation of their aspirations, values, and identities to reach their full potential and accomplish their vision (Avolio et al., 2004). The followers achieve higher order changes or outcomes, such as self-actualization (Bass, 1996).

In their Leadership Model, Kouzes and Posner (2007) describe effective leadership practices that leaders use all the time. They do not classify the personal attributes as transactional or transformational. Instead they describe effective leadership practices that integrate both transformational and transactional leadership concepts within the five practice domains (Patrick, 2010). Their Leadership Model is based on five fundamental practices that support leaders to mobilize others and achieve extraordinary things in organizations and on the assumption that ordinary people can achieve extraordinary success. The five leadership practice domains include: model the way, inspire a shared vision, challenge the process, enable others to act, and encourage the heart (Kouzes \& Posner, 2007). Each practice domain has a subset of associated leadership behaviours. Kouzes and Posner propose that leaders have a tendency to use all or most of the five leadership practices simultaneously, as opposed to one at a time. The domains represent the actions and activities of exemplary leadership that have transformative outcomes for its leaders and followers. 


\section{Model the Way}

The leadership practice domain of model the way involves setting an example for other individuals to follow. In other words, leading involves being a good example. To do that, Kouzes and Posner (2007) suggest that leaders, formal or informal, must have clarity of their values, so that their actions are in alignment with their guiding principles. Leaders need to know who they are, in order for them to stay on the path they have chosen. By demonstrating integrity between their values and actions, leaders demonstrate commitment to their values so they model the way for others to follow.

\section{Inspire a Shared Vision}

The leadership practice domain of inspiring a shared vision involves enlisting other people in a shared vision by appealing to their dreams, aspirations, hopes, visions, and values. Leaders express enthusiasm for a future filled with exciting possibilities. They inspire a unified purpose "by showing their constituents how the dream is for the common good" (Kouzes \& Poser, 2007, p. 18). They communicate their passion by using language that is vivid and expressive. The leader's enthusiasm and passion for the vision incites other people's inspiration (Kouzes \& Posner, 2007).

\section{Challenge the Process}

Every successful leadership story involves some form of challenge, which entails a change from the existing conditions (Kouzes \& Posner, 2007). Challenging the process involves leaders seeking opportunities to innovate, improve, and grow. They listen to others to recognize and support good ideas. They experiment and take risks. Leaders take initiative (Patrick, 2010). They have a willingness to challenge current systems to realize innovative ways to improve their 
actions. Leaders celebrate small victories to build confidence that even the bigger challenges can be overcome (Kouzes \& Posner, 2007).

\section{Enable Others to Act}

The leadership practice domain of enabling others to act refers to fostering group “collaboration and individual accountability" (Kouzes \& Posner, 2007, p. 20). Leaders create social support (Patrick, 2010). Leaders foster collaboration by building trust and facilitating strong relationships between group members. Exemplary leaders also strengthen other people by making them feel that they have the strength and capability to achieve goals and positive results. Leaders share their power by ensuring that others have a sense of ownership of their activities or projects. Enabling others to act involves a leader who continuously seeks the opinion of others to educate and inform her/himself, as well as build the capabilities of her/his colleagues. Trust, teamwork, and empowerment are essential elements of this leadership practice domain (Kouzes \& Posner, 2007).

\section{Encourage the Heart}

Exemplary leaders uplift the heart and draw people onward through genuine acts of caring (Kouzes \& Posner, 2007). Kouzes and Posner suggest that leaders recognize others' contributions through private one-on-one conversations with the individual or in front of other people. It is also part of a leader's job to celebrate the values and victories of others to create a collective identity and spirit of community. In doing so, a leader prevents others from giving up and, instead, encourages them to move forward (Kouzes \& Posner, 2007).

\section{Person-Centred Nursing}

Sandy's and Alaia's lived and told stories also reveal how they practice personcentredness by caring for patients and other members of the OR team, in order to effectively lead 
at the point-of-care. Sandy and Alaia embody person-centred care with patients and peers to improve their point-of-care nursing leadership capacity in the OR. McCormack and McCance's (2010) Person-Centred Nursing helps me interpret the participants' stories of caring for patients and other team members, as well as to consider the reasons nurses engage in certain leadership actions. By examining their caring practices in the OR, I also gain insight into how they enhance their nursing leadership potential at the point-of-care.

Person-centred care "is an approach to practice" that is formed through the formation of relationships between healthcare team members, which include care providers, patients, and/or families (McCormack et al., 2010, p. 13). Such relationships are established on mutual understanding, trust, and sharing of knowledge (McCormack \& McCance, 2006). Values of respect for persons, empathy, and self-determination underpin this approach (McCormack et al., 2010). Person-Centred Nursing is a theoretical framework that describes and operationalizes person-centred care in nursing practice. The concept of person is central in this theoretical framework. Person refers to the attributes "that represent our humanness and the way in which we construct our life" (McCance et al., 2010, p. 5). As humans, we have free will and moral freedom, and as such are distinguished from other living beings by our ability to engage in reflection to guide our choices and actions (McCormack \& McCance, 2010). We are selfdetermined beings who are co-creators of the social world. Within the context of the care relationship, McCormack and McCance (2010) define the person as all the individuals engaged in the care partnership. These researchers explicitly state that "the person refers to all those involved in caring interactions and therefore encompasses patients, clients, families/carers, nursing colleagues and other members of the multidisciplinary team" (p. 4). This definition 
considers how staff relationships and team effectiveness also impact the creation of the care environment.

McCormack and McCance (2010) define four core concepts of Person-Centred Nursing framework, "being in relation, being in a social world, being in place, and being with self" (p. 26). These concepts move away from the medically-driven and fragmented focus, to one that has a broader orientation that considers the context and relationships. Person-centred care is not only about focusing on individual needs, but it also takes into account the interactions amongst all individuals participating in the care in a given place.

Person-centred care is operationalized in practice by McCormack and McCance (2010) in their Person-Centred Nursing framework, which can be used to facilitate nurses' exploration of person-centred care in their nursing practice. Throughout this thesis, I use the terms personcentred care and person-centredness interchangeably to reflect the four concepts that inform the theoretical underpinnings of Person-Centred Nursing framework (McCormack \& McCance, 2010, p.26). This framework uses the four constructs to operationalize therapeutic caring of all persons involved in the care partnership, which include the patient, family, nurses, and other care providers. The four constructs comprise of prerequisites, care environment, person-centred care processes, and outcomes. The four constructs also have similarities with the three commonplaces (temporality, place, and sociality) described by Connelly and Clandinin (2006), which are elucidated in more detail in the following section. The commonplace of temporality interplays within every human experience, therefore, it is embedded throughout the four constructs.

\section{Prerequisites}

According to McCormack and McCance (2010) the nurse needs to have specific attributes before s/he can provide person-centred care to patients, families, and other care 
providers involved in the multidisciplinary team. Prerequisites include: being professionally competent, having developed interpersonal skills, being committed to the job, demonstrate clarity of beliefs and values, and knowing self. Prerequisites are what I refer to in this inquiry as the personal conditions, which aligns with Connelly and Clandinin's writings about the commonplace of sociality, described earlier in Chapter Three.

\section{The Care Environment}

The care environment centers on the context where care is provided, which has the highest potential to constrain or improve the person-centred care processes. McCormack and McCance (2010) distinguish the following contextual factors that are conducive to personcentred care: workplace culture, appropriate skill mix, systems that support shared decisionmaking, power sharing, effective staff relationships, supportive organizational systems, possibility for risk-taking and innovation, and physical environment. The care environment is also what I refer to as the care landscape, which is congruent with Connelly and Clandinin's commonplace of place.

\section{Person-Centred Care Processes}

This is the construct that focuses on all the persons within the context of care delivery. With this view, caring processes involve both, nurses caring for patients, as well as other team members, and vice versa. Care processes are interwoven and delivered through an array of activities. These include having sympathetic presence, engagement, shared decision-making, and provision of holistic care (McCormack \& McCance, 2010). The care processes are the commonplace of sociality, which makes up the relational component of experience in Narrative Inquiry (Connelly \& Clandinin, 2006).

\section{Outcomes}


The construct of outcomes constitutes the effects of person-centred care. Patient satisfaction can reflect the organization's effectiveness. By measuring patients' feelings of involvement in their care and feelings of well-being, the effectiveness of nursing care can be evaluated (McCormack \& McCance, 2010). Self-reports from nurses and other healthcare providers may also be measured to evaluate the effectiveness of person-centred care. In this inquiry I am not evaluating the outcomes of the care processes, therefore, this construct is not used during this level of practical justification. However, this remains a future research opportunity.

\section{Using Two Theoretical Frameworks to Understand}

\section{Point-of-care Nursing Leadership in the OR}

In Chapter Eight, I reveal the practical justification of this Narrative Inquiry. I analyze and interpret Sandy's and Alaia's stories of point-of-care nursing leadership, using Leadership Model and Person-Centred Nursing in a complimentary way. Leadership Model provides me a venue through which to interpret and situate the participants' stories within the context of pointof-care nursing leadership in the OR, while Person-Centred Nursing helps me make sense of Sandy's and Alaia's caring practices towards their patients and peers within their informal leadership practices. By using the two frameworks synergistically I gain a deeper and broader understanding of participants' lived and told stories of point-of-care leadership in the OR, which would not have been possible with either one alone.

Sandy and Alaia speak of how they live point-of-care nursing leadership with their patients and peers in the OR. By knowing their patients, their environment (physical, social, and political), and themselves, Sandy and Alaia are better able to influence others to work towards the common good for their patients and for their peers. Sandy and Alaia use their knowledge and 
competencies to establish credibility in their relationships and lead at the point of their care. By using Leadership Model and Person-Centred Nursing, I gain insight into how and why nurses engage in leadership at the point-of-care. I come to understand how person-centred care informs their leadership practices in the OR.

In this chapter, I have explicated the two theoretical frameworks that I use in my inquiry. In the next chapter, I reveal the outcome of my critical reflection at the second level of justification, the practical. More specifically, I discuss the overarching narrative thread of communication that is pervasive throughout the told stories, followed by the three narrative patterns revealed in the told stories.

As I take further steps across the glacier, my eyes peer through the small opening between my hat and scarf. I begin to see variations in ice formations on the surface of the glacier. Enamored by its beauty, I am inspired to mindfully press on towards the summit. 


\section{CHAPTER EIGHT}

\section{REPLENISHING MY ENERGY BY THE GLACIER STREAM:}

\section{PRACTICAL JUSTIFICATION}

As I continue to climb, I look around and admire the different ice shapes along my path. I see water running downward through small channels embedded in the glacier. Being careful not to fall into the glacial streams, I fill my bottle with water. After hydrating myself, I continue my hike along this challenging plane.

By using Leadership Model and Person-Centred Nursing frameworks, I critically analyze the prominent thread, communication, and the three narrative patterns that emerge from the participants' told stories: advocacy, relationships, and teaching and learning. I re-present each narrative discussion through free verse poetry, using participants' words. I conclude this chapter with a reflection on how Sandy's and Alaia's stories impact my own evolving understanding of perioperative point-of-care nursing leadership in the OR. This is the second level of justification of Narrative Inquiry analysis process, the practical. The key terms from each framework, Leadership Model and Person-Centred Nursing, as well as the three dimensions of Narrative Inquiry, are italicized for emphasis throughout this chapter.

\section{Second Level of Analysis: Practical Justification}

Leadership Model and Person-Centred Nursing are applied synergistically as theoretical lenses to critically analyze point-of-care nursing leadership. In Narrative Inquiry, the threedimensional analysis process is used throughout the three levels of personal, practical, and social justifications. Narrative Inquiry's three commonplaces (temporality, sociality, and place) are embedded in every human experience (Connelly \& Clandinin, 2006). Therefore, I use the three- 
dimensional analysis process to analyze the interplay between time, place, and personal-social conditions in the point-of-care leadership experiences of Sandy and Alaia.

Along the way the reader comes to understand how the narrative patterns and threads are not mutually exclusive. Rather, narrative threads that are related are grouped together to form narrative patterns, which are analyzed and interpreted through a chosen theoretical lens or lenses. However, sometimes one narrative thread is so prominent that it permeates all narrative patterns, and so is accorded its own section. In this thesis, that narrative thread is communication. Another important note is that narrative patterns and their threads do not necessarily happen sequentially. As it is in life, the commonplaces of temporality, sociality, and place of human experience are integrated and overlap throughout this stage of the analysis process (Figure 3).

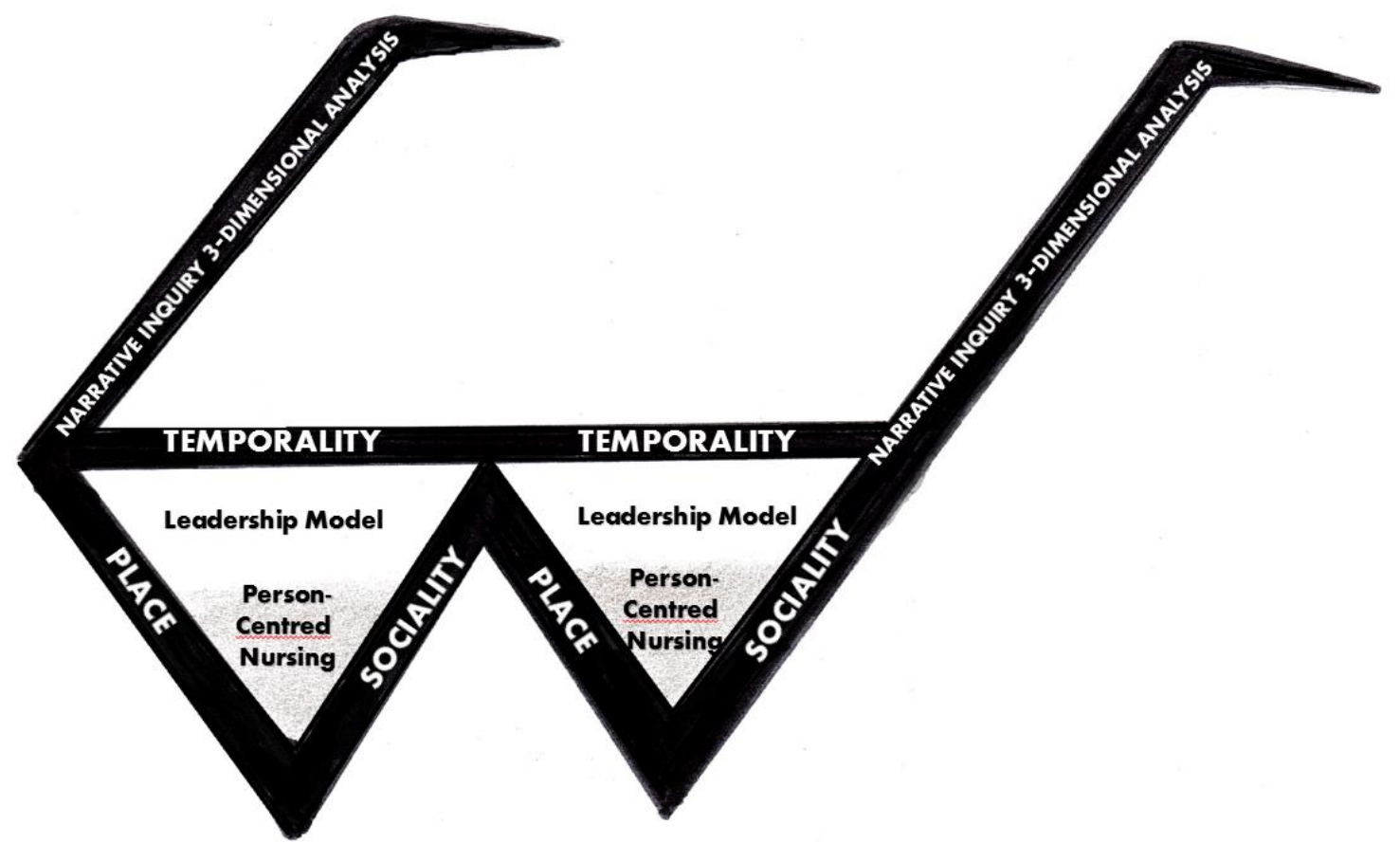

Figure 3. Narrative Inquiry with Integration of Leadership Model and Person-Centred Nursing 
This pictogram serves to visually demonstrate how I use the Narrative Inquiry threedimensional analysis process and the two theoretical frameworks, Leadership Model and PersonCentred Nursing, synergistically to critically analyze the point-of-care nursing leadership experiences of Sandy and Alaia. The frame of the glasses represents Narrative Inquiry's threedimensional commonplaces (temporality, sociality, and place). The bifocal lens represents the two theoretical frameworks, the Leadership Model and Person-Centred Nursing. I use them as complimentary theoretical lenses to more fully examine the storied experiences of point-of-care nursing leadership, thereby gaining a clearer understanding of this phenomenon. By using both theoretical lenses, I come to a deeper understanding why and how Sandy and Alaia practice leadership at the point-of-care.

\section{Re-Presentation of Narrative Patterns using Free Verse Poems}

In Narrative Inquiry, meanings of an experience are usually expressed through words or "literary forms of language" (Clandinin, 2007, p. 4). Artistic self-expression, such as drawing and poetry, may also be used, through which meanings are expressed, shared, or re-presented. In the composition of free verse poetry there are no imposed structures in verse, rhythm, or rhyme, giving me the freedom to use participants' words to reflect their voice (Lapum, Ruttonsha, Church, Yau, \& David, 2011). In this inquiry I use free verse poems to re-present participants' told stories of point-of-care nursing leadership in the OR, as they are discussed in each narrative pattern. The meanings of their storied experiences are expressed through the aesthetic plotline of each poem.

I use poetry as a tool through which the readers can imagine and embody what it is like to be a point-of-care leader in the OR. Through imagination, the readers can view the world through another lens, thus cultivating a sense of empathy (Lapum et al. 2011) with nurses' 
experiences. Through poetry, the engagement of other nurses and care providers is facilitated, further strengthening the transferability of Sandy's and Alaia's storied experiences.

\section{Communication}

Communication is a narrative thread that prevails throughout all three narrative patterns of this Narrative Inquiry, and can be defined in multiple ways, depending on the context. Fundamentally, communication is an act of transmitting or a process of information exchange that occurs between persons (Cypress, 2011). Perioperative nurses use numerous techniques of communication, such as silence, commands, and jokes (Espin \& Lingard, 2001). Communication is also a defining attribute of staff nurse 'clinical leadership' (Patrick, 2010), which is the term used by Patrick to describe what I refer to in this thesis as point-of-care nursing leadership.

When trying to articulate the essence of point-of-care nursing leadership, Alaia focuses on the importance of communicating openly with peers:

It's a matter of communicating. It's the way you say something and that is what makes up leadership. If you see someone struggling, you can help them. We make suggestions to try this or that.

Communication is a narrative thread that is predominant in Alaia's story. To Alaia, point-of-care nursing leadership involves open communication with reciprocal exchanges of feedback and recommendations between professionals for improvements in professional practice. Alaia's willingness to help others and share suggestions are also reflections of the leadership practice domain, enabling others to act. Kouzes and Posner (2007) suggest that exemplary leaders foster team collaboration through sharing information. By having open lines of communication, the team members are able to raise questions or concerns, which nurtures trust and collaboration where people feel more involved. Alaia alludes to the social quality of her space where there is a 
workplace culture that values learning as an integral component of practice. This reveals a place that supports person-centred care (McCormack \& McCance, 2010). Through Alaia's excerpt I am cognizant of how a person-centred environment that values learning facilitates point-of-care leadership actions of information sharing between team members.

Alaia uses her interpersonal skills when communicating with others within the context of her peer relationships. Alaia speaks of using humour in her workplace to express a clear message:

So, if you use humour, I think it really serves you to get the point across. Sometimes, humour actually works. Other times, people may not find it funny.

Communication is core behaviour in all the leadership practice domains of model the way, encouraging the heart, inspiring a shared vision, challenging the process, and enabling others to act (Patrick, 2010). Alaia uses humour to connect with her colleagues and to communicate information that might remain unsaid. However, Alaia also notes that humour may be ill received in other circumstances. Hughes (2005) agrees with her, suggesting that laughter can be an effective technique for reducing emotional tension. He further comments that humour may also be used to convey a clear message and nurture transparent relationships between leaders and followers, but it must be used with caution. Humour may be rendered ineffective and potentially harmful to the nurse's inner person and her/his relationships, if used haphazardly.

Alaia's story reveals how person-centred communication is an important element of nursing leadership. Person-centred communication involves communication with others based on what is known about them as persons (McCormack \& McCance, 2010). McCormack and McCance (2010) suggest that nurses need to develop interpersonal skills, which they link to emotional intelligence, in order to "accurately perceive, appraise, and express emotions" (p. 49). 
Emotional intelligence entails two components, interpersonal intelligence and intrapersonal intelligence. By understanding ourselves as emotional beings, we can respond to the emotional behaviours of others effectively. Nurses must understand others and self to regulate their emotions and expressions towards emotional and intellectual growth. In Alaia's situation, she strives to appraise others' emotions and concerns before using humour to convey a clear message and induce responses from others. Humour can potentially induce negative or positive social responses (Hughes, 2005), therefore, nurses must be self-aware and practice self-regulation, empathy, and adept social skills (McCormack \& McCance, 2010) when using humour as a communication technique.

In this narrative thread, once again, I see the interconnection of person-centred care and point-of-care nursing leadership. Alaia demonstrates how it is important for nurses to develop emotional intelligence to articulate information to others. By communicating effectively, nurses establish credibility in their relationships with patients and other team members (Patrick, 2010), which, according to Kouzes and Posner (2007), is the foundation of leadership.

Sandy describes how she takes initiative to prevent or solve problems by communicating with team members:

$$
\begin{aligned}
& \text { Point-of-care nursing leadership is about taking initiative. Instead of waiting to find } \\
& \text { out what the surgeon needs for the fourth case, you would ask them in the beginning. } \\
& \text { You can give yourself time to get it organized... and there won't be a delay. }
\end{aligned}
$$

She engages in challenging the process and enabling others to act by taking initiative and engaging in collaborative practices. Sandy recognizes the need to be proactive. She demonstrates taking initiative, which is a prominent behaviour in challenging the process. She also collaborates with her surgeon colleague, thereby demonstrating enabling others to act. Sandy 
engages in collaboration and coordination by communicating, prioritizing, and organizing her care. She uses her clinical expertise to guide her actions and navigate through her environment. Sandy's clinical expertise, related to her knowledge of surgical procedures, surgeons, and how they work, is made visible in this narrative thread. She uses her personal-social conditions, such as her knowledge, competencies, and relationships, to guide how she prioritizes and coordinates her work. She speaks with surgeons at the start of each shift in order to minimize potential problem and time delays. In this narrative thread, she demonstrates how interplay of personal-social conditions in the OR space facilitates her ability to carry out her roles and responsibilities as a perioperative nurse. Furthermore, it is evident that time continues to shape Sandy's professional practice, as she continuously strives to improve her practice. From the perspective of the three commonplaces of Narrative Inquiry, we see that there is this interplay of place, temporality, and sociality that facilitates her ability to enact leadership at the point-of-care in her workplace.

One of the most observable displays of communication between team members in the OR is the surgical briefings. Alaia also takes initiative by initiating these communication practices:

It is everyone's responsibility. It's mostly nurses who initiate the briefing, timeout, or debriefing.

The World Health Organization (WHO) refers to these briefings as the Surgical Safety Checklist, which provides a visual tool for standardized communication for OR teams. The briefings are to be carried out by surgical teams at three different points of the procedure: before anaesthesia induction, before skin incision, and before the patient leaves the OR (Lyons \& Popejoy, 2014). This is a critical time when all care providers communicate pertinent information to each other about the patient with the patient, such as allergies, intravenous access, and risk for blood loss 
(Lyons \& Popejoy, 2014). The briefings highlight a space within perioperative nursing practice where nurses may engage in point-of-care nursing leadership in the OR. Alaia stresses the importance of conducting these briefings, which are often initiated by perioperative nurses. Alaia demonstrates taking initiative to enact leadership at the point-of-care. Although taking initiative is a core behaviour in all leadership practice domains, it is more a prominent behavioural indicator in challenging the process (Kouzes \& Posner, 2007; Patrick, 2010). Alaia enacts pointof-care nursing leadership by initiating input from peers and positively influencing team compliance, which in turn has positive implications for persons involved in the care. In a metaanalysis by Lyons and Popejoy (2014), the results suggest that the completion of Surgical Safety Checklists in the OR have positive effects on teamwork, communication, and safety measures compliance. Furthermore, reductions in patient morbidity and mortality are observed when the checklists are completed.

Sandy's and Alaia's stories reveal how person-centred communication informs their leadership practices in the OR. Effective communication that is person-centred is a vital skill that nurses need when carrying out point-of-care nursing leadership actions that involve other team members (Heid, 2010). As mentioned earlier in this section, communication permeates all three narrative patterns. Sandy and Alaia use interpersonal communication in their advocacy, interpersonal relationships, and teaching and learning. This further demonstrates how the narrative patterns and threads are integrated as they interplay in every human experience.

\section{Narrative Patterns}

In their accounts, Sandy and Alaia recognize how their stories of point-of-care nursing leadership are embedded within the stories of person-centred care. Each narrative pattern, 
advocacy, relationships, and teaching and learning, is composed of corresponding narrative threads.

\section{Advocacy}

Advocacy is a significant concept in Sandy's and Alaia's experiences of point-of-care nursing leadership. Their acts of advocacy are informed by what they know about the persons that comprise the OR team, as well as the place within which advocacy transpires. In Sandy's and Alaia's stories, advocacy occurs at different levels: patient advocacy, peer advocacy, and professional advocacy. Advocacy is the behavioural response involved in the participants' enactment of sympathetic presence, which is a space where point-of-care nursing leadership and person-centred care overlap.

Patient advocacy. Sandy recognizes the importance of advocating for the patient when she describes her teddy bear metaphor. Alaia also believes that patient advocacy is an enactment of point-of-care nursing leadership.

When somebody is not doing or thinking about the patient's well-being...then 1 go all mama bear and tell that person not to do that and do this instead. (Sandy)

I had to stand up for what I believed in. Not all of our patients are developmentally delayed. (Alaia)

Advocacy is a concept embedded within the construct of point-of-care leadership by nurses (Heid, 2010; Patrick, 2010). Advocacy, within the context of the nurse-patient relationship, involves nurses translating information between patients and members of the medical profession, in both directions (O’Connor \& Kelly, 2005). Sandy and Alaia play an intermediary role between their patients and other healthcare providers. They demonstrate leadership behaviour under the domains of inspiring a shared vision and challenging the process. They demonstrate challenging 
the process through their eagerness to change current practices that potentially risk patients' health. Sandy and Alaia seize the challenge by communicating their concerns. By doing this, they inspire their colleagues to act in ways that achieve their shared vision of quality patient care and well-being. Sandy's and Alaia's personal conditions, as exhibited in their readiness and willingness to advocate, influence their social conditions by impacting current and future social attitudes, as well as institutional policies and practices, with the purpose of helping their patients overcome barriers, meet their needs, and respect their rights as persons.

Alaia's story reflects how point-of-care leadership behaviours are embedded in their person-centred care. Alaia's story reflects one of McCormack and McCance's (2010) caring processes called sympathetic presence, which is a form of engagement where the nurse recognizes the uniqueness and value of person in the care partnership, by responding and maximizing coping resources to meet her/his needs and desired outcomes. She recognizes her patient's right to be treated as a person and to participate in decision-making, despite his developmental delay. She does this by including his parent to provide comfort and inclusiveness in the surgical briefing. Alaia's sympathetic presence involves a behavioural response of patient advocacy that aligns with the leadership practices.

Alaia's story brings to mind Hanks' (2007) notion of nurses experiencing a conflict of interest between their responsibility to the patients and their duty to their healthcare institution, which may lead to lack of peer support, creating barriers to patient advocacy. Despite the objections from Alaia's colleagues, she recognizes the patient's needs based on his cognitive, socio-emotional, motor, visual, and speech skills and she proceeds accordingly. By knowing the patient, which is one of the fundamental principles of person-centred care (McCormack et al., 2011), Alaia is more informed and able to advocate for him. 
Peer Advocacy. Nurses also engage in peer advocacy. Alaia recalls advocating for a circulating nurse who was faced with the challenge of completing multiple tasks.

We would say to a complaining surgeon, "It's not her fault. So, will you relax?"

Alaia demonstrates how a nurse may act as a liaison between peers in the OR. Throughout Alaia's story, she describes how time has enabled her to develop knowledge of the team members' work and the nature of her relationships with them, which demonstrates the clinical leadership attribute of clinical expertise described by Patrick (2010). Alaia's expressed words imply her informal power within her professional relationships with peers. Informal power influences a leader's ability to inspire a shared vision, encourage the heart, and enable others to act within a group (Patrick, 2010).

This narrative thread demonstrates how point-of-care nursing leadership behaviours are embedded in person-centred care processes. By verbally reacting to a surgeon's complaints, Alaia demonstrates peer advocacy, which is a behavioural element of sympathetic presence that is characteristic of inspiring a shared vision. She encourages her surgeon colleague to recognize others' contributions in the care partnership. Alaia also encourages the heart by providing social support and by recognizing a nurse's contributions. In the process, Alaia empowers a nurse colleague who needed support, thereby demonstrating enabling others to act. Alaia understands and recognizes the struggles experienced by a fellow nurse, which motivates her to advocate. Alaia bridges the gap by using her informal power to take the risk and advocate for a peer.

Alaia expresses sharp disapproval of the surgeon's behaviour, which is a communication technique called rebuke (Espin \& Lingard, 2001). O'Connor and Kelly (2005) suggest that conflict and confrontation could potentially have damaging impact on nurses, both personally and professionally. However, it appears that experienced nurses perceive less stress because they 
have developed strategies to deal with conflict and confrontation. Nurses develop cultural and political sensibilities to work through a multitude of working relationships with other nurses, physicians, and healthcare workers (MacDonald, 2006). This relates to Alaia who has developed working relationships with colleagues through which she exercises her moral agency to advocate for vulnerable peers.

Professional advocacy. Sandy engages in professional advocacy to solve institutional problems that affect her perioperative nursing practice. She describes her struggle and resolution:

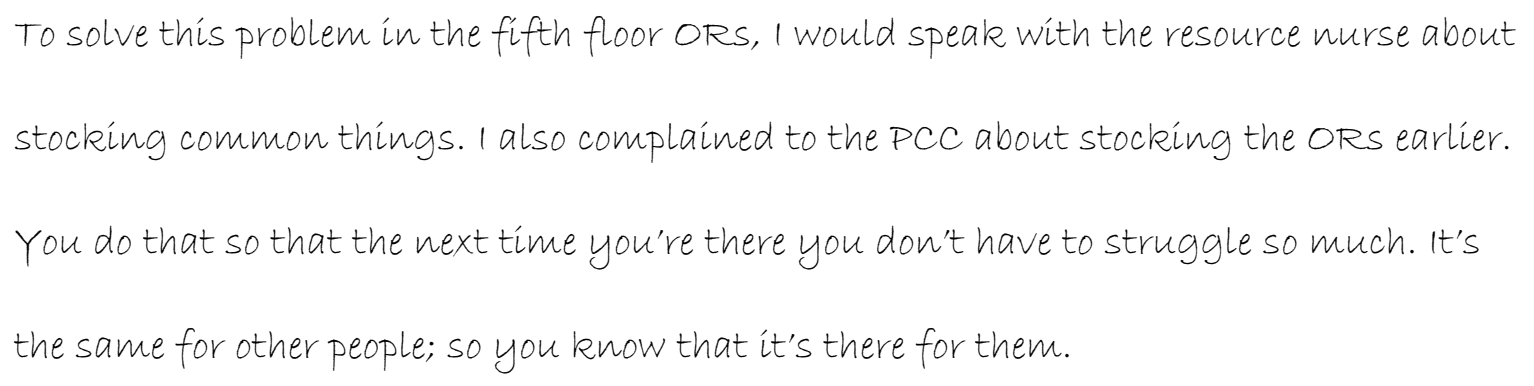

Sandy shares her concern for the OR suite's supplies insufficiency and the inaccessibility of surgical instrumentation. Arora et al. (2010) and dos Santos, da Silva, and Gomes (2014) suggest that difficulty in accessing surgical supplies further intensifies tensions between the OR team members, and consequently negatively affecting the outcomes of care. Having an optimal physical environment with adequate supplies and equipment create a desirable workplace where perioperative nurses can optimally provide care for patients (Parsons \& Newcomb, 2007). This is congruent with Sandy's story where the physical boundaries of a given place impact the professional practices of perioperative nurses.

Nurses must engage in leadership actions to overcome barriers that prevent them from enacting their patient care (Sorensen et al., 2008). The notion of professional advocacy is a form of advocacy that extends beyond the patient towards the wider context in which nursing ensues 
(Grace, 2001). Nurses can use their voice and engage others to influence changes in policies and practices of an institution or the broader context of nursing and healthcare (Canadian Nurses Association, 2015). In Sandy's story, her sympathetic presence with her colleagues' shared struggle motivates her to advocate at the institutional level for changes in her physical environment that impedes quality care. Sandy influences changes in her environment towards achievement of nursing's broader goal of furthering health (Grace, 2001). This exhibits how person-centredness informs point-of-care leadership by perioperative nurses, like Sandy, who challenge existing healthcare practices or policies.

Sandy also demonstrates how professional advocacy is the behavioural response of this caring process of sympathetic presence. Sandy demonstrates the leadership behaviours congruent with challenging the process. She uses her clinical expertise to identify a solution of changing the stocking patterns in the OR. Sandy takes initiative and communicates with the management. She does this with the hope of coordinating a change in her physical environment. In the process, Sandy also enables others to act by coordinating access to resources for her colleagues in her surgical service department. By questioning leaders regarding the adequacy of resources needed for care delivery, Sandy demonstrates point-of-care nursing leadership that is congruent with Patrick’s (2010) concept of clinical leadership.

Alaia also engages in professional advocacy at the institutional level. She explains why she writes incident reports to influence change in her care landscape:

You don't have to wait for the cords to be completely broken to write a report. Just take it out of circulation before something goes wrong... Your mom could be the next person coming in and would you want that box in there? 
Alaia takes the initiative to solve the problem of broken cords through change-oriented behaviours. She demonstrates challenging the process by seizing an opportunity to change the broken cords in her workplace through writing incident reports. By doing this, she promotes the safety of patients who enter her surgical institution, thus enabling others to act. By ensuring that resources are accessible and safe to use, she helps her colleagues practice safely, thus safeguarding the quality of care received by patients.

Alaia's actions are motivated by her personal experience as a daughter whose mother may be on that OR table. She establishes engagement with all potential patients by recognizing that they are all humans and potentially mothers. Engagement is a person-centred care process that involves this connectedness between two persons, such as a nurse and patient (McCormack \& McCance, 2010). Alaia establishes a human connection with patients, which motivates her professional advocacy. Through incident reporting Alaia believes she is involved in changing her care landscape. This narrative thread reveals how the sociality of the personal and social conditions can stimulate future changes in a place where caring transpires, demonstrating all three commonplaces of Narrative Inquiry.

The narrative threads related to patient advocacy, peer advocacy, and professional advocacy reveal a relationship between person-centred care and point-of-care leadership practices of nurses. Perioperative nurses, like Sandy and Alaia, recognize the humanness of their patients and peers, which provide them with the impetus to advocate for changes. By knowing their patients and their social, physical, and political environment, nurses are better prepared to advocate at multiple levels, from the nurse-patient relationship all the way to the policy level. Moreover, it is also evident how point-of-care leadership behaviours are inherent in the caring 
process of sympathetic presence. Conceptual overlaps in person-centred caring processes and point-of-care nursing leadership behaviours are illuminated in this narrative pattern of advocacy.

Re-presentation of narrative pattern: Advocacy. In this free verse poem, entitled "Stand up", the patient is central in the care partnership.

\section{Stand up}

Leadership involves standing up

for the patient

for yourself

for each other

...a parent coming into the OR?

"We don't ...never...haven't done that before."

they say

I had to stand up

speak out for the patient

What harm did it really do?

it's about the patient

the right thing to do

I hope..hope...hope they wake up 


\section{Relationships}

Point-of-care nursing leadership transpires in relationships. Sandy and Alaia traverse through a myriad of relationships with patients, as caregivers, and with peers, as colleagues. These two narrative threads are explicated below.

Nurse-patient therapeutic relationships. Sandy's description of her teddy bear metaphor reflects her therapeutic relationships with patients:

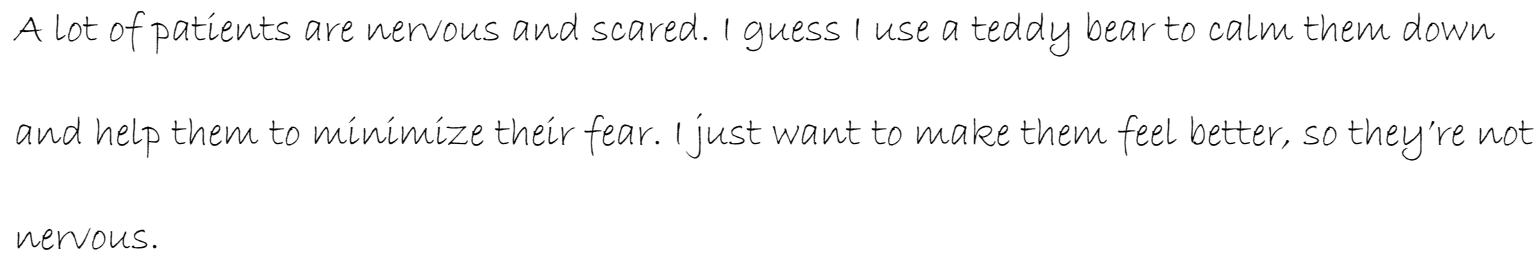

Sandy's teddy bear metaphor reflects for her, her ability to relate to her patients' feelings of anxiety and fear before surgery. Nurses in the OR must recognize and quickly respond to patients' cues, in order to connect with them and respond to their needs, demonstrating engagement. Perioperative nurses understand the essence of their care is making a difference in the surgical experiences of patients by making it more bearable for them (Sigurdsson, 2001). The interactions of the Narrative Inquiry commonplaces of time, sociality, and place are apparent in this person-centred care process. Sandy focuses on the interaction with that particular patient at that particular time and place where each person is valued as a human being.

Sandy elaborates on her connection with her patients as they step into the OR:

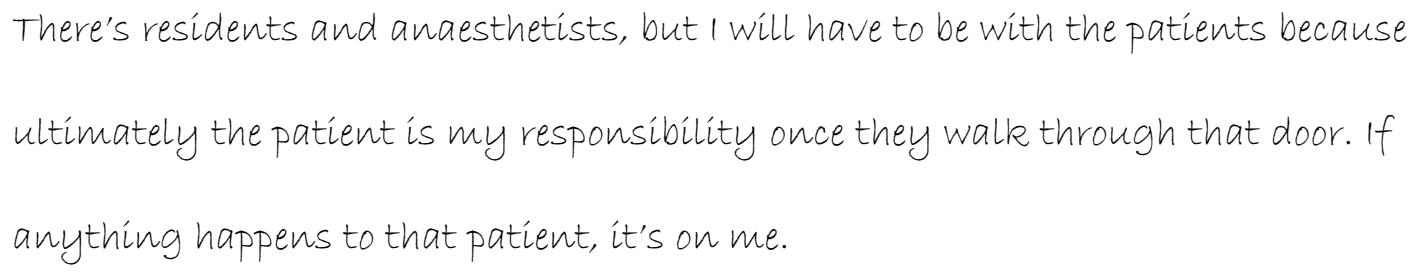


Although there are other members of the team, Sandy perceives a stronger sense of accountability for the welfare of her patients. Sandy's statements imply her perceived obligation to care for patients. The construction and enactment of this professional obligation to care is underpinned by her professional code of ethics based on the value of patient well-being, which demonstrates how the social influences the personal conditions. Ontario's provincial regulatory body of nursing, CNO (2009), has outlined ethical values in providing nursing care, such as client well-being, respect for life, client choice, truthfulness, maintaining commitments, and fairness. I espouse McCormack and McCance's (2010) view that values are a person's standard of behavior, which governs what s/he thinks should be done. Sandy demonstrates the attribute of clarity of values. She maintains a sense of integrity between her value of patient well-being and her actions, which is a necessary attribute for nurses to practice person-centred care, according for McCormack and McCance (2010). Kouzes and Posner (2007) also suggest that exemplary leaders must have a self-awareness of their values and beliefs to be able to stand up for what they believe in and care most about.

Alaia establishes engagement in her relationships with patients by ensuring their questions are answered before surgery:

For patients, the only time you really get to interact with them is during the introduction. Despite these time limitations, it is a really good thing to ask the patients if they have any questions and assure them that the team will be there for them.

Alaia's behaviour is also congruent with the clinical leadership attribute of interpersonal understanding described by Patrick (2010), which is defined as the ability and desire to comprehend a situation from another person's point-of-view. Knowing the patient is a building block for developing therapeutic nurse-patient relationships (McCormack et al., 2011). McGrath, 
Holewa, and McGrath (2006) suggest that nurses need time and contact with patients and families to understand their world. By doing this, nurses are better able to convey their insights on the patient's and family's perspectives to other healthcare colleagues. Alaia recognizes sites of tensions related to the limited time and contact with her patients in her practice, yet she retains the patient at the forefront and situates her perioperative nursing practice in person-centred care.

Sandy describes the technical aspects of care within her nurse-patient relationships. Sandy's story illuminates a space within perioperative nursing practice where her point-of-care nursing leadership actions may be needed to ensure the patient's health and safety are safeguarded:

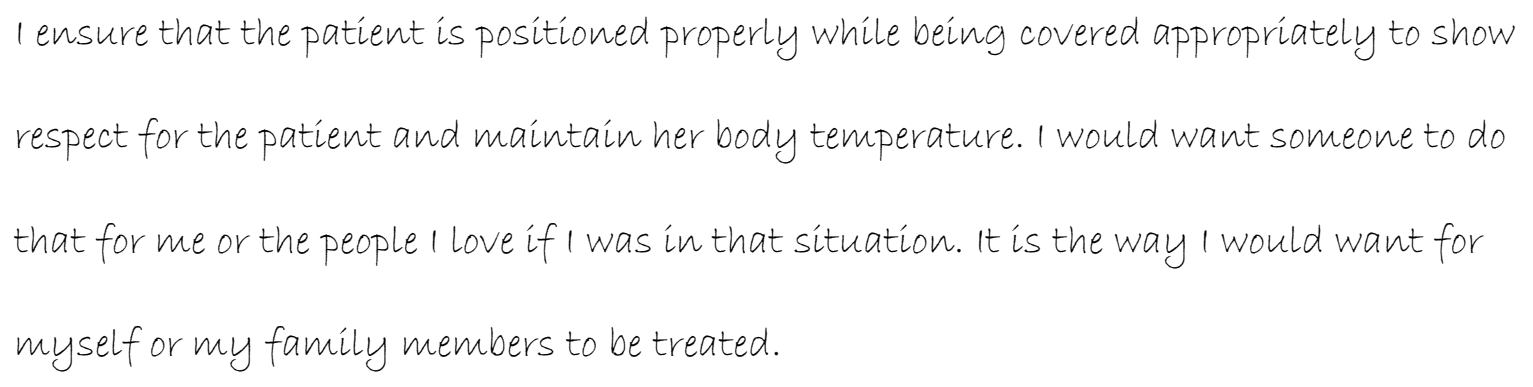

Sandy's words reveal the connection she feels with her patients on the OR bed who are also human beings. In a hermeneutic phenomenology study by Sigurdsson (2001), the perioperative nurses' ability to relate to their patients stems from their personal experiences as patients or family members. Sandy exhibits this association as she describes her belief that patients are an extension of herself or a family member, which speaks to the interconnection between her personal and professional experiences.

Sandy embodies person-centred care by ensuring the patients' physical needs are met. Positioning a surgical patient represents an aspect of providing holistic care, which is a personcentred care process. McCormack and McCance (2010) describe providing holistic care as the 
delivery of technical and physical elements of care. In the OR, sedated or anaesthetized patients are incapable of repositioning themselves as needed throughout the surgery, therefore, perioperative nurses must physically position the patients' bodies to prevent injury (Spruce \& Van Wicklin, 2014).

Peer relationships. Sandy and Alaia recognize the importance of a functioning team to achieve their shared purpose of patient well-being:

It is every team member's role to ensure that patient is safe and we do not do anything

that would harm her. (Sandy)

I feel like we have the same goal. A functioning team is good for the patient. (Alaia) According to Sillen-Lipponen et al. (2011), a well-functioning OR team is composed of care providers who are technically oriented while being socially mature with high levels of flexibility. They maintain timely and skillful operational actions while being supportive of a safe and high quality team learning atmosphere. Keeping this in mind, perioperative nurses must value and respect each care provider's knowledge and skills, while encouraging interactions with them to harmonize the OR work environment (dos Santos et al., 2014; Sigurdsson, 2001). This aligns with the Leadership Model, which suggests that leaders must build a climate of trust and facilitate relationships to nurture collaboration in teams. Throughout Alaia's story, there is a sense of mutual trust and respect between her team members. In addition, Alaia engages in open communication with her peers and they share the responsibility of tasks completion, which is reflective of the leadership domain of enabling others to act. By recognizing her peers' contributions, Alaia encourages the heart, where a sense of community has developed, enabling them to achieve their shared purpose. In Sandy's story, she also enables others to act by facilitating the growth of trust and engaging in collaborative practices with her colleagues. 
If they want it faster they have to help out. There has to be teamwork.

Sandy's words reveal that there are tensions in the social conditions of her workplace. Sandy recognizes this time pressure and she engages in cooperative relationships as a coping strategy, which is consistent with some of the clinical nursing leadership team-based behaviours described by Patrick et al. (2011). The word teamwork captures my attention as Sandy enlists the help of others to care for patients in the OR while dealing with institutional pressures to be efficient. Based on a concept analysis, teamwork encompasses a concerted effort by a group of individuals who engage in interdependent collaboration and shared decision-making (Xyrichis \& Ream, 2007). Sandy exemplifies the leadership domain of enabling others to act by engaging in this ongoing process of team building. Sandy develops cooperative peer relationships. She makes negotiations with colleagues while providing support and working to achieve goals. Sandy forms partnerships and bonds of support with colleagues to achieve their purpose and cope with the imposed time pressures, which, according to the Kouzes and Posner (2007), reflect actions of exemplary leaders.

Sandy describes the development of her peer relationships, which has facilitated her ability to speak up at work:

My relationships with my nursing, anaesthetist, and surgeon colleagues have also

changed because I know them a lot better now. I feel more comfortable in terms of my environment. My confidence has increased. I'm able to voice out more.

Sandy describes how time has supported the development of her confidence and professional relationships with colleagues, which strengthened her ability to speak up. Sandy's ability to voice her position, within the context of her peer relationships, reflects the existence of power 
sharing between colleagues. This is congruent with MacDonald (2006) who suggests that nurses' relationships with other healthcare workers impact their capacity "to advocate in patient-care situations" (p. 125). Place is interwoven with temporality to produce matured personal and social conditions that enable Sandy to engage in power sharing and establish effective staff relationships described in Person-Centred Nursing framework. An OR team with effective staff relationships involves a group of persons who value and respect the knowledge and skills that every person, including the patient, brings into the care partnership. Interactions are encouraged to harmonize the OR work environment (dos Santos et al., 2014; Sigurdsson, 2001). By establishing supportive and positive working relationships that are built on trust, nurses feel supported and empowered to enact advocacy (MacDonald, 2006), which is evident in Sandy's story. Her point-of-care nursing leadership potential is strengthened by her tenure and peer relationships.

The motivation and intention for teamwork in the OR is expressed in Alaia's words: People are really working hard to make the room work because they are all new people. When you're new you know all the hard things and all the struggles. We all share that. Alaia's words give insight into her team's source of motivation for teamwork. The care providers all share struggles related to environmental unfamiliarity, competing priorities, and time pressures, which motivate them towards enactment of teamwork. Alaia demonstrates what McCormack and McCance call engagement within the context of peer relationships in the OR. Engagement with colleagues involves a connection between persons involved in a care partnership where each person is valued as a human being (McCormack \& McCance, 2010). Alaia provides insight into why care providers work together as a team for the patient and each other. Alaia's actions are motivated by this collective struggle, which is shared by her peers. This 
demonstrates how person-centredness may inform team-based leadership behaviours of nurses and other healthcare providers. In this narrative thread I awaken to how the personal connects with the social conditions, through this shared struggle, to potentiate changes in the workplace.

Alaia describes the presence of a social hierarchy in the OR that negatively impact peer relationships:

I think there is a social hierarchy between RNs, RPNs, doctors, and attendants. It depends on who is working.

Alaia recognizes the presence of a social hierarchy in the OR, which can pose as a barrier to effective staff relationships. There are tensions between the following professional groups, RNs and surgeons (Higgins \& MacIntish, 2010; Sigurdsson, 2001), RNs and RPNs and/or surgical technologists, and nurses and care assistants (Sigurdsson, 2001). Gillespie, Chaboyer, Wallis, Chang, and Werder (2009) suggest that nurses in the OR possess leadership attributes and they use their situational knowledge to be able to share equal status with their physician colleagues, thereby enabling them to make clinical decisions based on care priorities. However, a social hierarchy still pervades the workplace culture in the OR care landscape.

I believe that the existence of this social hierarchy prevents power sharing. Nurses who are positioned lower in the hierarchy may have less influence over their social or political environment. As a result, the nurses' advocacy for patients, peers, or themselves may not always produce the positive changes they have envisioned. According to Kouzes and Posner (2007) exemplary leadership involves power-sharing within a team to support team performance and achieve their vision, purpose, or goals. Therefore, a social hierarchy that prevents distributed power becomes a barrier to the enactment of point-of-care nursing leadership. 
Alaia recounts an experience of incivility between nurses that inhibits person-centred care and point-of-care nursing leadership:

They never realized that they were actually criticizing you in front of others. People would think that you were not good. It makes you feel awful.

Alaia's story reflect the prevalence of incivility in the OR between nurses, which is a feature of a workplace culture that can have negative impacts on nurses' sense of self. Andersson and Pearson (1999) define incivility as a social interaction between two or more persons characterized by rude or discourteous actions that have no regard for others, which violate the norms for respect. Uncivil behaviours are low intensity deviant actions where intent to harm is ambiguous. When looking at the notion of incivility, it is evident how the place, with its social and political elements, has negative implications on Alaia's personal conditions, as well as the social processes that occur around her in the OR. McCormack and McCance (2010) call for new ways to understand causes of interpersonal conflict between nurses, with the purpose of producing a workplace culture that is conducive to safe professional practice. A solution is needed to address the ongoing problem of uncivil interactions between nurses, as collaborative peer relationships and effective communication are essential core behaviours of exemplary clinical leadership according to Patrick (2010).

Alaia practices person-centredness and she opposes this social hierarchy by valuing a colleague's knowledge:

I have no idea which trays we need. If the RPN goes to check, he actually knows which trays we need. He has knowledge and you have to appreciate that. Alaia engages in a partnership with a colleague to learn from him, which demonstrates valuing of his contributions. Kouzes and Posner (2007) suggest that acknowledging colleagues' expertise 
makes them feel empowered. Furthermore, recognizing colleagues for their work creates a climate for collaboration. In Alaia's story, she recognizes the expertise and contributions of a colleague, thereby demonstrating the leadership behaviours associated with encouraging the heart. By recognizing and valuing the contributions of an RPN colleague, Alaia is integrating teamwork in her practice that potentiates changes in the workplace culture towards rejection of a social hierarchy. Alaia demonstrates how there is a potential for the personal to influence changes in the social conditions of her workplace.

Re-presentation of narrative pattern: Relationships. I re-present Sandy's and Alaia's stories related to their peer relationships in free verse poem number two, entitled "Each other".

\title{
Each other
}

\section{We see each other and we just know support and motivate each other}

\section{Same goal \\ help appreciate trust learn}

from one another

\author{
All the hard things - struggles \\ We all share that \\ hospital management, policies, rules \\ more surgeries, more money \\ they don't really know
}


they ask us "be faster...be safe"

surgeons rush you

faster

anaesthetists rush you

faster

Yes we're going

Yes we're going

...Keep the patient Safe

instruments

so far away

in the basement

down the hall

back and forth

back and forth

\section{Frustrated}

How much faster can we get?

I'm fast enough

Cannot ...go...any...faster

If they want it faster

they have to help out

There has to be teamwork

for the patient

It is the way I would want for myself ...my family 


\section{Teaching and Learning}

When telling their lived stories of point-of-care nursing leadership, Sandy and Alaia describe their experiences as learners and teachers in the OR. Role modeling, preceptorship, and personal and professional development are the narrative threads that compose this narrative pattern.

Role modeling. Alaia tells me her experience of changing her workplace culture through modeling supportive behaviours.

When you say leadership, I think of it as being an example. The more people see that change in practice, the more they start doing it.

One of the ways that Alaia has influenced her workplace culture is through her modeling of supportive behaviours. She exemplifies the leadership practice domain of model the way. In Alaia's story, she describes how she steps away from the sterile field after setting up her sterile OR table during a period when she is not needed as a scrub nurse, removing her sterile gown and gloves in the process. She does this to provide support for her fellow perioperative nurses who are struggling with their circulating roles. Alaia sets an example for her colleagues and consequently changing their behaviours and the department's overall routine practices. Alaia's story demonstrates how role modeling has the potential to inspire a shared vision with colleagues. By collectively demonstrating supportive behaviours, Alaia testifies that her neurosurgery department has established a workplace culture where they respect and value everyone's contributions and recommendations for professional development. This also demonstrates the Narrative Inquiry commonplaces, and how the sociality of the personal and social conditions, changes over time to modify the workplace culture of a healthcare landscape. 
In a phenomenological study by Perry (2009), one major finding suggests that exemplary nurses are also excellent role models who purposely set an example for other nurses, including novices, by making their effective actions and behaviours visible. Exemplary role models make connections with patients and healthcare colleagues to achieve positive affiliation with them. By treating colleagues with respect, they feel more included in the team as valued team members (Perry, 2009). This connects to the sociality of Alaia's experience of modeling supportive behaviours. Alaia demonstrates the point-of-care nursing leadership behaviour of enabling others to act. Alaia supports her colleagues, especially during periods of struggle, while affirming their value as contributing care providers.

Preceptorship. During my conversations with Sandy, she has largely explored her role as a preceptor, which she considers as part of her point-of-care nursing leadership experiences. Sandy describes her purpose as a preceptor:

Part of leadership is supporting and helping them see the big picture.

To Sandy, preceptorship involves helping students see the big picture, especially when perioperative nursing is so different from other nursing fields, such as medicine and intensive care units. I understand how she views herself as a facilitator of the students' socialization into this new world of perioperative nursing. In a qualitative study by Hill, Melender, Salmu, and Jonsen (2014, p. 1422), nurse preceptors describe how they walk "side by side" with their students where the preceptors play a supportive role in the background to strengthen the students' weak points and reduce their fears. Similarly, Sandy understands that her role as a preceptor requires nurturing and guiding students. Sandy's actions are congruent with the leadership practice domain of enabling others to act. She describes her preceptor role as part of her point-of-care leadership experience, which entails guiding and supporting new nursing staff 
and/or students towards professional practice development. Sandy shares information and resources to provide visible support during her students' transition, with the purpose of selfactualization of her students' learning needs.

When describing her teddy bear metaphor, Sandy describes her role as a protector of students. By knowing her student, Sandy advocates for the student's learning needs:

To me, I felt that I had to protect her because I didn't think that certain things he wanted her to do was beneficial for her.

Sandy embodies person-centredness in her approach to preceptorship through sympathetic presence, whereby she responds to her student's unique learning needs. Sandy engages in advocacy, which reflects the leadership practice domain of inspiring a shared vision. In this context of nurse-teacher-student relationship, their shared purpose is the facilitation of the student's learning. Sandy knows the student's specific learning needs, which motivates her to advocate for the student whose learning needs focus on a particular area of perioperative nursing practice that did not align with another colleague's teachings. Sandy's story reflects how personcentredness informs point-of-care nursing leadership behaviour of inspiring a shared vision within the context of nurse-teacher-student relationship. Sandy also exposes the conceptual overlaps between point-of-care nursing leadership behaviours and person-centred caring processes. Sandy's act of advocacy is a response that is embedded in her depiction of sympathetic presence. This further validates how point-of-care nursing leadership and personcentred caring processes have parallels because of staff nurses' position at the clinical level where they have direct involvement in care of patients and nursing students. This prominence of sympathetic presence throughout the narrative patterns of advocacy and teaching and learning, once again demonstrates where leadership and person-centred care overlap. 
Give them an example of how to do things, but at the same time, it doesn't necessarily

mean that's the only way to do it. You show them one way, but you could tell them,

"Oleay, once you've developed your practice, you could do it the way you want to do it."

Sandy embodies person-centredness in her role as a preceptor by supporting students'

involvement in shared decision-making related to their learning. In a qualitative study by Hilli, Melender, Salmu, and Jonsen (2014), nurse preceptors explain that students are more likely to ask questions and reflect on different topics if they feel safe in their relationships with preceptors. This is related to Sandy who facilitates a safe space that encourages students to explore multiple ways of knowing and doing for the purpose of personal and professional development in their new role as perioperative nurses.

Sandy's words reflect her value of openness to different ways of knowing and doing. Sandy recognizes that there are good ideas from other sources. According to Patrick (2010), the value of openness is needed to inform the core leadership behaviours of challenging the process, such as thinking creatively, demonstrating flexibility, and seeking opportunities for changes. In the following narrative thread, Sandy demonstrates how she enacts her value of openness through her engagement in personal and professional development activities.

Personal and professional development. Sandy describes her ongoing learning as a nurse in the OR:

I'm still learning every day and I will make mistakes.

Sandy recognizes that she too makes mistakes and she is willing to learn to facilitate competent and safe practice. Sandy is constantly researching unfamiliar surgical procedures. Her actions reflect the attribute of commitment to the job. McCormack and McCance (2010) describe 
commitment to the job as a nurse's dedication to provide best care to patients. Sandy's intention or commitment is manifested in her actions towards personal and professional development.

Sandy demonstrates her self-awareness, which is a significant attribute of point-of-care nurse leaders (Patrick, 2010). Kouzes and Posner (2007) emphasize the need for leaders to "explore [their] inner territory" to find their voice (p. 50). By finding who we are, we can act with integrity and stand up for what we believe in and care most about (Kouzes \& Posner, 2007). This notion of self-awareness is also congruent with McCormack and McCance's (2010) attribute of knowing self that is needed by nurses to provide person-centred care. Knowing self refers to the personal pattern of knowing related to our understanding of how we function as human beings, which is needed if we are to help others.

Sandy's sense of self-awareness and commitment to her job inform her to point-of-care nursing leadership behaviours, which are congruent with the leadership practice domain of challenging the process. Sandy's story reflects a nursing praxis (being/thinking/doing) that is driven to continuously learn from others. Sandy takes the initiative to improve her nursing knowledge and competencies to be able to care for patients and adapt to the evolving and complex care landscape. Sandy demonstrates flexibility by her willingness to continuously learn from other sources, such as surgical fellows and online nursing resources.

Alaia describes her funnel metaphor to express her belief in the importance of maintaining her professional competency through openness to different perspectives: Things don't have to be so narrow and dark... we have to be open to different ideas and different ways of thinking related to patient care.

When describing her funnel metaphor, Alaia makes explicit her values of creativity and openness. Throughout her story, Alaia also demonstrates a nursing praxis that is driven to engage 
in on-going learning. This is consistent with Heid (2010) who proposes that point-of-care nursing leadership involves this drive to learn more. Alaia enacts the leadership domain of challenging the process. She demonstrates flexibility in terms of her ideas and actions, which is evident in her other narrative threads related to patient advocacy, open communication, and recognition of peers' contributions. Alaia is willing to consider different opinions. She is open to different kinds of situations, which is crucial for all perioperative nurses who are constantly working with unique persons in a growing, multifaceted, and technical care landscape.

Patrick (2010) suggests that nurses who demonstrate clinical expertise are perceived by other team members as powerful. These nurses are better able to "challenge the process and negotiate the best care for patients" (p. 21). Sandy and Alaia will need to engage in continuous personal and professional development to improve their clinical expertise. By doing this, they will enhance their informal power within their professional relationships with peers, thereby improving their ability to influence others.

Re-presentation of narrative pattern: Teaching and learning. I re-present Sandy`s and Alaia`s stories related to their teaching and learning in the following free verse poem, entitled "Teaching and learning".

\section{Teaching and learning}

You don't really know until you're in that situation

Help them see the big picture

\section{Pass on the torch}

sharing suggestions

role modeling

supporting 
Give them an example

Try this...or that

check-in the patient

Try this...or that

how to organize themselves

When a situation turns sour

protect her

I did not know about teaching anybody

but I was trying

I'm still learning

\section{Unfamiliar...}

new surgeries and equipment

so many different trays

\section{Nervous...}

I will make mistakes

\section{Hope...}

many possibilities

take initiative

follow the creative side

be Open......to different ideas...different ways 


\section{Impact of Sandy's and Alaia's Stories on Me}

Narrative Inquiry is a relational inquiry where the participant and the researcher enter the field influencing each other and, at the same time, being influenced by their environment (Clandinin, 2013; Connelly \& Clandinin, 2006). In this section, I discuss how Sandy's and Alaia's stories of point-of-care nursing leadership influence my own evolving understanding of this human experience under study.

As a novice nurse, I understood that it was my professional responsibility to be an advocate for the patients in my care. However, my understanding of nursing leadership at the point-of-care was narrow and I focused mainly on patient advocacy. As I engaged in conversations with Sandy and Alaia, over time I developed a deeper understanding of the meaning of point-of-care nursing leadership within the broader context of the OR team, which places the patient at the centre. I learned how point-of-care nursing leadership is manifested in core leadership behaviours, such as recognizing peer contributions, open communication, taking risks, challenging existing processes, amongst others discussed above. I also practice nursing leadership within my role as a perioperative nurse. Through my relationships with patients and peers, I strive to enable, encourage, and inspire others. I challenge existing structures to improve my workplace conditions. I am a role model for my work colleagues, especially new perioperative nurses.

Sandy's and Alaia's stories of point-of-care nursing leadership teach me that voice is a powerful instrument for change. Point-of-care nurse leaders use their voice to influence others towards achievement of this shared purpose of health and safety for all persons involved in the care partnership. The nurse's voice is informed by her/his self- and social-awareness. In other words, by knowing our personal selves, patients, peers, and the situational factors, we are better 
able to use our voice to influence changes in our social, political, and physical environments. I learned that I need to establish credibility to have a more effective voice. I can cultivate my credibility by having a vision or purpose, and by being honest, competent, and inspiring in my relationships with patients and peers. By developing my credibility, I gain informal power that is needed to inspire others towards positive change. I continue to keep this in mind as I move forward in my personal and professional life as a leader.

After reflecting on the shared stories by Sandy and Alaia, I realize that I practice personcentred care in my therapeutic nurse-patient relationships. I connect with my patients by being fully present in the moment with them, and by responding to their vulnerabilities and fears, helping me connect with them. I use comfort measures during our one-on-one interactions and by preventing harm to them intraoperatively. I realize that by engaging in the caring processes of engagement and sympathetic presence, my knowledge of the patient is improved. By knowing the patients, I am better equipped to advocate for them when circumstances warrant it.

I have a new understanding related to person-centredness that fosters peer relationships, which, in turn, facilitates nurses' leadership experiences at point-of-care. By recognizing the humanness of my peers, I understand and appreciate this common struggle and shared purpose that binds us. Through the humanness of care, I can achieve and/or maintain credibility, foster collaboration, and build trusting relationships with peers. Consequently, I can increase my informal power and voice to influence others to improve existing working conditions and provide the best care for patients. I will keep this in mind when I engage in future opportunities for participation in the social influence process of leadership within the context of peer relationships. 
Based on my inquiry, I have developed a new term called person-centred point-of-care leadership to describe the point-of-care leadership practices that are informed by person-centred care. I envision person-centred point-of-care leadership as a social process of intentional influence whereby an individual inspires another towards positive changes in the personal and social situations. These point-of-care leadership actions are informed by attributes of personcentred care. Healthcare providers, by knowing themselves and the persons in their care, are better able to facilitate holistic care, shared decision-making, engagement, and sympathetic presence with their patients and peers. This, in turn, informs their leadership practices at the point-of-care. The desired outcomes are the health and well-being of the persons involved in the care partnership, which include patients, families, nurses, and other care providers. I refer to this new concept of person-centred point-of-care leadership, as I discuss the social significance of this Narrative Inquiry in Chapter Nine. To reflect my new understanding I constructed the following free verse poem, "My new awakening".

\section{My new awakening}

Through the told stories,

I am awakened to the human connection we all share I need to know...

myself

patients

peers

places

They, too, can be... parents children vulnerable struggling 


\section{By being with them...I can inspire change.}

As I reach the ending of my second level of practical justification, the narrative patterns with their corresponding narrative threads, are revealed, as are the puzzles for future inquiry. In the next chapter, I conduct the third level of justification, the social, where I consider the lived and told stories of Sandy and Alaia within a broader social context. I explicate the implications for nursing and healthcare practice, education and research.

$\S$

As I approach the summit, the mountain incline becomes steeper. I encourage myself by quietly repeating a mantra: I'm almost there. I'm almost there. 


\section{CHAPTER NINE}

\section{OVERCOMING THE ELEMENTS OF RAIN, ICE, AND WIND: SOCIAL JUSTIFICATION}

As I move higher on the glacier, the terrain becomes more challenging. The winds strengthen and the glacier is more slippery as the rain hits the ground. It is harder for my crampons to penetrate through the ice. I know this weather system is temporary and I press on, focused on my path. Looking towards the summit, I see a blue sky patch.

As I move to the third level of justification of Narrative Inquiry, the social, I discuss the significance of my inquiry in the greater social context of healthcare, as well as potential transferability of findings to other disciplines. I use business discipline, as an example, to illustrate the potential value of my inquiry in fields other than nursing. I chose business because in this inquiry I use Kouzes and Posner's Leadership Model, which originated in the discipline of business, and this is my way of giving back.

\section{Third Level of Analysis: Social Justification}

In this chapter, I explicate the social justification of this Narrative Inquiry. To address future directions, I discuss the significance of my inquiry, especially person-centred point-ofcare leadership, for practice, education, and research in nursing and healthcare as a whole. I also consider transferability of the findings to other disciplines, and use the business discipline as one such example.

\section{Considerations for Nursing and Healthcare Practice, Education, and Research}

\section{Nursing and Healthcare Practice}

During this inquiry and my own professional experiences as a perioperative nurse, I recognize how point-of-care leadership involves a continuous cycle of development. Therefore, 
healthcare providers must continuously engage in personal and professional development to develop their professional competencies, such as emotional intelligence. By having selfawareness, social awareness, and emotional regulation, person-centredness (McCormack \& McCance, 2010) and leadership (Delmatoff, 2014; Parker \& Sorenson, 2008) by nurses and healthcare providers are supported. By doing this, healthcare providers, as well as colleagues in others disciplines, such as business, may be better informed to practice person-centred point-ofcare leadership.

Throughout this inquiry, I discuss the barriers related to the physical environment, institutional policies, social hierarchy, incivility, and time restrictions that constrain Sandy's and Alaia's experiences of point-of-care nursing leadership. These sources of tension need to be addressed to ensure the persons in our care, which include patients and peers, are healthy and safe. Future inquiries may examine effective ways to address these barriers. For example, future studies may explore how the policies at the institutional, municipal, provincial, and/or federal levels constrain healthcare providers' professional practices. Policies impact patients' and healthcare providers' perceptions of empowerment in healthcare institutions, and may be evaluated to identify policies that require change.

In my inquiry, I draw attention to how perioperative nurses strive to embody personcentredness in their care partnerships in a landscape that is filled with technical complexities and demands for efficiency. I recommend that healthcare providers make every patient and peer interaction a person-centred experience, even during the short moments of engagement. In doing so, relationships are nurtured, and the human experience is respected and valued across the continuum of care in all healthcare contexts, thus enabling person-centred point-of-care leadership. This is also relevant to other disciplines. Business workers and managers in retail or 
other service organizations can use caring processes of shared decision-making, engagement, and sympathetic presence to respect and value the clients' humanness. By embodying personcentredness, business managers value and respond to their clients and colleagues in ways that respect their human needs, rights, beliefs, and values, thereby supporting the unique human experience of every person in the business partnership.

\section{Nursing and Healthcare Education}

Based on my research, I believe that there is a need to integrate person-centred care in nursing and healthcare education because care providers, who exemplify person-centred care, honour and value all persons of the care partnership. I recommend the integration of personcentred care in nursing and healthcare education to teach the students why and how they can recognize and respond in ways that respect and value the personhood of the patients/clients, families, communities, and healthcare workers they work with. Healthcare providers who learn person-centred care through their education, theoretically and experientially, will learn how their actions can be guided by values of respect, empathy, and self-determination. By embodying person-centredness in their practice, they will be more informed to empower the persons in their care by mobilizing resources that respect human rights, values, and beliefs. These person-centred informed actions of mobilizing access to human and material resources are some of the practices that encompass person-centred point-of-care leadership.

Based on the narrative pattern of communication in the second level of practical justification, I recognize a need for healthcare providers to incorporate emotional intelligence in education curricula. I also see the significance of integrating emotional intelligence in other disciplines, such as business education, which is congruent with other research. Business studies have examined and evaluated the effectiveness of emotional intelligence education for potential 
managers and leaders (Boyatzis \& Saatcioglu, 2007; Groves, McEnrue, \& Shen, 2008). Thus, a potential future inquiry puzzle may be: How does emotional intelligence of clients influence their relationships with business organizations?

Based on this inquiry's narrative pattern of advocacy, there is a need to include advocacy in healthcare education from the patient/client relationships to the broader context of healthcare. This is congruent with existing research (Long et al., 2011; Sorensen et al.; 2008). The education curriculum may involve advocacy skills courses, internships, and mentored scholarly actions focusing on population health (Long et al., 2011). By developing advocacy skills, nurses (Sorensen et al., 2008) and other healthcare providers (Long et al., 2011) may enhance their ability to engage in leadership practices, such as health advocacy. Other studies have also identified the need for developing advocacy skills at all levels (Cawley \& McNamara, 2011; Hanks, 2010; O’Connor \& Kelly, 2005; Vaarto, Leino-Kilpi, Salantera, \& Suominen, 2006).

\section{Nursing and Healthcare Research}

After conversing with Sandy and Alaia and reviewing the literature, I believe that an increase in research studies that explore the sociality of point-of-care leadership experience would help in humanizing the social influence process of leadership that occurs in teams. In this Narrative Inquiry, I discovered how nurses’ person-centred care informs their leadership practices at the point-of-care. I recommend researchers in future studies examine this new concept of person-centred point-of-care leadership. The antecedents, attributes, and/or consequences of this person-centred approach to leadership, require further investigation to bring this concept into fruition.

There is also a need to increase studies that examine point-of-care leadership from different perspectives of patients and other members of the healthcare team. Potential topics may 
include patients' experiences of receiving care within the OR setting. Other healthcare providers' experiences of point-of-care leadership within the context of the OR team may also be explored. And, considering other disciplines, I also see the potential value of studying clients' experiences of informal point-of-care leadership by professionals of private and/or public business organizations.

I recognize that patient advocacy (Hanks, 2008; McSteen \& Peden-McAlpine, 2006; Sorensen \& Iedema, 2007) and professional advocacy (Cawley \& McNamara, 2011; Hanks, 2010; Hellwig, Yam, \& Di Guilio, 2003; Jugessur \& Iles, 2009; Long et al., 2011) have been examined in healthcare research. My literature review reveals no healthcare research that explores peer advocacy. My inquiry exposes a need to explore peer advocacy within the context of multidisciplinary teams. Further research could explore this phenomenon from the perspective of other inter-professional healthcare team members, such as respiratory therapists, physicians, nurse-practitioners and others.

Sandy's and Alaia's construction and enactment of point-of-care nursing leadership are impacted by their social, physical, and political landscape. In my research, I explicated how time restrictions, institutional policies, social hierarchy, workplace incivility, and physical environment negatively impact healthcare workers' person-centred care and point-of-care leadership experiences. By addressing the barriers and facilitators through future research, solutions may be developed to empower us, as caregivers, and the persons in our care, by respecting their rights, values, beliefs, desires, and wishes as human beings.

My inquiry also has potential implications for future business studies. This, once again, demonstrates the transferability potential of Narrative Inquiry that transcends specific context of this study, which is the OR. I use the discipline of business to demonstrate this potential. For 
example, through my inquiry, I present a framework for future inquiries that explore stories from workers in the business discipline. I envision an exploration of how business workers, such as retail or other service organizations, experience and express point-of-care leadership, with business clients as the receivers of their 'care'. Potential research might inquire into how business workers experience point-of-care leadership in their partnerships with clients and/or colleagues.

In this chapter I provide the social justification of this Narrative Inquiry. I explicate the significance of the key concepts, as well as the considerations for practice, education, and research. I discuss the significance of person-centred care, emotional intelligence, advocacy, and environmental barriers to nursing and healthcare. Through using the business discipline, as an example, I also demonstrate transferability of Narrative Inquiry to other contexts. In the epilogue, I reflect on how Sandy’s and Alaia’s stories have impacted my own evolving understanding of person-centred point-of-care nursing leadership.

Being aware of my centre of gravity, I stay focused on my strides and I ensure that my balance is maintained as I battle the strong gusts of wind that temporarily tip my body from side to side. I stay motivated and I maintain my composure to reach the mountain top, where I hope to see a panoramic view of the natural beauty of this mountainous landscape. 


\section{REACHING MY SUMMIT:}

\section{EPILOGUE}

I take my final stride and reach the peak of the mountain. As I admire the textured beauty of the landscape that is before me, I think back to the small village I left behind at the base of the mountain. Since the start of my journey I have enjoyed and endured many experiences, some challenging, but all satisfying. I turn and look at the horizon in the distance and see so many majestic mountain peaks reaching to the sky. I pause to reflect on my mountain hike as a whole.

As you recall, dear reader, the mountain hike is my metaphor for my thesis process, my journey of discovery. As this exploration comes to a close, I reflect on my evolved understanding of person-centred point-of-care nursing leadership.

\section{My Metaphor for Person-centred Point-of-care Leadership: Crossing Wooden Bridges}

Through the telling and re-telling of lived stories, Sandy, Alaia, and I explored how perioperative nurses experience leadership at the point-of-care. Based on this relational inquiry

process, I now construct the metaphor for my evolved understanding of the new concept personcentred point-of-care leadership (Figure 4). 


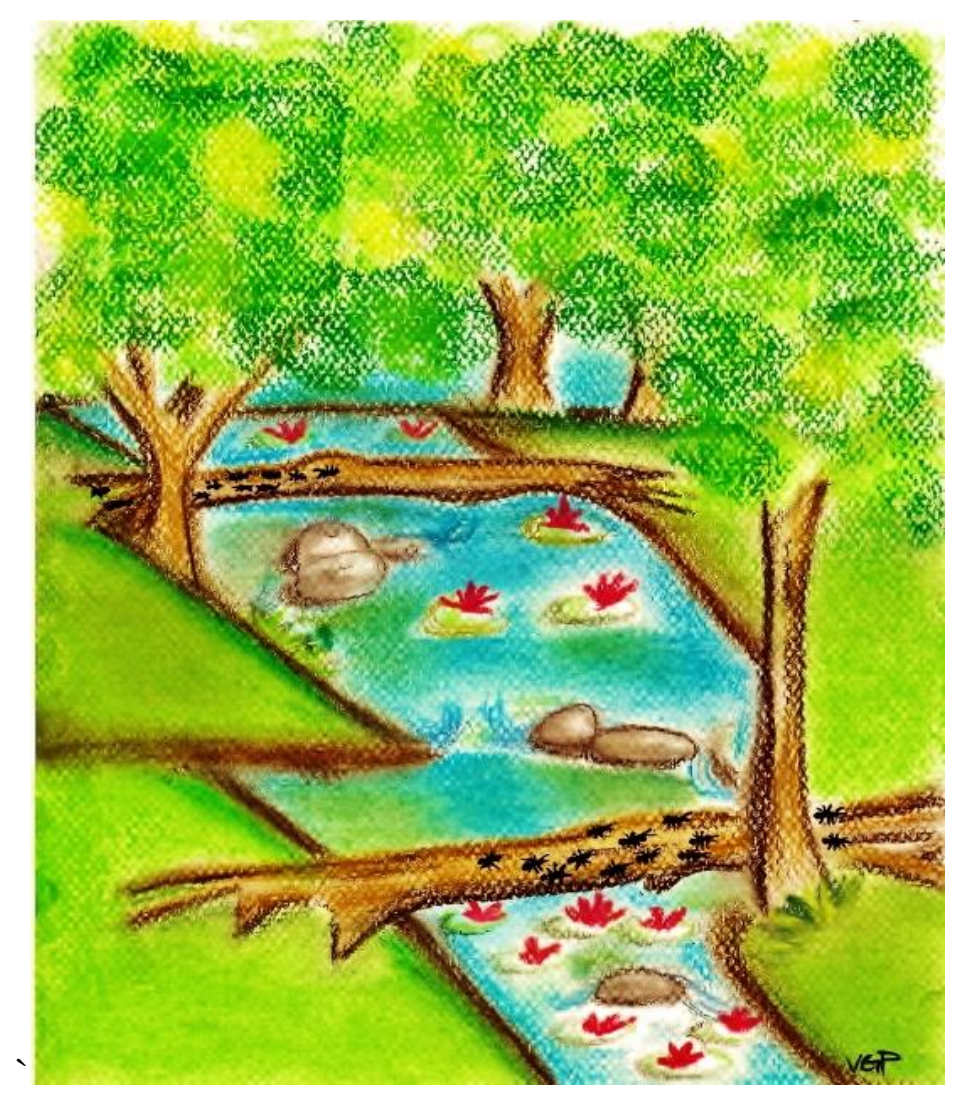

\section{Figure 4. My Metaphor for Person-centred Point-of-care Leadership}

Creating my metaphor painting, using soft pastels as a medium, is an embodied experience where my mind, heart, and fingers connect and glide with the pigments across the paper to express my inner thoughts and feelings about this new concept of leadership. I envision how person-centred point-of-care leadership is a process of crossing multiple bridges made out of fallen tree trunks. The unstructured wooden bridges signify for me the organic origin of person-centred point-of-care leadership. The bridge is the space where point-of-care leadership and person-centred care interconnect. As care providers, we have within us the capacity to lead at the point-of-care. Patients and care providers are bound together by these shared human attributes that facilitate our relationships and behaviours. By embodying person-centredness, care providers are more informed and capable of influencing others to achieve their purpose. 
However, it is up to the person, within her/his environment, to enact these opportunities for informal leadership by standing up, as the poem suggests (p. 109).

Within the context of healthcare teams, we, as care providers, must work together towards actualization of health and well-being of the persons in the care partnership. Together as a team, patients and care providers, represented by the ants in the metaphor painting, are in continuous motion between the two banks of the river, the evolving care landscape.

As my thesis comes to a close, it is my hope that the stories shared by Sandy, Alaia, and me have inspired you, dear reader, with personal revelations leading to puzzles that ignite your own journey of discovery into point-of-care leadership. I hope that our experiences continue with you as you live your life as a human being who is also a leader.

$\S$

The sun shines through the clouds. From this elevation, I see the vast landscape before me. After overcoming what I thought would be an insurmountable feat, I feel inspired to go again on another hike, to be surrounded by new landscapes and challenges, to discover new knowledge, and so to further expand my understanding of person-centred point-of-care leadership. These mountain peaks call to me, to be climbed, discovered and explored in not so distant future ... 


\begin{abstract}
APPENDIX A
Email Invitation for Participant Recruitment Hello Registered Nurses of the (name of hospital) Operating Room!

I am a graduate student from Ryerson University's Master of Nursing program. As part of my degree requirements, I am conducting a nursing research study. I would like to invite you to participate in a nursing research study where you can share your experiences of nursing leadership when you take care of your patients in the operating room.

Participation is voluntary.

If you are interested in participating or have questions about the study, please contact me, Victoria Gaudite, by telephone (telephone number) or email (email)
\end{abstract}

(A copy of the recruitment poster will be attached to the email) 


\section{APPENDIX B}

\section{Recruitment Poster for Participant Recruitment}

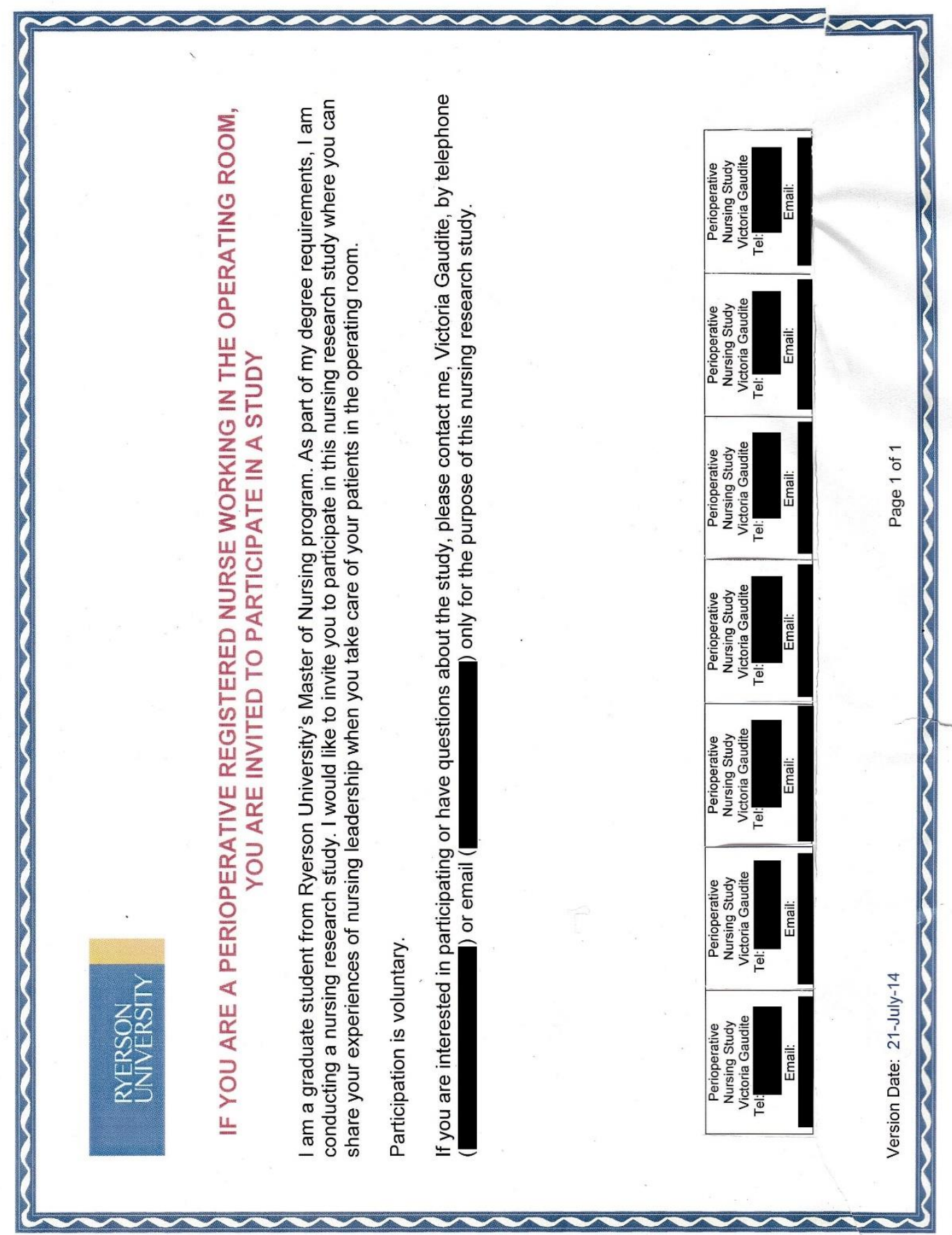




\section{APPENDIX C \\ Ryerson University Research Ethics Board Approval}

To: Victoria Gaudite

Daphne Cockwell School of Nursing

Re: REB 2014-309: Perioperative Nurses' Experiences of Point-of-care Nursing

Leadership in the Operating Room: A Narrative Inquiry

Date: October 16, 2014

Dear Victoria Gaudite,

The review of your protocol REB File REB 2014-309 is now complete. The project has been approved for a one year period. Please note that before proceeding with your project, compliance with other required University approvals/certifications, institutional requirements, or governmental authorizations may be required.

This approval may be extended after one year upon request. Please be advised that if the project is not renewed, approval will expire and no more research involving humans may take place. If this is a funded project, access to research funds may also be affected.

Please note that REB approval policies require that you adhere strictly to the protocol as last reviewed by the REB and that any modifications must be approved by the Board before they can be implemented. Adverse or unexpected events must be reported to the REB as soon as possible with an indication from the Principal Investigator as to how, in the view of the Principal Investigator, these events affect the continuation of the protocol.

Finally, if research subjects are in the care of a health facility, at a school, or other institution or community organization, it is the responsibility of the Principal Investigator to ensure that the ethical guidelines and approvals of those facilities or institutions are obtained and filed with the REB prior to the initiation of any research.

Please quote your REB file number (REB 2014-309) on future correspondence.

Congratulations and best of luck in conducting your research.

(name of chairperson)

Chair, Research Ethics Board 


\section{APPENDIX D}

Consent Form

RYERSON

UNIVERSITY

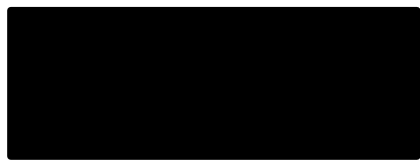

CONSENT FORM TO PARTICIPATE IN A RESEARCH STUDY

Title

Perioperative Nurses' Experiences of Point-of-care Nursing Leadership: A Narrative Inquiry

Principal Investigator

(name of investigator), $\mathrm{RN}, \mathrm{PhD}$

(name of hospital)

Tel: (telephone number)

Co-Investigators

Victoria Gaudite, RN, BScN, MN (c)

Master of Nursing Student

Ryerson University

Tel: (telephone number)

Email: (email)

Dr. Jasna Schwind, RN, PhD

Thesis Supervisor

Ryerson University

Tel: (telephone number)

\section{Introduction:}

You are being asked to take part in a research study. This research study is being conducted by a Master of Nursing graduate student as part of the degree requirements. Please read the information provided in this form. The form includes details about the study, including the risks and benefits that you should know if you decide to take part. You should take as much time as you need to make your decision about participating in the study. You should ask the study co-investigator (Victoria Gaudite) or her supervisor (Dr. Jasna Schwind) to explain anything that you do not understand and ensure that all of your questions are answered before signing the consent form. Participation in this study is voluntary.

\section{Background/Purpose:}

It is becoming increasingly important for front line clinical nurses to engage in nursing leadership at the point of contact to effectively promote the health of the persons in their care. Registered Nurses' Association of Ontario's Developing and Sustaining Nursing Leadership Best Practice Guideline encourages all nurses, including nurse educators, administrators, and clinicians, to develop leadership skills and competencies to adapt to 
the growing pressures of cost savings and increasing productivity while responding to the demands from the aging population, technological advancements, and sophisticated consumerism. Although point-of-care nursing leadership is being progressively identified as critical to the growth of the nursing profession, research on point-of-care nursing leadership is still very limited. Understanding the experience of point-of-care nursing leadership is evidently needed. The purpose of this study is to give voice to your experiences of point-of-care nursing leadership as a perioperative registered nurse in the operating room (OR). This study seeks two perioperative registered nurses from the OR department of the (name of hospital) site.

\section{Study Design:}

You will be asked to take part in two meetings to share your experiences and feelings of point-of-care nursing leadership as a perioperative registered nurse in the OR. There will be one face-to-face meeting lasting approximately 2 hours in length, which will include one semi-structured one-on-one narrative interview/storytelling activity, where the co-investigator (Victoria) will ask you a few questions to guide the conversation about your experience. Following the narrative interview/storytelling activity, you will be asked to take part in a creative self-expression activity. You will be asked to select, draw, and describe a metaphor or a symbolic image that represents your experience of point-of-care nursing leadership.

Approximately 2 weeks after the first meeting, the co-investigator (Victoria) will contact you by email followed by telephone meeting to check whether your stories accurately captured your experience of point-of-care nursing leadership in the OR.

\section{Study Visits and Procedures:}

Face-to-Face Meeting with Interview/Storytelling and Creative Self-Expression Activities: This will be audio-taped and transcribed. This is expected to require approximately 2 hours of your time.

You will be invited to share your experiences of point-of-care nursing leadership as a perioperative registered nurse in the OR. The following questions may be asked to guide the interview/storytelling process:

1. Tell me about your choice to be a perioperative nurse in the OR.

2. How would you define nursing leadership at the point-of-care using your own words?

3. How do you understand leadership when you are taking care of your patients in your current nursing practice as a perioperative nurse?

4. Describe your experiences/feelings of nursing leadership at the point-of-care as you provide nursing care to your patients and work together as part of an interdisciplinary team in the OR?

5. How is your leadership experience different now from the time you first started your nursing practice as a perioperative nurse? 
6. What kind of internal or external challenges did you face in your experiences of point-of-care nursing leadership in the OR?

You will then be invited to take part in a creative self-expression activity where you will be asked to select, draw, and describe a metaphor or a symbolic image to represent your experience of point-of-care nursing leadership in the OR. Your symbolic image will be photocopied and the original drawing will be returned to you.

Email and Telephone Meeting: Approximately 2 weeks after the face-to-face meeting, the study co-investigator (Victoria) will contact you by email with your stories of experience of point-of-care nursing leadership in the OR. Approximately one week after the email, the study co-investigator (Victoria) will contact you for a telephone meeting to inquire if the stories accurately captured your leadership experience. This telephone meeting will require approximately 30 minutes of your time. This will audio-recorded and transcribed.

\section{Risks Related to Being in the Study:}

There are no medical risks related to participating in this study. Being in the study might make you feel emotionally uncomfortable when you share your stories of point-of-care nursing leadership. If this occurs, you may refuse to answer the questions or stop the interview, without any penalty. If you feel emotionally distressed at any point of the study, the co-investigator will ask for your permission to provide you with information about resources available, such as Employee Assistance Programs and existing personal networks.

\section{Benefits Related to Being in the Study:}

You may or may not receive direct benefits from being in this study. This study can provide information that may or may not directly benefit you and/or your patients receiving your nursing care. However, participation in this study may positively contribute to your self-reflective practice and annual CNO Reflective Practice mandate. Furthermore, this study may have indirect benefits of inspiring you and/or your colleagues to engage in professional dialogue about your nursing leadership at the point-of-care and increase awareness about practice issues.

\section{Confidentiality:}

\section{Personal Health Information}

If you agree to participate in this study, the research team will only collect the personal health information needed for the study, which include:

- Name

- Contact Telephone Number

- Contact Email address 
The information collected for the purpose of the study, such as personal health information, interview audio-recordings, and drawing, will be stored in a locked space in a secure research environment at Ryerson University for the duration of 5 years. The information collected for the study will be destroyed after 5 years from the time of participant recruitment. The information will be confidential and the study team or persons or groups identified will be allowed to look at the study records.

The following persons or groups may look at the study records for the purpose of ensuring the collected information is correct and the laws and guidelines are followed by the study team:

- Representatives of (name of hospital) and Ryerson University Research Ethics Board (REB)

\section{Study Information that Does Not Identify You}

There will be some study information that will be shared outside of (name of hospital) to Ryerson University. Any information about you that is shared outside (name of hospital) will have a code and will not show your name, telephone number, email address, or any information directly identifying you.

Any publications, reports, or presentations that may arise from this study will not include your name, telephone number, or email address. If you decide to leave the study after consenting to participate, the information about you prior to your withdrawal from the study will still be used. There will be no new information collected without your permission.

\section{Voluntary Participation:}

Your participation in this study is voluntary. You may decide not to be in this study, or you may decide to be in the study now and then change your mind later. You may choose to stop participating at any point of the study without penalty or loss of benefits. Your decision not to participate in the study will not influence your relationships with the researchers, Ryerson University, or (name of hospital) either now, or in the future.

\section{Withdrawal from the Study:}

You can stop your participation in the study for any reason, at any time, if you decide to do so. Your refusal to answer particular questions or stop your participation in the study altogether will not affect your relationships with the researchers, Ryerson University, or (name of hospital) either now, or in the future.

\section{Costs and Reimbursement:}

You will not have to pay for the activities involved in this study. You will be provided a $\$ 10$ coffee gift card as a thank you for your time at the end of the interview and creative self-expression activities. At any point, if you choose to leave the study or withdraw your participation, you will still be given a coffee gift card. 


\section{Rights as a Participant:}

You will receive care if you become emotionally uncomfortable and/or distressed as a result from participating in the study. Any reasonable costs of the care will be covered for any emotional harm or distress that directly results from participation in this study. By signing this form you do not give up any of your legal rights against the investigators, sponsor or involved institutions for compensation, nor does this form relieve the investigators, sponsor or involved institutions of their legal and professional responsibilities.

\section{Conflict of Interest:}

The study Principal Investigator and Co-Investigators have an interest in completing this study, however, their interest in this study should not influence your decision to participate in this study. You should not feel pressured to participate in this study.

\section{Questions about the Study:}

If you have any questions, concerns or would like to speak to the study team for any reason, please call: Victoria Gaudite at (telephone number), Dr. Jasna Schwind (telephone number), or (name of investigator) (telephone number).

If you have any questions about your rights as a research participant or have concerns about this study, contact the Chairs of the Ryerson University and/or (name of the hospital) Research Ethics Board (REB). You can also email Ryerson University REB at (email) or call the (name of hospital) Research Ethics office number at (telephone number). The (name of the hospital) and Ryerson University REBs are groups of people who oversee the ethical conduct of research studies. The (name of the hospital) and Ryerson University REBs are not part of the study team. Everything that you discuss will be kept confidential.

You will be given a signed copy of this consent form.

\section{Consent:}

This study has been explained to me and any questions I had have been answered.

I know that I may leave the study at any time. I agree to the use of my information as described in this form. I agree to take part in this study.

Print Study Participant's Name

Signature

Date

I agree to be audio-taped during the sharing of my stories about my experiences as a perioperative registered nurse. 
Print Study Participant's Name Signature Date

I agree to have my artwork photocopied for data analysis.

Print Study Participant's Name

Signature

Date

I agree to have my photocopied artwork displayed publicly.

Print Study Participant's Name

Signature

Date

My signature means that I have explained the study to the participant named above. I have answered all questions.

$\overline{\text { Print Name of Person Obtaining Consent }} } \overline{\text { Date }}$

Was the participant assisted during the consent process? $\square$ YES $\square$ NO

If YES, please check the relevant box and complete the signature space below:

$\square$ The person signing below acted as an interpreter for the participant during the consent process and attests that the study as set out in this form was accurately interpreted has had any questions answered.

Print Name of Interpreter

$\overline{\text { Signature }} \overline{\text { Date }}$

Relationship to Participant

Language

$\square$ The consent form was read to the participant. The person signing below attests that the study as set out in this form was accurately explained to, and has had any questions answered.

Print Name of Witness

Signature

Date 
Relationship to Participant 


\title{
APPENDIX E
}

\author{
Study Information Letter
}

RYERSON

UNIVERSITY

\section{STUDY INFORMATION LETTER}

Title:

Perioperative Nurses' Experiences of Point-of-care Nursing Leadership: A Narrative inquiry

My name is Victoria Gaudite and I am a Master of Nursing graduate student from Ryerson University. I am conducting the above titled study, as part of my degree requirements. My supervisor is Dr. J. K. Schwind of Ryerson University.

\section{Purpose:}

To give perioperative nurses the opportunity to share how they experience leadership at the point of care in the operating room $(\mathrm{OR})$ as a perioperative nurse

\section{Participation Criteria:}

Perioperative registered nurses who are currently employed at (name of institution) OR

\section{Involvement in Study:}

There will be one face-to-face meeting, lasting approximately 2 hours in duration, where participants will be invited to tell their stories of their experiences of providing leadership during their care of patients in the OR. The face-to-face meeting will include one semistructured one-on-one narrative interview/storytelling activity, where the co-investigator (Victoria) will ask each participant a few questions to guide the conversation their conversations about their experiences. Following the interview/storytelling activity, each participant will be asked to take part in a creative self-expression activity. Each participant will be asked to select, draw, and describe a metaphor or a symbolic image that represents her/his experience of point-of-care nursing leadership. This meeting will be audio recorded and transcribed.

Approximately 2 weeks after the face-to-face meeting, the co-investigator (Victoria) will email the story and setup a follow-up telephone meeting with each participant. During the telephone meeting, the co-investigator (Victoria) will inquire if the stories accurately captured the each participant's leadership experience. The telephone meeting may last approximately 30 minutes and it will be audio recorded and transcribed.

\section{Benefits:}


Participation in this study may positively contribute to participants' self-reflective practice and annual CNO Reflective Practice mandate. Furthermore, this study may have indirect benefits of inspiring participants and/or their colleagues to engage in professional dialogue about their nursing leadership during their care of patients in the OR and so increase awareness about practice issues.

Participation in this study is completely voluntary. Your personal and professional relations with (name of institution) or Ryerson University will not be affected in any way whether or not you choose to participate in this study. If you decide to participate, you are free to withdraw or stop your participation in the study at any point without penalty or loss of benefits at your place of employment.

The data collected through this study will not be shared directly with Ryerson University or (name of institution) employees, employers, volunteers, or patients.

If you are interested in participating or have questions about the study, please contact me, Victoria Gaudite, by telephone (telephone number) or email (email). 


\section{REFERENCES}

Adams, C. (2010). Dying with dignity in America: The transformational leadership of Florence Wald. Journal of Professional Nursing, 26(2), 25-32. Retrieved from http://www.professionalnursing.org/article/S8755-7223\%2809\%2900188-4/abstract

Aksenchuk, K. (2013). Patients' experiences of interprofessional care: A narrative inquiry (Unpublished master's thesis). Ryerson University, Toronto, Canada.

Alleyne, J. \& Jumaa, M. O. (2007). Building capacity for evidence-based clinical nursing leadership: The role of executive co-coaching and group clinical supervision for quality patient services. Journal of Nursing Management, 15, 230-243. Retrieved from http://www.ncbi.nlm.nih.gov/pubmed/17352707

Andersson L.M. \& Pearson C.M. (1999). The spiraling effect of incivility in the workplace. Academy of Management Review, 24, 452-471. Retrieved from http://www.jstor.org.ezproxy.lib.ryerson.ca/stable/pdf/259136

Arora, S., Hull, L., Sevdalis, N., Tierney, T., Nestel, D., Woloshynowych, M., Darzi, A., \& Kneebone, R. (2010). Factors comprising safety in surgery: Stressful events in the operating room. The American Journal of Surgery, 190, 60-65. doi: 10.1016/j.amsurg.2009.07.036

Avolio, B. J., Walumba, F. O., \& Weber, T. J. (2009). Leadership: Current theories, research, and future directions. Annual Review Psychology, 60, 421-449. doi: 10.1146/annurev.psych.60.110707.163621

Avolio, B. A., Zhu, W., Koh, W., \& Bhatia, P. (2004). Transformational leadership and organizational commitment: Mediating role of psychological empowerment and moderating role of structural distance. Journal of Organizational Behaviour, 24, 951-968. 
doi: $10.1002 /$ job.283

Bass, B. M. (1996). Is there universality in the full range model of leadership? International Journal of Public Administration, 19(6), 731-761. Retrieved from http://www.tandfonline.com/doi/abs/10.1080/01900699608525119?journalCode=lpad20\# .VaQ7Dfn9mpo

Bergman, J.Z., Rentsch, J.R., Small, E.E., Davenport, S. W., \& Bergman, S. M. (2012). The shared leadership process in decision-making teams. Journal of Social Psychology, 152(1), 17-42. Retrieved from http://www.ncbi.nlm.nih.gov/pubmed/22308759

Boyatzis, R. E. \& Saatcioglu, A. (2007). A 20-year view of trying to develop emotional, social and cognitive intelligence competencies in graduate management education. Journal of Management Development, 27(1), 92-108. doi: http://dx.doi.org/10.1108/02621710810840785

Brown, C. D. (2010). The effects of leadership behavior on clinical registered nurse work satisfaction (Doctoral dissertation). Retrieved from CINAHL. (2011387314)

Bu, W. \& Jezewski, M. A. (2006). Developing a mid-range theory of patient advocacy through concept analysis. Journal of Advanced Nursing, 57(1), 101-110. doi: 10.111/j.13652648.2006.04096.x

Bull, R. \& FitzGerald, M. (2006). Nursing in technological environment: Nursing care in the operating room. International Journal of Nursing Practice, 26, 3-7. doi: 10.1111/j.1440$172 X .2006 .00542$

Burford, B., Morrow, G., Morrison, J., Baldauf, B., Spencer, J., Johnson, N., Rothwell, C., Peile, 
E., Davies, C., Allen, M., \& Illing, J. (2013). Newly qualified doctors' perceptions of informal learning from nurses: implications for interprofessional education and practice. Journal of Interprofessional Care, 27(5), 394-400. doi: 10.3109/13561820.2013.783558

Burke, C. S., Stagl, K. C., Klein, C., Goodwin, G. F., Salas, E., \& Halpin, S. M. (2006). What type of leadership behaviors are functional in teams? A meta-analysis. The Leadership Quarterly, 17(3), 288-307. Retrieved from https://www.vuiis.vanderbilt.edu/ welcheb/TTU/BMGT6200/ttu_mba_metaanalysis_welch.pdf

Burns, N. (2009). Clinical leadership for general practice nurses. Practice Nursing, 20(10), 519523. Retrieved from http://web.ebscohost.com/abstract?direct=true $\&$ profile=ehost $\&$ scope=site $\&$ authtype=cra wler\&jrnl=09649271\&AN=44255424\&h=q0KKtsgfUhLZORiqSFz7CEucKR1drmF96n w4riLsYuTrqpMACRw98dKR4\%2bZSrjXyXZGZq9EJmA\%2fjsdMTf5IB2Q\%3d\%3d\& $\mathrm{crl}=\mathrm{c}$

Canadian Nurses Association (2015). Advocacy. Retrieved from https://www.cnaaiic.ca/en/advocacy

Cawley, T. \& McNamara, P. M. (2011). Public health nurse perceptions of empowerment and advocacy in child health surveillance in West Ireland. Public Health Nursing, 28(2), 150158. doi: 10.1111/j.1525-1446-2010.00921.x

Clandinin, D. J. (2013). Engaging in Narrative Inquiry. United States of America: Left Coast Press Inc.

Clandinin, D. J. \& Connelly, F. M. (2000). Narrative inquiry: Experience and story in qualitative research. San Fransisco, CA: Jossey-Bass. 
Clandinin, D. J., Pushor, D., \& Orr, A. M. (2007). Navigating sites for Narrative Inquiry. Journal of Teacher Education, 58(1), 21-35. doi: 10.1177/0022487106296218

Clandinin, D. J \& Rosiek, J. (2007). Mapping a landscape of narrative inquiry: Borderland spaces and tensions. In J. Clandinin (Ed.), Handbook of narrative inquiry: Mapping a methodology (pp. 35-76). Thousand Oaks: Sage.

College of Nurses of Ontario. (2009). Ethics. Retrieved from http://www.cno.org/Global/docs/prac/41034_Ethics.pdf

Connelly, F. M. \& Clandinin, D. J. (1990). Stories of experience and narrative inquiry. Educational Researcher, 19(5), 2-14. Retrieved from http://www.tc.umn.edu/ dillon/CI\%208148\%20Qual\%20Research/Session\%2012/Narrat ive-Clandinin $\% 20 \mathrm{ER} \% 20$ article.pdf

Connelly, F. M. \& Clandinin, D. J. (2006). Narrative inquiry. In J. L. Green, G. Camilli, \& P. Elmore (Eds.), Handbook of complementary methods in education research ( $3^{\text {rd }}$ ed., pp. 477-487). Mahwah, NJ: Lawrence Erlbaum.

Cook, M. J. (2001). The renaissance of clinical leadership. International Nursing Review, 48, 3846. doi: 10.1046/j.1466-7657.2001.00040.x

Cook, M. J. \& Leathard, H. L. (2004). Learning for clinical leadership. Journal of Nursing Management, 12(6), 436-444. Retrieved from http://www.ncbi.nlm.nih.gov/pubmed/15509273

Creswell, J. W. (2013). Qualitative inquiry and research design: Choosing among five approaches. ( $3^{\text {rd }}$ ed.). Thousand Oaks, CA: Sage.

Cummings, G. G., MacGregor, T., Davey, M., Lee, H., Wong, C. A., Lo, E., Muise, M., \& Stafford, E. (2010). Leadership styles and outcome patterns for nursing workforce and 
work environment: A systematic review. International Journal of Nursing Studies, 47, 363-385. doi: 10.1016/j.ijnurstu.2009.08.006

Cummings, G. G., Olson, K., Hayduk, L., Bakker, D., Fitch, M., Green, E., Butler, L., \& Conlon, M. (2008). The relationship between nursing leadership and nurses' job satisfaction in Canadian oncology work environments. Journal of Nursing Management, 16, 508-518. doi: 10.1111/j.1365-2834.2008.00897.x.

Currie, K., Bannerman, S., Howatson, V., Macleod, F., Mayne, W., Organ, C., Renton, S., \& Scott, J. (2015). 'Stepping in' or 'stepping out': How first year nursing students begin to learn about person-centred care. Nurse Education Today, 35, 239-244. doi: http://dx.doi.org/10.1016/j.nedt.2014.06.008

Cypress, B. S. (2011). Exploring the concept of nurse-physician communication within the context of health care outcomes using the evoluationary method of concept analysis. Dimensions of Critical Care Nursing, 30(1), 28-30. doi: 10.1091/DCC.obo13e3181fd02e1

Delmatoff, J. (2014). The most effective leadership style for the new landscape of healthcare. Journal of Healthcare Management, 59(4), 245-249. Retrieved from http://www.creativehealthcare.com/pdf/The-role-of-Emotional-Intelligence.pdf

Devenny, B. \& Duffy, K. (2014). Person-centred reflective practice. Nursing Standard, 28(28), 37-43. doi: 10.7748/ns2014.03.28.28.37.e8068

Dewey, J. (1997). Experience and education (New York, Touchstone). (Original work published 1938.)

Dierckx de Casterle, B., Willemse, A, Verschueren, M, \& Milisen, K. (2008). Impact of clinical 
leadership development on the clinical leader, nursing team and care-giving process: a case study. Journal of Nursing Management, 16(6), 753-763. doi: 10.1111/j.13652834.2008.00930.x.

Doran, D., Koh, M., Dick, A., Hayes, L., van Wiechen, C., \& Yim, O. (2012). Leading practices and programs for developing leadership among health professionals at the point of care. Retrieved from http://www.inspirenet.ca/resources/final-report-leading-practices-andprograms-developing-leadership-among-health-professiona

dos Santos, F. K., da Silva, M. V., \& Gomes, A. M. (2014). Understanding the forms of care of nurses in the operating room - A construction based on the grounded theory method. Text Context Nursing, 23(3), 696-703. doi: http://dx.doi.org/10/1590/010407072014001140013

Espin, S. L., \& Lingard, L. A. (2001). Time as catalyst for tension in nurse-surgeon communication. Association of Operating Room Nurses. AORN, 74(5), 672-682. Retrieved from http://www.ncbi.nlm.nih.gov/pubmed/11725445

Gardner, W. L., Avolio, B. J., Luthans, F., May, D. R., \& Walumba, F. (2005). “Can you see the real me?" A self-based model of authentic leader and follower development. The Leadership Quarterly, 16, 343-372. doi: 10.1016/j.leaqua.2005.03.003

George, V., Burke, L. J., Rodgers, B., Duthie, N., Hoffmann, M. L., Koceja, V., Kramer, A., Maro, J., Minzlaff, P., Pelczynski, S., Schmidt, M., Westen, B., Zielke, J., Brukwitzki, G., \& Gehring, L. L. (2002). Developing Staff Nurse Shared Leadership Behavior in Professional Nursing Practice. Nursing Administration Quarterly, 26(3), 44-59. Retrieved from 
http://journals.lww.com/naqjournal/Fulltext/2002/04000/Developing_Staff_Nurse_Share d_Leadership_Behavior.8.aspx

Gillespie, B. M., Wallis, M., \& Chaboyer, W. (2008). Operating threater culture. Western Journal of Nursing Research, 30(2), 259-277. doi: 10.1177/0193945907303006

Gillespie, B. M., Chaboyer, W., Wallis, M., Chang, H., A., \& Werder, H. (2009). Operating theatre nurses' perceptions of competence: A focus group study. Journal of Advanced Nursing, 65(5), 1019-1028. doi: 10.1111/j.1365-2648.2008.04955.x

Government of Canada (2015). Privacy and Confidentiality. Retrieved from http://www.pre.ethics.gc.ca/eng/policy-politique/initiatives/tcps2-eptc2/chapter5chapitre5/

Grace, P. J. (2001). Professional advocacy: widening the scope of accountability. Nursing Philosophy, 2, 151-162. doi: 10.1046/j.1466-769X.2001.00048.x

Groves, K. S., McEnrue, M. P., \& Shen, W. (2008). Developing and measuring the emotional intelligence of leaders. Journal of Management Development, 27(2), 225-250. doi: http://dx.doi.org/10.1108/02621710810849353

Hanks, R. G. (2007). Barriers to nursing advocacy: A concept analysis. Nursing Forum, 42(4), 171-177. Retrieved from http://www.ncbi.nlm.nih.gov/pubmed/17944697

Hanks, R. G. (2008). The lived experience of nursing advocacy. Nursing Ethics, 15(4), 468-477. doi: $10.1177 / 0969733008090518$

Hanks, R. G. (2010). The medical-surgical nurse perspective of advocate role. Nursing Forum, 45(2), 97-108. doi: 10.1111/j.1744-6198.2010.00170.x.

Hayajneh, F. A. \& Shehadeh, A. (2014). The impact of adopting person-centred care approach 
for people with Alzheimer's on professional caregivers' burden: An interventional study. International Journal of Nursing Practice, 20, 438-445. doi: 10.1111/ijn.12251

Heid. A. L. (2010). Staff nurse leadership: Leading at the point of care. (Unpublished doctoral dissertation). University of North Dakota, Grand Folks, USA.

Hellwig, S. D., Yam, M., \& DiGuilio, M. (2003). Nurse case managers' perceptions of advocacy: A phenomenological inquiry. Lippincotts Case Management, 8(2), 53-63. Retrieved from http://www.ncbi.nlm.nih.gov/pubmed/12668923

Higgins, A., Begley, C., Lalor, J., Coyne, I., Murphy, K., \& Elliott, N. (2014). Factors influencing advanced practitioners' ability to enact leadership: a case study within Irish healthcare. Journal of Nursing Management, 22(7), 894-905. doi: 10.1111/jonm.12057

Higgins, B. L. \& MacIntosh, M. (2010). Operating room nurses' perceptions of the effects of physician-perpetrated abuse. International Nursing Review, 57(3), 321-327. doi: 10.1111/j.1466-7657.2009.00767.x

Hilli, Y., Melender, H., Salmu, M., \& Jonsen, E. (2014). Being a preceptor - A Nordic qualitative study. Nurse Education Today, 34, 1420-1424. doi: http://dx.doi.org/10.1016/j.nedt.2014.04.013

Hoch, J. E. (2014). Shared Leadership, diversity, and information sharing in teams. Journal of Managerial Psychology, 29(5), 541-564. doi: 10.1108/jmp-02-2012-0053

hooks, B. (1998). Wounds of passion. New York, NY: Henry Hold and Company.

Hughes, L. W. (2005). Developing transparent relationships through humor in the authentic leader-follower relationship. Authentic Leadership Theory and Pratice: Origins, Effects and Development Monographs in Leadership and Management, 3, 83-106. doi $10.1177 / 1350507608093713$ 
Jeon, Y. H., Luscombe, G., Chenoweth, L., Stein-Parbury, J., Brodaty, H., King, M., \& Haas, M. (2012). Staff outcomes from the caring for aged dementia care resident study (CADRES): a cluster randomised trial. International Journal of Nursing Studies, 49(5), 508-518. doi: 10.1016/j.ijnurstu.2011.10.020

Jugessur, T. \& Iles, I. K. (2009). Advocacy in mental health nursing: An integrative review of the literature. Journal of Psychiatric and Mental Health Nursing, 16, 187-195. doi: 10.1111/j.1365-2850.2008.01315.x.

Kallas, K. D. (2014). Profile of an excellent nurse manager: Identifying and developing health care team leaders. Nursing Administration Quarterly, 38(3), 261-268. doi: 10.1097/NAQ.0000000000000032

Kouzes, J. M. \& Posner, B. Z. (2007). The leadership challenge ( $3^{\text {rd }}$ Ed.). San Francisco, CA: Jossey-Bass.

Krugman, M., Heggem, L., Kinney, L. J., \& Frueh, M. (2013). Longitudinal Charge Nurse Leadership Development and Evaluation. Journal of Nursing Administration, 43(9), 438446. doi: 10.1097/NNA.0b013e3182a23b26

Kunzle, B., Zala-Mezo, E., Wacker, J., Kolbe, M., Spahn, D. R., \& Grote, G. (2010). Leadership in anaesthesia teams: the most effective leadership is shared. Qual Saf Health Care, 19, 1-6. doi: 10.1136/qshc.2008.030262

Kunzle, B., Kolbe, M., \& Grote, G. (2010). Ensuring patient safety through effective leadership behaviour: a literature review. Safety Science, 48, 1-17. Retrieved from http://psnet.ahrq.gov/resource.aspx? resourceID=11974

Kuo, C. C. \& Robb, W. J. (2013). Critical roles of orthopaedic surgeon leadership in healthcare 
systems to improve orthopaedic surgical patient safety. Clinical Orthopedics and Related Research, 471(6), 1792-1800. doi: 10.1007/s11999-012-2719-3

Lapum, J., Ruttonsha, P., Church, K., Yau, T., \& David, A. M. (2011). Employing the arts in research as an analytical tool and dissemination method: Interpreting experience through the aesthetic. Qualitative Inquiry, 18(1), 100-115. doi: 10.1177/1077800411427852

Lindsay, G. M. (2006). Constructing a nursing identity: Reflecting on and reconstructing experience. Reflective Practice, 7(1), 59-72. doi: 10.1080/14623940500489732

Lingard, L., Espin, S., Whyte, S., Regehr, G., Baker, G. R., Reznick, R., Bohnen, J., Orser, B., Doran, D., \& Grober, E. (2004). Communication failures in the operating room: An observational classification of recurrent types and effects. Quality Safe Health Care, 13, 330-334. doi: 10.1136/qshc.2003.008425

Lingard, L., Vanstone, M., Durrant, M., Fleming-Carroll, B., Lowe, M., Rashotte, J., Sinclair, L., \& Tallett, S. (2012). Conflicting messages: Examining the dynamics of leadership on interprofessional teams. Academic Medicine, 87(12), 1762-1767. doi: 10.1097/ACM.obo13e318271fc82

Linton, J. \& Farrell, M. J. (2009). Nurses' perceptions of leadership in an adult intensive care unit: A phenomenological study. Intensive and Critical Care Nursing, 25, 64-71. doi: 10.1016/j.iccn.2008.11.003

Loke, J. C. (2001). Leadership behaviours: effects on job satisfaction, productivity and organizational commitment. Journal of Nursing Management, 9, 191-204. Retrieved from http://web.b.ebscohost.com/ehost/pdfviewer/pdfviewer?sid=a06d283c-20d1-461c832f-38e1c621c494\%40sessionmgr115\&vid=1\&hid=124

Long, J. A., Lee, R. S., Federico, S., Battaglia, C., Wong, S., \& Earnest, M. (2011). Developing 
leadership and advocacy skills in medical students through service learning. Journal of Public Health Management, 17(4), 369-372. doi: 10.1097/PHH.0b013e3182140c47

Luscombe, G., Chenoweth, L., Stein-Parbury, J., Brodaty, H., King, M., \& Haas, M. (2012). Staff outcomes from the Caring for Aged Dementia Care Resident Study (CADRES): A cluster randomised trial. International Journal of Nursing Studies, 49, 508-518. doi: 10.1016/j.ijnurstu.2011.10.020

Lyons, V. E. \& Popejoy, L. L. (2014). Meta-analysis of surgical safety checklist effects on teamwork, communication, morbidity, mortality, and safety. Western Journal of Nursing Research, 36(2), 245-261. doi: 10.1177/0193945913505782

MacDonald, H. (2006). Relational ethics and advocacy in nursing: Literature review. Journal of Advanced Nursing, 57(2), 119-126. doi: 10.1111/j.365-2648.2006.04063.x

Mahoney, J. (2001). Leadership skills for the $21^{\text {st }}$ century. Journal of Nursing Management, 9 , 269-271. Retrieved from http://www.ncbi.nlm.nih.gov/pubmed/11879469

McCance, T., McCormack, B., \& Dewing, J. (2011). An exploration of person-centredness in practice. The Online Journal of Issues in Nursing, 16(2), 1. Retrieved from http://www.ncbi.nlm.nih.gov/pubmed/22088150

McCormack, B. \& McCance, T. (2010). Person-centred nursing: Theory and practice. West Sussex, UK: Wiley-Blackwell.

McCormack, B., Dewing, J., Breslin, E., Coyne-Nevin, A., Kennedy, K., Manning, M., Tobin, C., \& Slater, P. (2010). Developing person-centred practice: Nursing outcomes arising from changes to the care environment in residual settings for older people. International Journal of Older People Nursing, 5, 93-107. doi: 10.1111/j.1748-3743.2010.00216.x

McGrath, P., Holewa, H., \& McGrath, Z. (2006). Nursing advocacy in an Austrian 
multidisciplinary context: findings on medico-centrism. Scandinavian Journal of Caring Science, 20, 394-402. Retrieved from http://www.ncbi.nlm.nih.gov/pubmed/17116148

McSteen, K. \& Peden-McApline, C. (2006). The role of the nurse as advocate in ethically difficult care situations with dying patients. Journal of Hospice and Palliative Nursing, 8, 259-269. Retrieved from http://www.medscape.com/viewarticle/545616

Nicolaides, V., LaPort, K. A., Chen, T. R., Tomassetti, A. J., Weis, E. J., Zaccaro, S. J., \& Cortina, J. M. (2014). The shared leadership of teams: A meta-analysis of proximal, distal, and moderating relationships. The Leadership Quarterly, 25(5), 923-942. doi: 10.1016/j.leaqua.2014.06.006

O'Connor, T. \& Kelly, N. (2005). Bridging the gap: A study of general nurses' perceptions of patient advocacy in Ireland. Nursing Ethics, 12(5), 453-467. Retrieved from http://www.ncbi.nlm.nih.gov/pubmed/16178342

Parker, P. A. \& Sorensen, J. (2008). Emotional intelligence and leadership skills among NHS managers: An empirical investigation. International Journal of Clinical Leadership, 16, 137-142. Retrieved from http://www.ingentaconnect.com/content/rmp/ijcl/2008/00000016/00000003/art00005

Parsons, M. L. \& Newcomb, M. (2007). Developing a healthy OR workplace. AORN Journal, 85(6), 1213-1223. doi: http://dx.doi.org/10.1016/j.aorn.2007.03.004

Patrick, A. W. (2010). The effect of nursing leadership and structural empowerment on staff nurse clinical leadership. (Unpublished doctoral dissertation). University of Western Ontario, Toronto, Canada.

Patrick, A., Laschinger, H. K., Wong, C., \& Finegan, J. (2011). Developing and testing a new measure of staff nurse clinical leadership: The clinical leadership survey. Journal of 
Nursing Management, 19, 449-460. doi: 10.1111/j.1365-2834.2011.01238.x

Perry, B. (2009). Role modeling excellence in clinical nursing practice. Nurse Education in Practice, 9, 36-44. doi: 10.1016/j.nepr.2008.05.001

Peter-O'Grady, T. (2001). Profound change: $21^{\text {st }}$ century nursing. Nursing Outlook, 49(4), 182186. doi: $10.1067 / \mathrm{mno} .2001 .112789$

Peter-O'Grady, T. (2011). Future of nursing special: Leadership at all levels. Nursing Management, 42(5), 32-37. Retrieved from http://www.nursingcenter.com/journalarticle?Article_ID=1163290

Pearce, C. L. \& Barkus, B. (2004). The future of leadership: Combining vertical and shared leadership to transform knowledge work. The Academy of Management Executive, 18(1), 47-59. Retrieved from http://www.jstor.org/stable/4166034

Pearce, C. L. \& Conger, J. A. (2003). All those years ago. In C. J. Pearce \& J. A. Conger (Eds.), Shared leadership: Reframing the hows and whys of leadership (p. 1-18). Thousand Oaks, CA: Sage Publications.

Registered Nurses' Association of Ontario. (2013). Developing and sustaining nursing leadership best practice guideline. Retrieved from http://rnao.ca/bpg/guidelines/developing-and-sustaining-nursing-leadership

Rolfe, P. (2011). Transformational leadership theory: What every leader needs to know. Nurse Leader, 9(2), 54-57. doi: 10.1016/j.mnl.2011.01.014

Salanova, M., Lorente, L., Chambel, M. J., \& Martinez, I. M. (2011). Linking transformational leadership to nurses' extra-role performance: The mediating role of self-efficacy and work engagement. Journal of Advanced Nursing, 67(10), 2256-2266. doi:

10.1111/j.1365-2648.2011.05652.x 
Salmela, S., Eriksson, K., \& Fagerstrom, I. (2012). Leading change: A three-dimensional model of nurse leaders' main tasks and roles during a change process. Journal of Advanced Nursing, 68(2), 423-433. doi: 10.1111/j.1365-2648.2011.05802.x

Sax, H. C. (2012). Building high-performance teams in the operating room. Surgical Clinics of North America, 92, 15-19. doi: 10.1016/j.suc.2011.11.005

Schwind, J. K. (2003). Reflective process of the study of illness stories as experienced by three nurse teachers. Reflective Practice, 4(1), 19-12. doi: 10.1080/1462394032000053521

Schwind, J. K. (2008). Accessing humanness: From experience to research, from classroom to praxis. In J.K. Schwind \& G. M. Lindsay (Eds., pp. 77-94), From experience to relationships: Reconstructing ourselves in education and healthcare. Charlotte, NI: Information Age Publishing.

Schwind, J. K. (2009). Metaphor-reflection in my healthcare experience. Aporia, 1(1), 15-21. Retrieved from http://www.researchgate.net/publication/26645037_Metaphorreflection_in_my_healthcare_experience

Schwind, J.K., Cameron, D., Franks, J., Graham, C., \& Robinson, T. (2011). Engaging in Reflective practice to fine tune self-as-instrument-of-care. Reflective Practice, 1, 1-13. doi: $10.1080 / 14623943.2011 .626030$

Schwind, J. K., Lindsay, G. M., Coffey, S., Morrison, D., \& Mildon, B. (2014). Opening the black-box of person-centred care: An arts-informed narrative inquiry into mental health education and practice. Nurse Education Today, 34, 1167-1171. doi: http://dx.doi.org/10.1016/j.nedt.2014.04.010

Schwind, J. K., Santa-Mina, E., Metersky, K., \& Patterson, E. (2015). Using the Narrative 
Reflective Process to explore how students learn about caring in their nursing program: an arts-informed Narrative Inquiry. Reflective Practice, 1-13. doi: http://doi.org/10.1080/14623943.2015.1052385

Schwind, J., Zanchetta, M., Aksenchuk, K., \& Gorospe, F. (2013). Nursing students' international placement experience: an arts-informed Narrative Inquiry. Reflective Practice, 14(6), 705-716. Retrieved from https://fcsktp.ryerson.ca/xmlui/handle/123456789/154\#sthash.218NQspo.dpuf

Sjogren, K., Lindkvist, M., Sandman, P., Zingmark, K., \& Edvardsson, D. (2013). Personcentredness and its association with resident well-being in dementia care units. Journal of Advanced Nursing, 69(10), 2196-2206. doi: 10.1111/jan.12085

Smythe, M. A., Bentham, P., Jenkins, C., \& Oyebode, J. R. (2015). The experiences of staff in a specialist mental health service in relation to development of skills for the provision of skills for the provision of person-centred care for people with dementia. Dementia, 14(2), 184-198. doi: $10.1177 / 1471301213494517$

Sorensen, R. \& Iedema, R. (2007). Advocacy at the end-of-life. International Journal of Nursing Studies, 44, 1343-1353. doi: 10.1016/j.jnurstu.2006.07.019

Sorensen, R., Iedema, R., \& Severinsson, E. (2008). Beyond professionalism: Nursing leadership in contemporary healthcare. Journal of Nursing Management, 16, 535-544. doi: $10.1111 / \mathrm{j} .1365-2834.2008 .00896 . \mathrm{x}$

Spruce, L. \& Van Wicklin, S. A. (2014). Back to basics: Positioning the patient. AORN Journal, 100(3), 299-305. doi: http://dx.doi.org/10.1016/j.aorn.2014.06.004

Stanley, D. J. (2006). In command of care: Toward the theory of congruent leadership. Journal of Research in Nursing, 11(2), 132-144. doi: 10.1177/1744987106059459 
Steenbergen, E. (2013). Perspectives of person-centred care. Nursing Standard, 27(48), 35-41. Retrieved from http://www.ncbi.nlm.nih.gov/pubmed/23902217

Streubert, H. J. \& Carpenter, D. R. (2011). Qualitative research in nursing: Advancing the humanistic imperatives. ( $5^{\text {th }}$ ed.). Philadelphia: Lippincott, Williams \& Wilkins.

Tang, C. J., Chan, S. W., Zhou, W. T., \& Liaw, S. Y. (2013). Collaboration between hospital physicians and nurses: An integrated literature review. International Nursing Review, 60(3), 291-302. doi: 10.1111/inr.12034

Vaartio, H., Leino-Kilpi, H., Salantera, S., \& Suominen, T. (2006). Nursing advocacy: how is it defined by patients and nurses, what does it involve and how is it experienced? Scandinavian Journal of Caring Science, 20, 282-292. Retrieved from http://www.ncbi.nlm.nih.gov/pubmed/16922982

Walji, N. (2015). Nurses' experiences of creating an artistic instrument for their nursing practice and professional development: An arts-informed Narrative Inquiry (Unpublished master's thesis). Ryerson University, Toronto, Canada.

Walumba, F. O., Wang, P., Wang, H., Shaubroeck, J., \& Avolio, B. J. (2010). Psychological processes linking authentic leadership to follower behaviors. The Leadership Quarterly, 21, 901-914. doi: 10.1016/j.leaqua.2010.07.015

Weberg, D. (2012). Complexity leadership: A Healthcare Imperative. Nursing Forum, 47(4), 268-277. doi: 10.1111/j.1744-6198.2012.00276.x

Wong, C. A., \& Cummings, G. G. (2007). The relationship between nursing leadership and patient outcomes: A systematic review. Journal of Nursing Management, 15, 508-521. doi: 10.1111/jonm.12116

Xyrichis, A. \& Ream, E. (2007). Teamwork: A concept analysis. Journal of Advanced Nursing, 
61(2), 232-241. doi: 10.1111/j.1365-2648.2007.04496.x

Yukl, G. (2010). Leadership in Organization. Upper Saddle River, NJ: Pearson. 